UNIVERSIDADE DE SÃO PAULO

FACULDADE DE FILOSOFIA, CIÊNCIAS E LETRAS DE RIBEIRÃO PRETO DEPARTAMENTO DE PSICOLOGIA PROGRAMA DE PÓS-GRADUAÇÃO EM PSICOLOGIA

\title{
Padrões normativos do Psicodiagnóstico de Rorschach em adolescentes de 12 a 14 anos
}

Roberta Cury de Paula Jacquemin

Dissertação apresentada ao Programa de PósGraduação em Psicologia da Faculdade de Filosofia, Ciências e Letras de Ribeirão Preto da Universidade de São Paulo, como parte das exigências para a obtenção do título de Mestre em Ciências. Área: Psicologia. 
ROBERTA CURY DE PAULA JACQUEMIN

\section{Padrões normativos do Psicodiagnóstico de Rorschach em adolescentes de 12 a 14 anos}

Dissertação apresentada ao Programa de Pós-Graduação em Psicologia da Faculdade de Filosofia, Ciências e Letras de Ribeirão Preto da Universidade de São Paulo, como parte das exigências para a obtenção do título de Mestre em Ciências. Área: Psicologia.

Orientadora:

Profa. Dra. Sonia Regina Pasian

Ribeirão Preto 
Autorizo a reprodução e divulgação total ou parcial deste trabalho, por qualquer meio convencional ou eletrônico, para fins de estudo e pesquisa, desde que citada a fonte.

Catalogação na Publicação

Serviço de Biblioteca e Documentação

Faculdade de Filosofia, Ciências e Letras de Ribeirão Preto

Universidade de São Paulo

Cury-Jacquemin, Roberta de Paula

Padrões normativos do Psicodiagnóstico de Rorschach em adolescentes de 12 a 14 anos. Ribeirão Preto, 2012.

$281 \mathrm{f}$.

Dissertação de Mestrado apresentada à Faculdade de Filosofia, Ciências e Letras de Ribeirão Preto/USP. Departamento de Psicologia. Programa de Pós-Graduação em Psicologia. Área de concentração: Psicologia.

Orientador: Pasian, Sonia Regina.

1. Rorschach. 2. Normas. 3. Adolescentes. 4. Avaliação Psicológica. 5. Técnicas projetivas. 6. Personalidade. 


\section{FOLHA DE APROVAÇÃO}

Nome: Roberta Cury de Paula Jacquemin

Título: Padrões normativos do Psicodiagnóstico de Rorschach em adolescentes de 12 a 14 anos

Dissertação apresentada ao Programa de Pós-Graduação em Psicologia da Faculdade de Filosofia, Ciências e Letras de Ribeirão Preto da Universidade de São Paulo, como parte das exigências para a obtenção do título de Mestre em Ciências. Área: Psicologia

Aprovado em:

\section{Banca Examinadora}

Prof. Dr.

Instituição: Assinatura:

Prof. Dr.

Instituição: Assinatura:

Prof. Dr.

Instituição: Assinatura: 


\section{RESUMO}

Cury-Jacquemin, R. P. (2012). Padrões normativos do Psicodiagnóstico de Rorschach em adolescentes de 12 a 14 anos. Dissertação de Mestrado, Faculdade de Filosofia, Ciências e Letras de Ribeirão Preto, Universidade de São Paulo, Ribeirão Preto.

Acompanhando tendência mundial de aprimoramento dos instrumentos de avaliação psicológica, é possível observar, no contexto brasileiro, esforços de diversos pesquisadores em busca da qualidade e adequado uso dessas técnicas. Dentre os métodos pesquisados e bastante utilizados no Brasil e no mundo encontra-se o Psicodiagnóstico de Rorschach que, apesar de constituir importante técnica de avaliação da personalidade, ainda exige investigações científicas na realidade brasileira, de modo a oferecer o adequado suporte para sua utilização clínica em diferentes contextos. Dificuldades são encontradas, sobretudo, no tocante aos referenciais normativos para interpretação dos indicadores técnicos, em especial na investigação do desenvolvimento infanto-juvenil. Nesse contexto, o presente estudo objetivou elaborar padrões normativos do Método de Rorschach (Escola Francesa) em adolescentes de 12 a 14 anos de idade, de ambos os gêneros, de forma a oferecer referenciais técnicos para subsidiar processos analítico-interpretativos deste instrumento projetivo para a referida faixa etária, na realidade sociocultural contemporânea. Para tanto, avaliou-se amostra de 174 estudantes de escolas públicas e particulares da cidade de Ribeirão Preto, interior do Estado de São Paulo (SP). Os adolescentes foram examinados, individualmente, por questionário de histórico pessoal (respondido por seus pais e/ou responsáveis), pelo Teste de Inteligência Não Verbal (INV - forma C) e pelo Psicodiagnóstico de Rorschach (Escola Francesa). Os dois primeiros instrumentos serviram como critérios de seleção dos participantes, de modo a compor amostra de adolescentes com indícios de desenvolvimento típico. Cada protocolo do Rorschach coletado foi codificado por três juízes independentes, com posterior análise da concordância entre avaliadores. Foram examinados resultados dos adolescentes em 56 variáveis da Escola Francesa do Rorschach em termos descritivos (média, desvio-padrão, mediana, valores mínimo, máximo) e inferenciais, utilizando-se do método de regressão linear e distribuição binomial, a depender da variável analisada, a fim de verificar possíveis influências do gênero, idade e origem escolar na produção. Um quadro geral dos atuais referenciais normativos assinalou os seguintes índices médios: a) produtividade e de ritmo: $\mathrm{R}=21,3$ respostas; $\mathrm{TLm}=17,6$ segundos e $\mathrm{TRm}=29,6$ segundos; b) modos de apreensão: $\mathrm{G}=25,7 \%, \mathrm{D}=45,7 \%, \mathrm{Dd}=27,3 \%$ e $\mathrm{Dbl}=1,3 \%$; c) determinantes e índices formais: $\mathrm{F} \%=45,2 \%$ e $\mathrm{F}+\mathrm{ext} \%=65,5 \%$; d) estilo de vivência afetiva predominante: extratensivo; e) conteúdos predominantes: $\boldsymbol{\Sigma} \mathrm{A}=53,8 \%$ e $\boldsymbol{\Sigma} \mathrm{H}=22,7 \%$; f) Ban=14,8\%. A análise do possível efeito das variáveis gênero, idade e procedência escolar sobre a produção do Rorschach na amostra examinada apontou diferenças estatisticamente significativas em reduzido número de variáveis deste método projetivo, permitindo formulação de padrões normativos globais e atlas único para os adolescentes de 12 a 14 anos, de ambos os gêneros, provenientes do ensino público e privado do interior do Estado de São Paulo, cumprindo-se os objetivos aqui delineados, possibilitando aprimoramento em processos analítico-interpretativos deste método projetivo na realidade brasileira contemporânea. (CAPES)

Palavras-Chave: Rorschach. Normas. Adolescentes. Avaliação Psicológica. Técnicas projetivas. Personalidade. 


\begin{abstract}
Cury-Jacquemin, R. (2012). Normative data for the Rorschach Psychodiagnostic Test in adolescents aged 12 - 14 years. Dissertation (Master's Degree), Faculty of Philosophy, Science and Letters of Ribeirão Preto, University of São Paulo, Ribeirão Preto.
\end{abstract}

Accompanying a worldwide trend towards the improvement of the psychological assessment instruments, it is possible to observe, in the Brazilian context, efforts of many researchers seeking quality and encouraging the appropriate use of these techniques. Among the methods studied and widely used in Brazil and abroad lies the Rorschach Psychodiagnostic Test that, although it is an important technique of personality assessment, still requires scientific research in the Brazilian environment, in order to provide appropriate support for its clinical use in different contexts. Difficulties are found particularly as regards the elaboration of appropriate normative reference to interpret technical indicators, especially in investigating the development of children and adolescents. In this context, this study aims to establish normative patterns of the Rorschach Method (French School) for 12-14-year-old adolescents, from both genders, with typical development indicators, in order to provide technical references to support analytical and interpretive processes of this projective instrument for this age, in contemporary sociocultural reality. For this purpose, a sample of 174 students from public and private schools from the city of Ribeirão Preto, in the country region of the State of São Paulo (SP), was evaluated. The adolescents were examined, individually, by an informative questionnaire about participants' life history (responded by their parents and/or guardians), by the Non Verbal Intelligence Test (INV - form C), and by the Rorschach Method (French School). The first two instruments were used as selection criteria of participants in order to compose a sample of adolescents with indicative signs of typical development. Each Rorschach protocol collected was coded by three independent judges, with subsequent analysis of inter-rater agreement. The results of the adolescents were examined in 56 variables of the Rorschach French School in descriptive (mean, standard deviation, median, minimum, maximum) and inferential terms, using the method of linear regression and binomial distribution, depending on the variable analyzed in order to evaluate possible influences of gender, age, and school origin in the production. An overview of the current normative references indicated the following mean indexes: a) productivity and rhythm: $\mathrm{R}=21,3$ responses; TLm $=17,6$ seconds and $\mathrm{TRm}=29,6$ seconds; $\mathrm{b}$ ) apprehension models: $\mathrm{G}=25,7 \%, \mathrm{D}=45,7 \%, \mathrm{Dd}=27,3 \%$ and $\mathrm{Dbl}=1,3 \%$; ) determinants and formal indexes: $\mathrm{F} \%=45,2 \%$, and $\mathrm{F}+\mathrm{ext} \%=65,5 \%$; d) predominant affective experience style: extratensive; e) contents predominant: $\sum \mathrm{A}=53,8 \%$ e $\sum \mathrm{H}=22,7 \%$; f) $\mathrm{Ban}=14,8 \%$. The analysis of the possible effect of variables such as gender, age and school origin on the production of the sample examined, showed statistically significant differences in a reduced number of variables of this projective method, so as to enable the formulation of global normative data and a single atlas for adolescents aged 12 - 14 years of both genders, coming from public and private schools in the country region of the State of Sao Paulo, fulfilling the goals outlined here, enabling improvements in analytical-interpretative processes of this projective method in the contemporary Brazilian reality. (CAPES)

Key-words: Rorschach. Norms. Adolescents. Psychological Assessment. Projective Techniques. Personality. 


\section{LISTA DE TABELAS}

Tabela 1 - Estudos normativos do Rorschach apresentados nos últimos eventos científicos da área de Avaliação Psicológica e Métodos Projetivos no Brasil, ocorridos no período de 2006 a 2011.

Tabela 2 - Caracterização da amostra deste estudo normativo do Rorschach, em função da idade, gênero e origem escolar $(n=174)$.

Tabela 3 - Percurso amostral do estudo em função da origem escolar.

Tabela 4 - Distribuição dos casos do Rorschach entre os examinadores independentes.

Tabela 5 - Estatística descritiva da produtividade no Rorschach da amostra $(\mathrm{n}=174)$

Tabela 6 - Resultados (frequência simples e porcentagem), para cada cartão, das variáveis associadas à produtividade no Rorschach.

Tabela 7 - Distribuição em frequência simples $(f)$ e porcentagem (\%) do total de respostas $(\mathrm{R}=3706)$ nas diferentes categorias de classificação da Escola Francesa do Rorschach. .82

Tabela 8 - Distribuição dos adolescentes $(n=174)$ em frequência simples $(f)$ e porcentagem (\%), em função do Tipo de Vivência Afetiva (TRI) e da Fórmula das Tendências Latentes (TL). 86

Tabela 9 - Distribuição dos resultados globais (somatória e dados médios) da amostra em algumas variáveis do Rorschach associadas ao controle afetivo.

Tabela 10 - Resultados da comparação estatística das variáveis relacionadas à produtividade e ritmo no Rorschach, em função do gênero. .88 
Tabela 11 - Resultados da comparação estatística das principais variáveis da Escola Francesa do Rorschach, em função do gênero.

Tabela 12 - Resultados da comparação estatística das variáveis relacionadas a produtividade e ritmo no Rorschach, em função da origem escolar.

Tabela 13 - Resultados da comparação estatística das principais variáveis do Rorschach, em função da origem escolar. .94

Tabela 14 - Resultados da análise estatística das variáveis relacionadas a produtividade e ritmo no Rorschach, em função da idade (em anos). .99

Tabela 15 - Resultados da análise estatística das principais variáveis do Rorschach, em função da idade (em anos). 100

Tabela 16 - Resultados médios descritivos e inferenciais das variáveis do Rorschach na $\operatorname{amostra}(n=174)$. .105

Tabela 17 - Lista das respostas banais ao Rorschach, identificadas a partir do conjunto de respostas emitidas pela amostra total ( $\mathrm{n}=174)$ 109 


\section{LISTA DE APÊNDICES E ANEXOS}

APÊNDICE A - Carta de apresentação da pesquisa e autorização da instituição escolar.....143

APÊNDICE B - Termo de Consentimento Livre e Esclarecido

APÊNDICE C - Questionário informativo sobre histórico pessoal.

APÊNDICE D - Glossário referente ao processo de classificação das variáveis do Rorschach (adaptado de Rausch de Traubenberg, 1998; Pasian, 2000; Azoulay, 2007) 155

APÊNDICE E - Atlas referente às localizações e à qualidade formal das respostas produzidas pela amostra deste estudo. .165

ANEXO A - Aprovação do Comitê de Ética em Pesquisa. .275

ANEXO B - Escala de Percentis do INV - Forma C para adolescentes alfabetizados (Weil \& Nick, 1971)..... 279 


\section{SUMÁRIO}

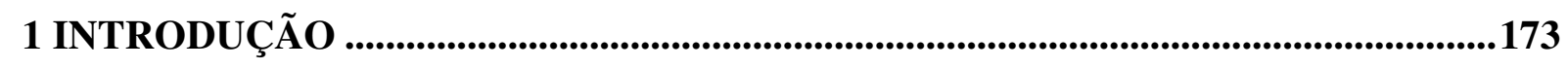

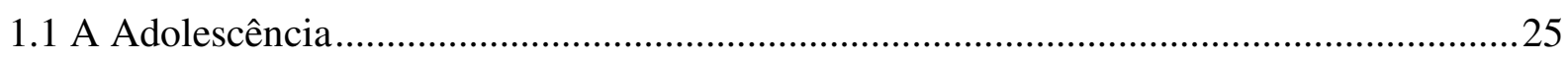

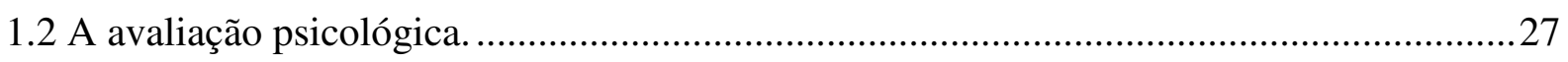

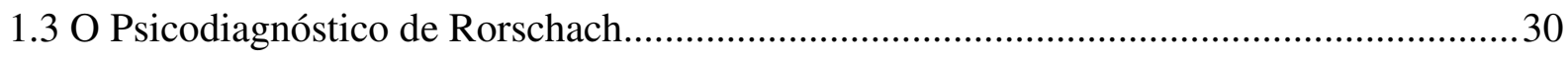

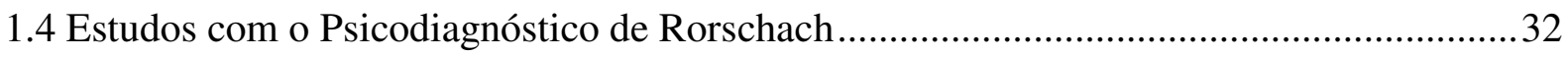

1.5 Estudos com o Psicodiagnóstico de Rorschach no Brasil ..................................................41

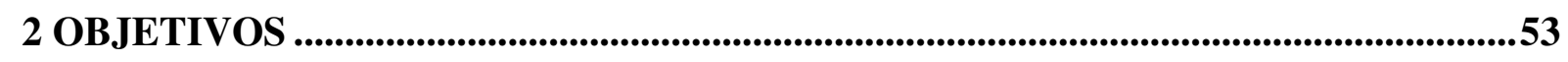

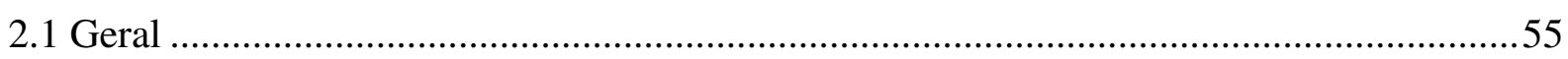

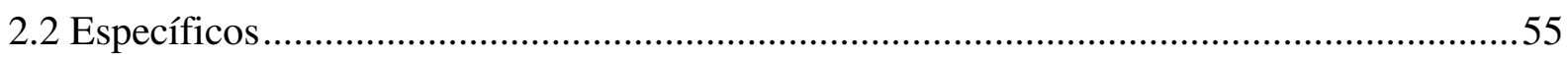

3 MÉTODO

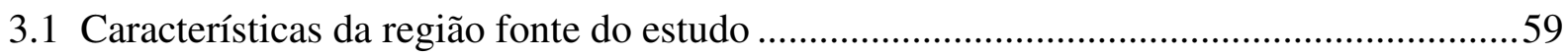

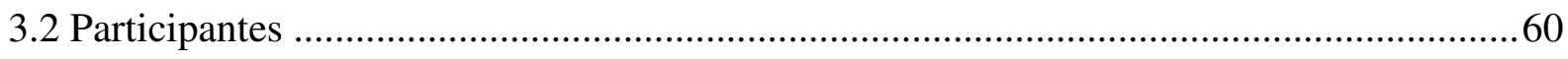

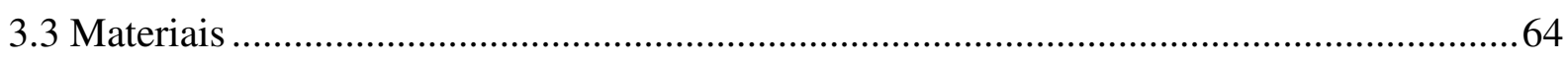

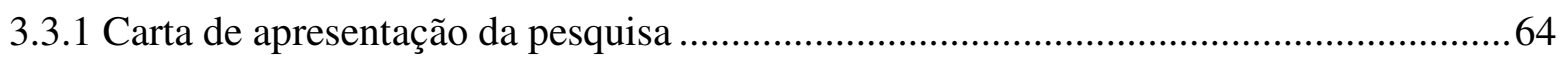

3.3.2 Termo de Consentimento Livre e Esclarecido (TCLE) ...............................................64

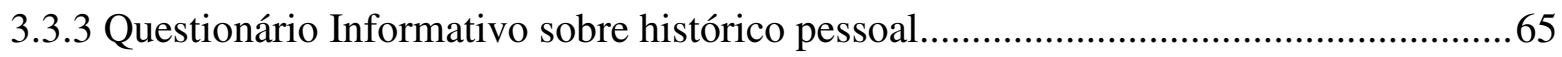

3.3.4 Teste de Inteligência Não Verbal (INV) - forma C .................................................65

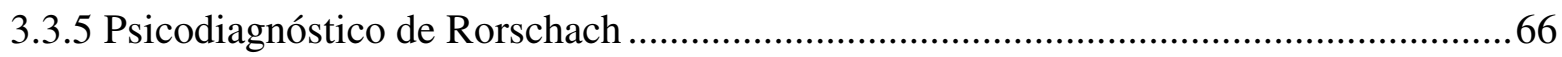

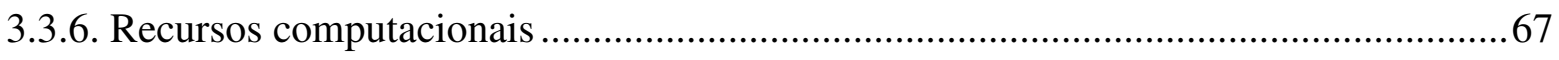

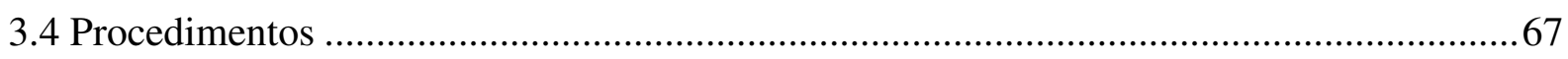

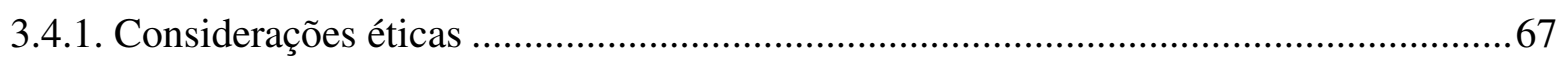

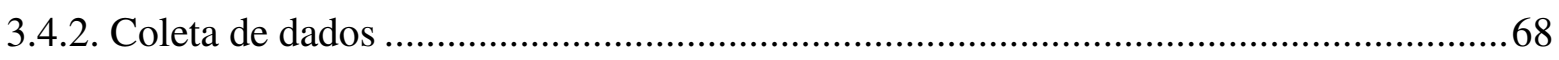

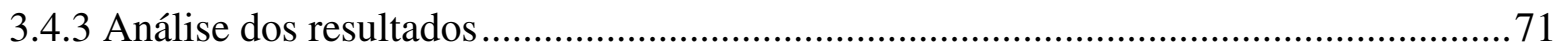

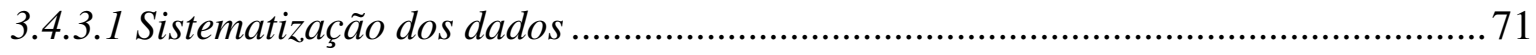

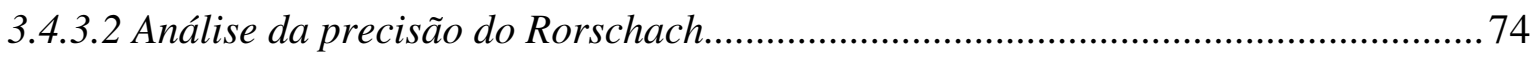

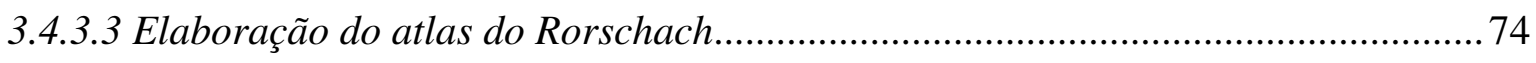

4 RESULTADOS

4.1 Precisão do Método de Rorschach................................................................................. 79 


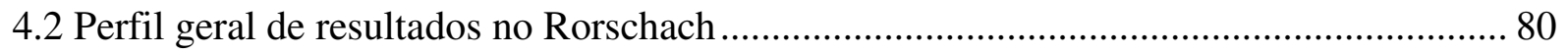

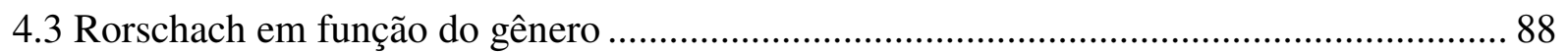

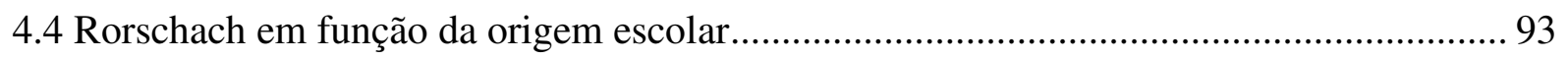

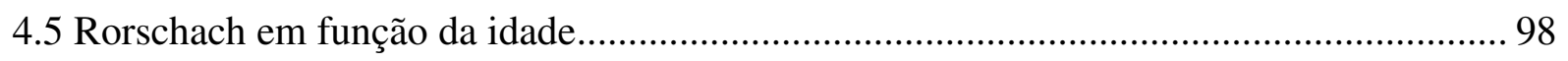

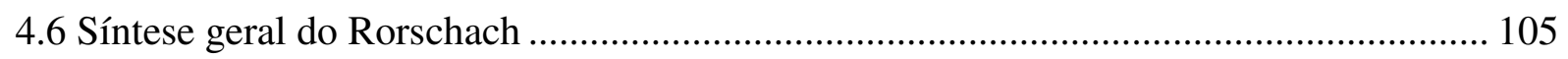

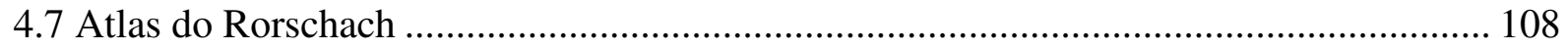

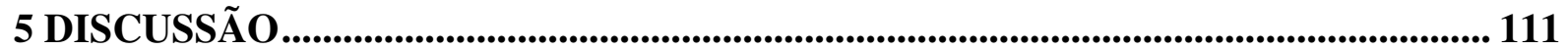

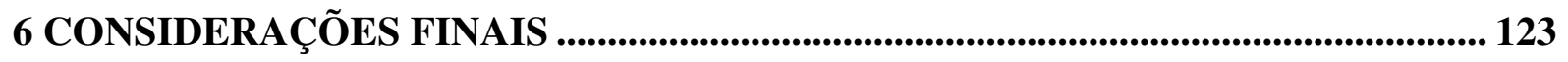

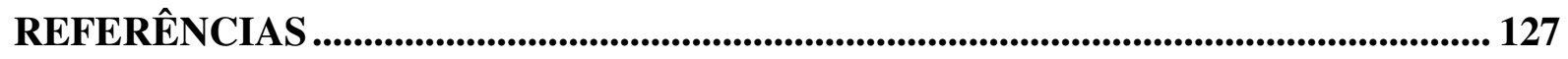

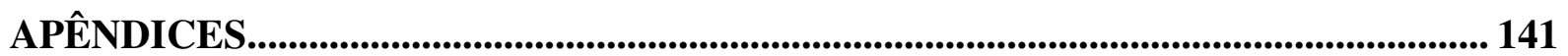

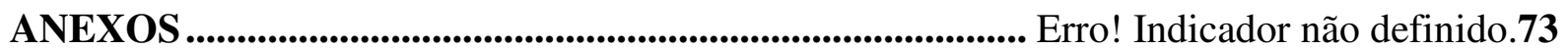


1 INTRODUÇÃO 


\subsection{A ADOLESCÊNCIA}

Dado que a fase da adolescência está estreitamente implicada no objetivo principal deste trabalho, uma vez que o intuito é avaliar o padrão de respostas de estudantes de 12 a 14 anos de idade ao Psicodiagnóstico de Rorschach, conjecturou-se ser válida uma caracterização preliminar desta etapa do desenvolvimento humano. Essa breve exposição de princípios teóricos sobre o tema poderão, posteriormente, amparar a interpretação dos resultados obtidos relativos aos indivíduos desta faixa etária.

De acordo com a Organização Mundial da Saúde (OMS, 1965), o adolescente é a pessoa que se insere na faixa dos 10 aos 19 anos de idade. Já para a lei brasileira, a partir do Estatuto da Criança e Adolescente - ECA (Lei no 8.069 de 13/07/90), a adolescência é o período que se estende dos doze aos dezoito anos de idade.

Apesar da polêmica em torno do início e da delimitação etária específica deste período do desenvolvimento humano, muitos concordam que a adolescência se caracteriza como uma passagem da etapa infantil para a fase adulta do desenvolvimento humano, iniciando-se com o advento da puberdade (Erikson, 1976; Knobel, 1981; Outeiral, 1994; Levisky, 2009). É um dos principais marcos no processo do desenvolvimento humano de acordo com Levisky (2009), que ainda caracteriza esta fase do desenvolvimento humano como "uma revolução biopsicossocial" (p. 21), influenciada pela cultura e sociedade nas quais o indivíduo está inserido.

Da mesma forma, Knobel (1981) também concedeu especial importância a este período específico do desenvolvimento humano. Este autor destacou algumas características peculiares do adolescente, tais como: necessidade de intelectualizar e de fantasiar; constantes flutuações do humor e do estado de ânimo; busca de si mesmo e da identidade própria. Acompanhando estas considerações, Outeiral (1994) também qualifica a adolescência como uma fase do crescimento humano marcada pela definição da identidade.

Nesse sentido, a adolescência se insere num período de desprendimento do que se viveu até então, ou seja, nesta fase, vive-se um processo de luto pelo corpo infantil e identidade de criança para se buscar uma nova relação com o mundo e consigo mesmo (Aberastury \& Knobel, 1981; Paladino, 2005). Paladino (2005) define bem, física e psiquicamente, o processo de construção da identidade:

A partir da puberdade, o corpo infantil é deixado de lado, e toda carga hormonal do futuro adulto entra em ação, determinando a entrada num novo ciclo, em que um novo corpo e novas sensações trazem também uma percepção e pensamento mais sofisticados. (p. 48) 
Erikson (1976) também postulou, em sua teoria do desenvolvimento, que a adolescência é um momento peculiar do crescimento humano, de integração das etapas anteriores, proporcionando ao indivíduo uma primeira percepção correta de si e do mundo no qual está inserido. Neste momento da vida, a crise psicossocial que o adolescente enfrenta é a da identidade versus confusão de papéis, aludindo à dificuldade de estabelecimento de uma identidade própria (Erikson, 1976). Segundo o autor, a identidade dos adolescentes não é formada a partir do modelo de outras pessoas, mas sim pela modificação e integração das identificações anteriores, a fim de constituir uma nova estrutura psicológica, que se dá por meio de processo complexo e multifacetado.

Nesse sentido, Weiten (2002) argumenta que, ainda que a aquisição de identidade seja um processo que acompanha o indivíduo durante todo o ciclo vital, é no período da adolescência que esta busca se torna mais clara e evidente. Isto porque, além das transformações corporais que estimulam o pensamento a respeito da autoimagem, há também modificações nos processos cognitivos (início das operações formais, segundo a terminologia de Piaget), que subsidiam maior introspecção do adolescente. De acordo com este autor, Erikson postula que:

O principal desafio da adolescência é a luta para formar um senso claro de identidade. Esta luta envolve a elaboração de um conceito estável de si mesmo como um indivíduo único e a adoção de uma ideologia ou sistema de valores que proveja um senso de direção. Na visão de Erikson, o adolescente enfrenta questões como: "Quem sou eu?" e "Aonde irei na vida?" (Erikson apud Weiten, 2002, p. 328).

Erikson (1976) ainda ressalta que a identidade não é um processo exclusivamente interno, uma vez que abarca aspectos sociais e culturais inerentes ao indivíduo. Dessa forma, a identidade está fortemente atrelada ao que o indivíduo pensa sobre ele mesmo, mas também ao que ele acredita que os outros pensam a respeito dele. Logo, as mudanças sociais profundas são grandes influenciadoras da modificação nos processos de formação da identidade humana.

Diante do exposto, e para se buscar compreender esse período do desenvolvimento humano, torna-se necessário considerar os aspectos socioculturais inerentes ao ambiente no qual o adolescente está inserido. Vale lembrar que as diferenças podem estar presentes em uma mesma sociedade, em um mesmo período de tempo, ou em sociedades e épocas distintas (Jardim-Maran, 2004).

Por conseguinte, cabe realçar que as considerações aqui expostas acerca da adolescência tiveram a finalidade de apresentar uma breve caracterização desta etapa do 
desenvolvimento humano, levando em consideração que o presente estudo tem o objetivo de avaliar, pelo Método de Rorschach, adolescentes de 12 a 14 anos de idade, com vistas a elaborar padrões normativos para este instrumento de avaliação psicológica junto à população adolescente. Diante deste panorama, doravante serão apresentados os aspectos relativos aos processos de avaliação psicológica envolvidos em investigações científicas desta natureza, procurando embasar a atual proposta de pesquisa.

\subsection{A AVALIAÇÃO PSICOLÓGICA}

Os testes psicológicos nasceram juntamente com os primeiros estudos psicológicos e educacionais, ao cabo do século XIX, e eram empregados, em especial, para examinar inteligência, interesses e aptidões dos indivíduos. Atendiam, primordialmente, a uma demanda a necessidades específicas de classificação, de seleção e de intervenção com diferentes grupos de indivíduos (Fernandes, 2006). Enquanto alguns cientistas da época se preocupavam em examinar as diferenças entre os indivíduos, outros focavam suas pesquisas ao que havia de similar, a fim de se elaborar descrições generalizadas do comportamento humano (Werlang, Villemor-Amaral \& Nascimento, 2010).

Atualmente, há uma expressiva diversidade de técnicas e de instrumentos de avaliação psicológica, empregados para atender a necessidade de investigação de diversas variáveis e processos psicológicos. Em cada instrumento utilizado pode-se encontrar atributos positivos, mas também limitações técnicas, cabendo ao psicólogo analisá-los para decidir por sua inclusão (ou não) em um processo avaliativo e em sua prática profissional (Fensterseifer \& Werlang, 2008). Neste trabalho citado, estas pesquisadoras discutem, sobretudo, a questão da cientificidade das técnicas projetivas de avaliação psicológica. Afirmam que "as técnicas projetivas, como instrumentos que geram hipóteses interpretativas, são importantes ferramentas para a identificação de características e traços de personalidade, bem como de sinais e sintomas relacionados a quadros psicopatológicos" (p. 15).

Os métodos projetivos podem, dessa forma, ser respeitáveis ferramentas na avaliação, tanto da personalidade quanto de outros elementos de relevante importância para a compreensão da pessoa em si ou de uma situação experienciada ou percebida por ela, como dinâmica familiar e relações interpessoais (Fensterseifer \& Werlang, 2008). Entretanto, para que estas técnicas se constituam como instrumentos válidos, capazes de oferecer informações relevantes e adequadas sobre os indivíduos, devem, de fato, ser constituídos com adequada base psicométrica e científica, representando de forma clara os construtos em análise. 
Na concepção de Urbina (2007), um teste psicológico bem construído e padronizado oferece a assistência necessária para a investigação de uma variedade de problemas práticos. Complementando este raciocínio, Cruz (2002) argumenta que o uso de instrumentos de avaliação psicológica presume a possibilidade de enriquecimento na identificação e na compreensão sobre características dos indivíduos.

Em acordo com uma tendência mundial de aprimoramento dos métodos de avaliação psicológica, pode-se observar, no contexto brasileiro, esforços de diversos pesquisadores nesta direção, buscando qualidade e adequado uso dos instrumentos psicológicos disponíveis (Noronha et al., 2005). Estes estudos enfatizam, portanto, a necessidade de revisão metodológica dos instrumentos psicológicos em uso no Brasil, como apontam Oliveira et al. (2005) e Noronha e Vendramini (2003), entre outros.

Acompanhando este cenário, o Conselho Federal de Psicologia (CFP, 2003) publicou uma resolução (Resolução 002/2003) que regulamenta o uso, a elaboração e a comercialização de testes psicológicos no Brasil, tendo em vista a preocupação tanto com as questões éticas envolvidas nos processos de avaliação psicológica, assim como com a qualidade metodológica dos instrumentos utilizados. A Resolução 002/2003 destaca, entre outros aspectos, a necessidade do aprimoramento dos instrumentos e procedimentos técnicos de trabalho dos psicólogos, exigindo revisão periódica dos métodos utilizados na avaliação psicológica. Estas medidas objetivam garantir intervenções profissionais de adequada qualidade técnica e ética à população brasileira usuária desses serviços. Além disso, esta resolução destaca a importância de se construir um sistema contínuo de avaliação dos instrumentos psicológicos, adequado à dinâmica da comunidade científica e profissional.

Dentre as estratégias para operacionalizar a Resolução do CFP acima referida, este órgão criou o Sistema de Avaliação de Testes Psicológicos (SATEPSI), sistema este que visa examinar minuciosamente a qualidade dos instrumentos psicológicos disponíveis no Brasil (CFP, 2003). Com isso, qualquer prova a ser utilizada no país destinada ao exame psicológico é primeiramente submetida, por especialistas da área, a uma análise de caráter objetivo, a partir de critérios adotados segundo normas internacionais que estabelecem o mínimo necessário para aceitação de uma técnica como instrumento de avaliação psicológica.

Apesar da polêmica gerada com essa medida, Pasian (2006) aponta bons resultados advindos deste sistema avaliativo dos instrumentos de avaliação psicológica no Brasil, visto que instaurou o questionamento tanto em relação às técnicas e suas características, quanto a respeito da formação dos profissionais que se utilizam destes instrumentos nos diferentes contextos de atuação. Estimulou-se, desse modo, o aprimoramento técnico-teórico dos 
processos psicodiagnósticos como uma necessidade básica e evidente na qualificação dos psicólogos brasileiros.

Apesar da inexistência de consenso teórico sobre as classificações dos testes psicológicos, duas grandes tipos de materiais de exame psicológico podem ser destacados: os mais estruturados e os menos estruturados. Nos primeiros encontram-se os testes psicométricos, baseados em critérios objetivos (concretos e observáveis), os quais, segundo Bandeira (2006), visam medir ou dimensionar determinado construto, direcionando-se para avaliação intelectual, percepções, aptidões e interesses. Na segunda classe estão os métodos projetivos, que se caracterizam pela apresentação de uma tarefa não estruturada ao indivíduo e que permite uma grande variedade de respostas, já que utilizam critérios dinâmicos e representantes conceituais (e não diretamente observáveis) para interpretar e/ou caracterizar um construto. Tais instrumentos são dirigidos principalmente à investigação da personalidade ou aspectos a ela relacionados, além de fatores de ordem emocional, como já referido no início deste trabalho. Desse modo, espera-se que o material suscitado pelo método projetivo sirva como uma tela, na qual o indivíduo deposita suas necessidades e seus conflitos, medos e agressões, assim como os processos característicos de pensamento (Anastasi \& Urbina, 2000; Cunha, 2000).

Os instrumentos projetivos de avaliação psicológica são caracterizados pelo aspecto dúbio de seus estímulos, apresentados de forma a não revelar seu verdadeiro intento, desfavorecendo um controle consciente e objetivo da atividade proposta (Cunha, 2000). Isso propicia liberdade de interpretação, valorizando aquilo que surge espontaneamente à consciência do avaliando, que pode, dessa forma, imprimir sua subjetividade ao estímulo. Nesse sentido, Anzieu (1986) aponta que os métodos projetivos são marcados pela não existência de boas ou más respostas pré-determinadas, sendo válido aquilo que sobressai à consciência. Nas palavras de Anzieu (1986):

Os testes projetivos, analogicamente, levam o sujeito a produzir um protocolo de respostas de tal modo que a estrutura do mesmo corresponde à estrutura de sua personalidade, estando conservadas no primeiro as características fundamentais da segunda. (p. 18)

Independentemente da natureza específica do método de avaliação psicológica (objetivo ou projetivo), para que possa ser considerado científico é de essencial importância a presença de adequados índices psicométricos, em especial validade e precisão. A fidedignidade ou precisão dos métodos projetivos, segundo Fensterseifer e Werlang (2008), pode ser alcançada pela concordância entre juízes independentes ao corrigirem e 
interpretarem, às cegas, os mesmos protocolos (casos avaliados). No tocante à validade, muitas alternativas operacionais tornam-se possíveis, como apontado por Primi e Nunes (2010), entre outros trabalhos.

Adicionalmente, a elaboração e a atualização de referenciais normativos tornam-se igualmente indispensáveis. Japur (1982) assinala a necessidade de se apontar o grupo de referência do avaliando ao se descrever a estrutura de sua personalidade, ao mesmo tempo em que se destacam as características que o convertem em um indivíduo específico. Neste sentido, Japur (1982) constatou que:

A necessidade de parâmetros se baseia no fato de que para descrever a estrutura de personalidade de uma pessoa é necessário indicar o grupo ao qual ela pertence e, ao mesmo tempo, destacar os traços individuais que a convertem em um indivíduo específico. Através desses parâmetros é possível visualizar o conjunto de respostas dadas por uma pessoa contra um fundo de respostas características de seu grupo. (p. 07)

Ao se confrontar características individuais de personalidade a dados concernentes ao grupo de referência ao qual este indivíduo se encaixa, faz-se possível formular hipóteses comparando indivíduo e grupo, na tentativa de situar cada um deles em determinado estado de desenvolvimento (Pasian, 1998). Seguindo esse pensamento, Cunha (2000) e Anastasi e Urbina (2000) apontam para a importância vital dos estudos normativos para o processo de avaliação psicológica.

Diante do exposto, há que se pensar sobre o panorama disponível dos estudos brasileiros com os métodos projetivos de avaliação psicológica, de modo a poder utilizá-los com adequado e suficiente embasamento técnico-científico, como proposto pelas diretrizes atuais do CFP (CFP, 2011). Dentre as alternativas metodológicas de base projetiva, destacase, neste momento, o Psicodiagnóstico de Rorschach, objeto do presente trabalho, a seguir brevemente apresentado em seus princípios.

\subsection{O PSICODIAGNÓSTICO DE RORSCHACH}

Em meio aos instrumentos projetivos de avaliação psicológica empregados no Brasil e em todo panorama mundial, encontra-se o Psicodiagnóstico de Rorschach, publicado em 1921, elaborado pelo psiquiatra suíço Hermann Rorschach (1884-1922). Esta técnica de investigação da personalidade tem apontado eficiência e sensibilidade na compreensão da dinâmica do psiquismo humano numa linguagem universal (Weiner, 1993; Anastasi \& Urbina, 2000). Este instrumento tem o desígnio de compreender aspectos da estrutura e da dinâmica da personalidade (Werlang, Villemor-Amaral \& Nascimento, 2010; Weiner, 2000), 
"por meio da análise de processos perceptivos envolvidos na produção de respostas" (Werlang, Villemor-Amaral \& Nascimento, 2010, p. 89). Não obstante o reconhecimento internacional em diversas áreas de aplicação, este instrumento possui evidências de validade em vários contextos socioculturais, o que reforça, de maneira indiscutível, sua possibilidade de contribuição científica para a compreensão da estrutura e do funcionamento psíquico dos indivíduos (Nascimento, 2002; Pasian, 2000).

A proposta de aplicação deste método, por ser considerado um instrumento projetivo, caracterizado pelo aspecto dúbio de seus estímulos, possibilita a livre associação por parte do examinando, isto é, desfavorece um controle consciente e objetivo da atividade proposta (Cunha, 2000). Habitualmente, esta condição relaxa defesas do respondente, possibilitando o advento de elementos inconscientes, embora ainda seja mantida certa resistência por parte do examinando durante o processo de associação das respostas, devido ao nível de tolerância de ansiedade para lidar com o material reprimido (Nascimento, 2010).

Para Weiner (2000), “a codificação das respostas do Rorschach considera o modo como o sujeito soluciona o problema de dizer o que as manchas poderiam ser, ao mesmo tempo em que reconhece que não passam de simples manchas" (p. 16). Para tanto, o respondente se atém a determinadas partes da prancha conforme seu modo particular de apreensão, caracterizando o instrumento como "uma tarefa de estruturação cognitiva que envolve processos de atenção, percepção, tomada de decisão e análise lógica” (p. 16). Ao mesmo tempo, este método de investigação alcança muito mais além, podendo explorar aspectos latentes do indivíduo, por meio de uma compreensão psicanalítica, envolvendo processos de associação, atribuição e simbolização (Weiner, 2000). Visto isso, ambos os processos, perceptivo e associativo, devem ser levados em consideração ao se tratar deste instrumento de avaliação psicológica.

Uma vez que se tenha acesso a características de personalidade tanto conscientes quanto inconscientes, há chance de se obter informações relevantes acerca da estrutura e da dinâmica de personalidade dos indivíduos (Adrados, 1985; Weiner, 2000). De tal modo, torna-se possível a apreensão global do indivíduo, abarcando seus recursos latentes e manifestos, como também seus aspectos de maior vulnerabilidade, dando respaldo a um aconselhamento psicológico, uma indicação terapêutica e um prognóstico evolutivo (Chabert, 2004).

O método de investigação da personalidade de Rorschach pode ser aplicado a pessoas procedentes de qualquer raça ou cultura, embora haja diferenças não simplesmente em aspectos individuais, mas também em fatores sociais e culturais (Nascimento, 2010). Para 
Weiner (2000), “um único conjunto de normas representativas não garante que um teste possa ser interpretado da mesma maneira, a despeito da idade, sexo e formação cultural do sujeito” (p. 48), pois a generalização exacerbada pode mascarar as diferenças existentes entre os grupos. Por este motivo, diversos estudos foram realizados durante o século XX para se abordar as questões relativas às divergências e similaridades entre os diferentes grupos culturais (Nascimento, 2010). Alguns destes trabalhos farão, portanto, o conteúdo do próximo tópico, relativo a estudos desenvolvidos na última década com este método projetivo de avaliação psicológica.

\subsection{ESTUDOS COM O PSICODIAGNÓSTICO DE RORSCHACH}

Pesquisadores de todo o mundo têm demonstrado interesse em elaborar padrões normativos para o Rorschach e reafirmam, a partir da sistematização de seus resultados, a importância de que mais estudos com este propósito sejam realizados em grupos populacionais de diversos países, para que se tenham dados representativos dos indivíduos que se busca avaliar. Esta recomendação técnica é encontrada em diversos trabalhos, como os de Resende, Rezende e Martins (2006); Andronikof, Chudzik e Gillaizeau (2008); Matsumoto, Morita, Suzuki, Tsuboi, Hatagaki e Shirai (2008); Nascimento, Brunoni, Sasaki, Bueno e Parsons (2008b); Nascimento, Batistuzzo, Sato, Brunoni, Bueno e Marques (2009), que assinalam diferenças entre dados normativos de acordo com padrões socioeconômicos e culturais peculiares dos vários países.

$\mathrm{Na}$ perspectiva de rastrear investigações científicas voltadas à elaboração de padrões normativos do Método de Rorschach, foi realizado um levantamento bibliográfico nos livros de resumos e de anais dos últimos congressos internacionais de Avaliação Psicológica realizados a partir de 2006, mais especificamente, o XIX Congresso Internacional de Rorschach e Métodos Projetivos, evento científico realizado pela International Society of Rorschach (ISR), acontecido em Julho de 2008 na Bélgica, e o VIII Congresso Iberoamericano de Avaliação Psicológica, ocorrido em 2011 em Portugal. A busca dos estudos focalizou eventos científicos da área de avaliação psicológica, com ênfase nos métodos projetivos, dado que, neste tipo de publicação, consegue-se obter um panorama mais atual e recente dos trabalhos ainda em desenvolvimento, nem sempre já formalmente publicados em periódicos indexados. A partir disso, foi possível encontrar pesquisas normativas do Rorschach sendo desenvolvidas em diferentes países, podendo-se destacar os estudos de Bagbag (2008) na Tunísia; Fernandez e Pardillo (2008) em Cuba; Andronikof, Chudzik e Gillaizeau (2008) na França; Matsumoto (2008) no Japão; Lis, Salcuni, Parolin, Di 
Riso e Laghezza (2008) na Itália; Yazigi, Ribeiro e Semer (2008), Nascimento (2008), Lelé (2008a) e Villemor-Amaral et al. (2008) no Brasil. Especificamente com a população adolescente, foco do presente estudo, foram encontrados os trabalhos de: Andronikof, Chudzik e Gillaizeau (2008, com 121 adolescentes de 14 a 17 anos), de Nascimento et al. (2008b, com 30 adolescentes de 14 a 17 anos), e de Matsumoto et al. (2008, com 352 participantes de 8 a 14 anos), todos pautados pelo Sistema Compreensivo do Rorschach (SC), o que afirma a relevância de se tentar, como presentemente proposto, elaborar padrões normativos para faixa etária da adolescência no Brasil, mas a partir do referencial da Escola Francesa do Rorschach.

Completando este panorama e para se buscar visão contemporânea e atualizada das investigações científicas a respeito do Método de Rorschach em publicações indexadas no cenário mundial, foi realizada uma pesquisa bibliográfica, em Fevereiro de 2011, com a palavra-chave "Rorschach" na base de dados Medline, referente ao período de 2005 a 2010. Foram encontrados 182 estudos, em diversos contextos socioculturais, nos quais este método de avaliação psicológica foi aplicado com o intuito de levantar indícios sobre estrutura e funcionamento psíquicos. Estes trabalhos foram realizados com indivíduos de diferentes faixas etárias, níveis de escolaridade e variadas condições socioeconômicas. Uma observação interessante se deu para o fato de que a maioria desses estudos identificados possui natureza clínica, investigando-se diferentes psicopatologias e, em vários trabalhos, buscou-se comparar resultados da produção no Rorschach de pacientes e de não-pacientes.

Ao se tentar circunscrever esta ampla gama de investigações internacionais sobre o Método de Rorschach, acrescentou-se a palavra-chave "Adolescente" ao levantamento bibliográfico previamente realizado, por se tratar do foco do presente trabalho. Nesta nova pesquisa, o número de estudos encontrados se restringiu a 43, sendo 13 deles realizados com adolescentes que apresentavam algum transtorno mental (Ilonen et al., 2010; Kernier, Canouï, Golse, 2010; Bram, 2010; Balotti et al., 2009; Franks et al., 2009; Rothschild, Lacoua \& Stein, 2009; Klinteberg, Johansson \& Gacono, 2008; Kochinski et al., 2008; Rothschild et al. 2008; Kimhy et al., 2007; Blatt, Besser, Ford, 2007; Grava et al., 2006; McGrath et al., 2005) e os demais trabalhos versavam sobre temas diversos desta etapa do desenvolvimento. Uma vez que a complexidade deste período de desenvolvimento pode ser disparadora para múltiplos focos de investigação científica, o pequeno número de trabalhos identificados na literatura científica internacional, indexada nesta reconhecida base de dados, sugere reduzido investimento sobre o processo de adolescência a partir do Psicodiagnóstico de Rorschach, método este capaz de acessar variáveis relevantes do processo de formação da personalidade. 
$\mathrm{Na}$ perspectiva de focalizar ainda mais a pesquisa bibliográfica, adicionou-se o descritor "Normas", restringindo os achados bibliográficos ao foco principal deste estudo. A partir de então, foram identificados sete trabalhos, dos quais quatro (Nascimento, 2007; Meyer, Erdberg \& Shaffer, 2007; Shaffer, Erdberg \& Meyer, 2007; Van Patten, Shaffer, Erdberg \& Canfield, 2007) pertenciam a uma mesma edição suplementar de um periódico intitulado Journal of Personality Assessment de 2007. De acordo com Nascimento (2010), a maior parte das pesquisas realizadas com o Rorschach na atualidade é publicada neste periódico, apontando para a importância de se abordar, de maneira especial, esta edição suplementar. Embora os trabalhos de Nascimento (2007) e de Shaffer, Erdberg e Meyer (2007) tenham sido identificados como estudos com adolescentes pela referida base de dados, a autora do primeiro estudo mencionado examinou 409 brasileiros de 17 a 64 anos e os outros autores desenvolveram padrões normativos a partir de uma amostra de 283 norte-americanos de 17 a 70 anos, podendo ser consideradas, portanto, como amostra de adultos. Dentre os outros três estudos encontrados, estão Tibon e Rothschild (2009); Hartmann, Norbech e Gronnerod (2006) e Dao e Prevatt (2006). Vale ressaltar que estes últimos também foram publicados no mesmo periódico já citado acima, porém em edições distintas, enfatizando a importância deste para os trabalhos com o Método de Rorschach.

O manuscrito de Tibon e Rothschild (2009) discute e problematiza achados relativos ao estudo apresentado por Meyer, Erdberg e Shaffer (2007). Estes últimos apontaram uma significativa variabilidade no padrão de respostas ao Método de Rorschach entre as amostras de crianças e adolescentes não pacientes incluídos no projeto internacional do Sistema Compreensivo (CS; Exner, 2003 apud Tibon \& Rothschild, 2009). Meyer et al. ainda afirmaram, no estudo de 2007, que haveria um risco técnico na aplicação rígida das orientações interpretativas padronizadas para crianças e adolescentes, podendo produzir algumas inferências incorretas sobre a saúde mental destes indivíduos. A partir destas considerações, Tibon e Rothschild (2009) elaboraram seu trabalho onde buscaram fornecer orientações básicas para a interpretação de protocolos de pacientes jovens, enfatizando a necessidade de se utilizar dados estruturais conjuntamente com variáveis do desenvolvimento e contextuais. Suas orientações técnicas foram, então, ilustradas em um estudo de caso apresentado por estes autores, compondo a essência deste trabalho.

O estudo realizado por Hartmann, Norbech e Gronnerod (2006) examinou a validade discriminante e convergente das variáveis teoricamente relevantes do Sistema Compreensivo de Rorschach (CS) (Exner, 2003 apud Hartmann, Norbech \& Gronnerod, 2006) e as variáveis de agressividade de Meloy e Gacono (1992 apud Hartmann, Norbech \& Gronnerod, 2006). 
Os pesquisadores compararam estudantes universitários, pacientes com esquizofrenia e presidiários considerados violentos. Estes últimos foram subdivididos em dois grupos: psicopatas e não-psicopatas em tratamento psiquiátrico. Os resultados indicaram que sete das 12 variáveis puderam discriminar significativamente os presos psicopatas dos não-psicopatas, sugerindo maiores distúrbios agressivos, cognitivos e interpessoais entre os presos psicopatas. Os autores também encontraram diferenças significativas entre os presidiários, os pacientes esquizofrênicos e os universitários. Para eles, esses achados empíricos confirmam a hipótese da psicopatia como uma forma particular de transtorno de personalidade anti-social, organizada em um nível patológico mais grave na estruturação da personalidade.

Ao estudar pacientes adultos, Dao e Prevatt (2006) investigaram indícios de confiabilidade e validade do Perceptual-Thinking Index (PTI; Exner, 2000a, 2000b apud Dao e Prevatt, 2006) do Sistema Compreensivo do Rorschach. Foram realizadas análises de confiabilidade e validade em 107 pacientes com esquizofrenia ou transtorno de humor, sem características psicóticas, segundo o Manual Diagnóstico e Estatístico de Transtornos Mentais. Os resultados deram suporte para a confiabilidade inter-observador, bem como para a consistência interna do PTI. Além disso, os autores afirmaram que o PTI se mostrou índice eficaz na diferenciação entre pacientes esquizofrênicos e pacientes diagnosticados com transtorno de humor, fortalecendo as evidências de validade do Método de Rorschach.

Com o intuito de ampliar o levantamento bibliográfico inicialmente realizado sobre os estudos normativos realizados de 2005 a 2010 com o Método de Rorschach na população de adolescentes, a base de dados PsycInfo também foi consultada. Nesta nova busca, utilizandose novamente os indexadores "Rorschach", "Adolescentes" e "Normas", 28 trabalhos foram encontrados, entretanto, apenas um deles (Azoulay, Emmanuelli, Rausch de Traubenberg, Corroyer, Rozencwajg, \& Savina, 2007) diferia dos que estão inseridos na já citada edição suplementar de 2007 do Journal of Personality Assessment, ressaltando a irrefutável relevância deste periódico na área de avaliação psicológica de natureza projetiva.

Neste estudo de Azoulay et al. (2007), realizado na França, foram investigados 278 indivíduos não pacientes de 13 a 25 anos de idade, de ambos os gêneros, utilizando-se dos referenciais técnicos da Escola Francesa do Rorschach. Os participantes foram distribuídos em três subgrupos etários: 13 a $15 \operatorname{anos}(\mathrm{n}=98), 16$ a $18 \operatorname{anos}(\mathrm{n}=87)$ e 19 a $24 \operatorname{anos}(\mathrm{n}=93)$ e também em outros três subgrupos de acordo com níveis socioeconômicos (favorecidos, intermediários e desfavorecidos). Os próprios autores foram os responsáveis pela coleta e análise dos protocolos, verificando inicialmente a concordância entre os avaliadores independentes (precisão metodológica) a partir da codificação de 50 casos. Os resultados 
indicaram grande similaridade entre as frequências de respostas localizadas em áreas $G$ $(43,3 \%)$ e D (43,6\%), que apresentaram uma relação de 1/1. Houve também grande quantidade de respostas determinadas pela forma $(\mathrm{F} \%=61,3 \%)$. Além disso, surgiram novas respostas Banalidade e respostas D, suscitando a elaboração de nova listagem de Banalidades e de respostas Detalhe. Neste estudo, não foram encontradas diferenças relevantes na análise das variáveis do Rorschach em função do gênero, da idade e do nível socioeconômico. No entanto, algumas especificidades de produção foram notadas, como o A\% maior entre os indivíduos de condição social desfavorecida em relação aos indivíduos classificados como economicamente favorecidos. Em relação aos determinantes, foi possível verificar que os adolescentes provindos de classe social menos favorecida apresentaram número inferior de respostas $\mathrm{K}$ ou de natureza mais sensorial ( $\mathrm{C}$ e E) em comparação aos participantes das demais classes socioeconômicas. Ao final, Azoulay et al. (2007) destacaram a inibição observada na análise dos protocolos dos indivíduos socialmente menos favorecidos e ainda sustentaram a necessidade técnica de se comparar resultados encontrados de amostras infantis e adultas, a fim de se alcançar adequada compreensão acerca da produção no Rorschach por parte de adolescentes e das especificidades das várias etapas do desenvolvimento humano.

Numa tentativa de ampliação dos achados bibliográficos identificados a respeito de estudos normativos do Rorschach realizados na última década, procurou-se examinar os dados apresentados em recente trabalho de doutoramento defendido por Jardim-Maran (2011). Esta pesquisadora valeu-se dos indexadores "Rorschach" e "Normas" para seu recorte bibliográfico, delineado a partir de três bases de dados distintas: PsycInfo, Pepsic e Lilacs, focalizando os trabalhos publicados de 2000 a 2011. Relatou ter identificado 38 estudos normativos com o Psicodiagnóstico de Rorschach, os quais foram desenvolvidos, em sua maioria, de acordo com o Sistema Compreensivo. Do total de trabalhos localizados, 34 foram na base de dados Psycinfo, outros quatro na Pepsic e, destes, dois também estavam na base de dados Lilacs. Mais uma vez, os 28 estudos publicados na edição especial de 2007 do Journal of Personality Assessment foram identificados nesta pesquisa bibliográfica. Os demais estudos (Ikiz, Zabci, Dusgor, Atak, Yavuz, Purisa, \& Catagy, 2010; Shweta, Baipai, Sengar, Singh, \& Desai, 2010; Riquelme \& De Taub, 2008; Azoulay et al., 2007; Chaudhury, Sudarshan, Seb, Saluja, Srivastava, \& Kundeyawala, 2007; Lelé, 2006; Nascimento, 2006; Singh, Singh, \& Singh, 2005; Sultan, Andronikof, Fouques, Lemmel, Mormont, Réveillère, \& Saïas 2004; Nascimento, 2002), distribuídos em diversos periódicos, tratam de amostras de idades distintas e apenas dois deles abordam a faixa etária adolescente, a saber: o de Azoulay et al. (2007), anteriormente descrito, e o de Ikiz et al. (2010). Pode-se, portanto, afirmar que 
houve convergência nos achados da pesquisa bibliográfica realizada por Jardim-Maran (2011) comparativamente ao trabalho presentemente desenvolvido, fortalecendo estes levantamentos como referências úteis para a atualização científica no tema em foco.

Dentre estes trabalhos, cabe destaque ainda neste momento, o estudo desenvolvido por Ikiz et al. (2010) na Turquia, visto que também se pautou na Escola Francesa do Rorschach, referencial técnico-científico a embasar a presente investigação. Nesta pesquisa foram avaliados 432 adolescentes turcos de 13 a 19 anos, não pacientes, de ambos os gêneros. Assim como na pesquisa de Azoulay et al. (2007), os adolescentes turcos foram divididos em subgrupos: de acordo com a idade (um grupo de 13 a 15 anos e outro de 16 a 19 anos) e também em relação aos níveis socioculturais (favorecidos, intermediários e desfavorecidos). Tal similaridade se deve ao fato de que este estudo foi realizado em colaboração com o Departamento de Psicologia Clínica e Psicopatologia da Universidade de Paris-Descartes, sob o auxílio das professoras C. Azoulay e M. Emmanuelli no que tangia às questões relacionadas à metodologia da pesquisa. As possíveis divergências de análise entre os nove pesquisadores foram resolvidas a partir da codificação inicial de 100 protocolos do Rorschach. Foram realizadas análises estatísticas e inferenciais dos dados, comparando-se o possível efeito das variáveis gênero, idade e origem socioeconômica sobre os resultados obtidos. De modo geral, não encontraram muitas diferenças estatisticamente significativas em função do sexo e das faixas etárias. Entretanto, ao comparar os adolescentes dos três diferentes grupos socioeconômicos, os autores puderem verificar que os adolescentes do nível mais desfavorecido apresentaram F\% maior que os demais, além de menor frequência de respostas G, juntamente ao aumento das respostas D. Compararam estatisticamente os achados deste estudo com os dados normativos desenvolvidos por Azoulay et al. (2007), podendo verificar que os participantes turcos apresentaram menor número médio de respostas, bem como inferior número de respostas sensoriais (C e E) em relação aos adolescentes franceses, apontando sinais de funcionamento psíquico com marcas de maior restrição nos adolescentes turcos. Por fim, os pesquisadores expuseram uma lista das respostas Detalhe (D) e Banais (Ban) encontradas no estudo, assinalando a possibilidade futura de se comparar adultos advindos do mesmo contexto sociocultural com os resultados obtidos com os adolescentes.

Ainda com uma perspectiva de estudo sobre a questão dos estudos normativos do Método de Rorschach, considera-se necessário retomar aqui a edição suplementar do Journal of Personality Assessment (no. 89, 1), dado incluir ampla gama de trabalhos realizados em múltiplos países. De fato, este número deste periódico científico foi elaborado, a convite do editor, para tratar dos estudos normativos do Rorschach desenvolvidos com base no Sistema 
Compreensivo, em diferentes regiões do mundo, incluindo países das Américas e da Europa, além de Japão e Austrália, após vários debates do tema em congressos internacionais da International Society of Rorschach (ISR). Ao todo, 28 trabalhos foram publicados número temático especial (Berant, 2007; Campo \& Vilar, 2007; Daraglou \& Viglione, 2007; De Ruiter \& Smid, 2007; Dumitrascu, 2007; Greenway \& Milne, 2007; Hamel \& Shaffer, 2007; Hansen, 2007; Ivanouw, 2007; Lis et al., 2007; Lis et al., 2007; Lunazzi et al., 2007; Matsumoto et al., 2007; Mattlar et al., 2007; Meyer et al., 2007; Mormont et al., 2007; Nakamura et al., 2007; Nascimento, 2007; Pertchik \& Shaffeer, 2007; Pires, 2007; Ráez, 2007; Salcuni et al., 2007; Sanz, 2007; Shaffer et al., 2007; Silva \& Dias, 2007; Tibon, 2007; Valentino et al., 2007; Valentino et al., 2007).

Observando o conjunto destes trabalhos, é possível constatar a preocupação de pesquisadores de vários países em elaborar referenciais normativos do Rorschach, analisando diferentes populações de faixas etárias e nacionalidades variadas. Isto realça a importância deste tipo de investigação científica para fundamentar uma adequada prática clínica. Contudo, dentre todos estes trabalhos encontrados, apenas três (Lis et al., 2007; Matsumoto et al., 2007; Van Patten et al., 2007) abarcaram a fase da adolescência, sendo que os demais estudos enfocaram as produções no Rorschach em crianças e adultos. Como a adolescência é o cerne do presente estudo, as pesquisas realizadas com esta faixa etária serão aqui detalhadas.

No contexto estadounidense, Van Patten et al. (2007) desenvolveram um estudo normativo avaliando 37 jovens com idade entre 15 e 17 anos. Foram excluídos de sua amostra aqueles com histórico de prisão e/ou hospitalização. Van Patten foi quem realizou as aplicações e as avaliou de acordo com Sistema Compreensivo (SC) do Método de Rorschach. Após esta primeira etapa, foram selecionados, aleatoriamente, 20 protocolos para que outra psicóloga, também treinada no mesmo sistema utilizado (SC), pudesse codificá-los novamente, a fim de se calcular a fidedignidade entre os avaliadores. Alcançaram índices de concordância entre $71 \%$ a $98 \%$, dependendo da variável analisada. Foi possível observar, neste estudo, um número médio de 24,7 respostas, com predomínio de respostas globais $(10,1)$ sobre respostas grande detalhe $(7,7)$ e pequeno detalhe $(6,8)$. Os resultados encontrados diferiram daqueles apresentados por Exner em 1995 em diversas variáveis como, por exemplo, a diminuição de respostas populares e o aumento de respostas pequeno detalhe (Dd). Os autores advertem que o número limitado de participantes desta amostra deve ser considerado, como também deve ser ponderado o fato dos indivíduos serem todos de uma mesma região de um país tão vasto. Por isso, assinalam a necessidade de ampliação e 
diversificação da amostra, de modo que esta se torne suficientemente representativa da população estudada.

Na Itália, ainda com a população adolescente, Lis, Salcuni e Parolin (2007) efetuaram uma pesquisa com 233 jovens, divididos em 116 pré-adolescentes, como foram chamados pelas autoras (com idade entre 12 e 14 anos) e 117 adolescentes (com idade entre 15 e 18 anos). Foram excluídos da amostra aqueles que apresentassem história de hospitalização psiquiátrica, tratamento psicológico nos últimos dois anos e/ou alguma doença grave ocorrida nos últimos seis meses. Tais informações foram obtidas ao final da avaliação psicológica, por meio de uma entrevista semiestruturada. A coleta de dados, neste caso, foi realizada por dez estudantes de Psicologia com, no mínimo, dois anos de prática em pesquisa com o Rorschach. Além desta experiência prévia com o método, a equipe de colaboradores recebeu treinamento específico para trabalhar neste estudo. Posteriormente à coleta e codificação dos protocolos pelos estudantes, estes foram recodificados por uma das duas primeiras autoras do trabalho. Em seguida, para se verificar a fidedignidade entre os avaliadores, selecionaram, de maneira aleatória, 30 protocolos para serem recodificados pela terceira autora deste estudo. Os índices de concordância variaram entre 81 a 97\%, dependendo da variável analisada. Os resultados apresentados indicaram uma média de respostas no grupo de pré-adolescentes de 22,31 com prevalência de respostas globais, e de 21,79 no grupo de adolescentes, com maior número de respostas detalhe. O questionamento levantado na discussão desse trabalho refere-se à possibilidade de generalização dos dados encontrados, uma vez que todos os participantes são provenientes de uma área específica do país. Por fim, pontuam que seria útil a realização de outras pesquisas desta natureza para ampliar a dimensão da amostra, assinalando, novamente, a importância do desenvolvimento contínuo de estudos normativos de modo a oferecer maior fundamentação aos próprios resultados regionais sobre o Rorschach, permitindo também identificação de variáveis com caráter universal.

O terceiro trabalho normativo envolvendo avaliação de adolescentes, anteriormente citado, é o de Matsumoto, Suzuki, Shirai e Nakabayashi (2007). Eles examinaram, a partir do Sistema Compreensivo (SC) do Rorschach, 346 crianças e adolescentes japoneses, não pacientes, provenientes de escolas públicas. Do total de participantes, 144 foram excluídos da amostra por produzirem menos de 14 respostas e outros 12 por apresentarem sinais de mal ajustamento ou alguma deficiência, a partir de informações fornecidas por seus professores. Dessa forma, foram considerados neste estudo apenas os protocolos de 190 estudantes, divididos entre cinco grupos: 24 crianças de cinco anos, 43 de oito anos, 42 de nove anos, 42 de 12 anos e 39 de 14 anos. Colaboraram com a coleta de dados nove psicólogas clínicas com experiência no Rorschach, 
tendo cada uma delas administrado cerca de 14 a 30 protocolos. Cada caso foi avaliado independentemente por dois juízes com experiência prévia no instrumento e, na ocorrência de desacordo entre esses examinadores, procurou-se chegar a um consenso entre os integrantes do grupo de pesquisa. Em seguida, para o cálculo da fidedignidade entre avaliadores, foram aleatoriamente selecionados 30 protocolos, resultando em índices de concordância que variaram de 87 a 100\%. Os achados indicaram que esses estudantes japoneses produziram um número médio de respostas entre 18 e 20, sendo que os índices médios de produtividade das crianças de idade inferior (cinco anos) foram ainda menores em relação aos demais grupos analisados. Os autores argumentaram que o baixo índice de produtividade obtido pelas crianças mais novas pode ser atribuído ao repertório verbal mais limitado e às restritas experiências vividas até esta fase da vida. Ao compararem seus achados aos de estudos internacionais, os pesquisadores concluíram que as crianças e os adolescentes japoneses avaliados sinalizaram indicadores de passividade nos relacionamentos interpessoais, evitando estímulos exteriores, assim como modesta expressão verbal e emocional, aspectos estes que devem ser devidamente compreendidos e interpretados dentro da cultura japonesa, visto que o método de Rorschach depende muito da expressão verbal do respondente. Para finalizar, ressaltaram a importância de se aumentar a dimensão da amostra a fim de se ampliar a base de dados normativa. Da mesma forma, enfatizaram a necessidade da elaboração de estudos transculturais com o Psicodiagnóstico de Rorschach, numa tentativa de se abarcar a diversidade social existente nos diferentes países e culturas, o que poderia explicar grande parte das divergências encontradas em estudos normativos realizados com este instrumento de avaliação psicológica.

Por fim, cabe ainda destacar, deste número temático especial do citado periódico científico, o trabalho de Meyer, Edberg e Shaffer (2007), uma vez que estes autores aspiraram averiguar a influência cultural nas produções no Rorschach de indivíduos advindos de diversos países e de diferentes faixas etárias. Eles examinaram os dados encontrados em 21 amostras normativas, compostas por adultos provenientes de 17 países, utilizando o Sistema Compreensivo. Notaram que o arranjo das amostras, bem como os resultados obtidos nestes trabalhos, foram bastante semelhantes. Ao analisar, porém, os dados de 31 amostras de crianças e adolescentes de cinco países diferentes (Estados Unidos, Itália, Japão, Dinamarca e Portugal), observaram diferenças significativas entre os resultados. A conclusão a que chegaram a partir desses achados é que as normas relativas à população mundial adulta poderiam ser, porventura, integradas. Por outro lado, tendo em vista as divergências encontradas nesta pesquisa integradora dos achados até o momento disponíveis, ainda não haveria a possibilidade de se elaborar um padrão de referência internacional único para a 
população infantil e juvenil. Os autores levantaram algumas hipóteses a respeito das possíveis causas destas diferenças, como, por exemplo, possíveis peculiaridades culturais e sociais de determinados contextos. Em suas considerações finais, eles sugerem a realização de demais pesquisas com o intuito de auxiliar na exploração e compreensão dessas diferenças e peculiaridades do desenvolvimento da personalidade de crianças e de adolescentes.

Este mapeamento dos trabalhos de investigação científica realizados nos últimos anos a respeito do Método de Rorschach, com uma perspectiva normativa, demonstra grande empenho dos pesquisadores de diversos países em busca de padrões analíticos de referência desta técnica projetiva de avaliação de personalidade, abordando as várias etapas do desenvolvimento humano. No Brasil, esta necessidade também está sendo reconhecida e trabalhos têm sido realizados a fim de se formular referenciais normativos que realmente representem a diversidade sociocultural deste país de tamanho quase continental, repleto de variabilidade humana. Este tema passará a ser foco no próximo tópico deste trabalho.

\subsection{ESTUDOS COM O PSICODIAGNÓSTICO DE RORSCHACH NO BRASIL}

Ao focalizar as possibilidades de utilização do Psicodiagnóstico de Rorschach, especificamente com adolescentes da realidade brasileira, nota-se que há maior investimento em pesquisas voltadas à investigação clínica de quadros clínicos, podendo-se citar como exemplos desta perspectiva, seguindo-se a ordem cronológica, os trabalhos de Aguirre (1995); Bellodi, Romão Jr. e Jacquemin (1997); Santoantonio (2001); Campagna (2003), Santoantonio, Yazigi e Sato (2004), Jordão e Ramires (2010), Oliveira-Cardoso e Santos (2012), entre outros.

Dentre os estudos de investigação clínica, encontra-se o de Aguirre (1995) que avaliou 40 gestantes adolescentes de 12 a 16 anos de idade, que freqüentaram o serviço de assistência pré-natal de três hospitais públicos da cidade de São Paulo, na tentativa de investigar possíveis motivações inconscientes e os recursos internos para lidar com a situação de gravidez na adolescência. Os métodos de investigação utilizados foram o Método de Rorschach, sob o referencial psicanalítico, e entrevistas semidirigidas. Os resultados indicaram que a grande maioria dos casos teve gestação não-intencional (cerca de 90\%), com sinais de intensa angústia e poderosos bloqueios afetivos por parte das gestantes, sugerindo reduzida disponibilidade e baixa maturidade psíquica para o estabelecimento de bom vínculo com o bebê. A partir de seus achados, a autora apontou a necessidade de acompanhamento psicológico das adolescentes nesse período de grandes mudanças corporais e de papéis, de 
modo a favorecer o enfrentamento das sobrecargas internas e externas, advindas da gestação nesta etapa do desenvolvimento.

Outro exemplo de estudo voltado à investigação clínica de adolescentes é o trabalho de Bellodi, Romão Jr. e Jacquemin (1997). Eles avaliaram dez pacientes, entre 11 e 17 anos, do grupo pediátrico de uma unidade de diálise, o qual foi subdividido em cinco pacientes em Hemodiálise e cinco em Diálise Peritoneal Ambulatorial Contínua. Foram utilizadas duas técnicas projetivas de avaliação de personalidade, os Desenhos Temáticos e o Psicodiagnóstico de Rorschach, enfatizando aspectos da imagem corporal e da relação de dependência ao tratamento em cada um dos sujeitos estudados. Os achados foram sugestivos de que adolescentes em hemodiálise apresentaram sinais de prejuízo na autoimagem, de desvalorização pessoal e de dificuldades de interação social. Já aqueles que estavam em diálise peritoneal contínua, em ambulatório, incluíram o conteúdo humano em suas relações, embora abordando os afetos de forma restritiva. Os resultados fortaleceram as evidências relativas à necessidade de intervenção psicológica com esses pacientes, buscando recuperar, na particularidade de cada indivíduo, o que lhes foi afastado devido à doença e ao tratamento médico contínuo.

Santoantonio (2001), em sua tese de doutorado, utilizou o Método de Rorschach para examinar características de personalidade de 30 adolescentes dentro da faixa etária de 12 a 17 anos, todas do sexo feminino, pacientes diagnosticadas com lúpus eritematoso sistêmico. Houve também um grupo controle com 32 adolescentes não pacientes, as quais foram pareadas segundo idade e nível socioeconômico. A partir dos achados, foi conferida uma importante disparidade quanto ao nível de escolaridade das voluntárias, relacionada à maior ausência das pacientes às aulas em virtude da doença. Em ambos os grupos foi identificada uma tendência a utilizar os processos de pensamento na solução de problemas. Apesar de não haver diferenças estatisticamente significativas entre os grupos, as pacientes apresentaram sinais sugestivos de maior dificuldade no manejo do estresse, tanto habitual quanto situacional, elevada interiorização dos afetos e indicadores de baixa autoestima e reduzida autopercepção. As pacientes também demonstraram menor habilidade em resolver questões da vida cotidiana, embora o déficit relacional estivesse presente nos dois grupos. A conclusão a que se chegou nesse trabalho foi que, quanto maior o grau de atividade da doença, maior a constrição afetiva das pacientes, justificando-se a investigação de seu funcionamento psíquico para também tentar favorecer sua recuperação individual. Posteriormente, este trabalho originou um artigo científico desenvolvido por Santoantonio, Yazigi e Sato (2004), publicado em periódico científico de destaque no contexto nacional. 
Ainda na linha de investigação dos processos de formação da personalidade durante a adolescência, Campagna (2003) pesquisou a organização da identidade feminina no início deste período da vida por meio do Psicodiagnóstico de Rorschach, Desenhos da Figura Humana e entrevistas. Participaram deste estudo 20 meninas de 12 anos de idade da cidade de São Paulo, procedentes da classe média e alta. Foi possível identificar que as adolescentes sinalizaram autoestima mais negativa que positiva, identificando-se de maneira mais fantasiosa que real com seus pais, familiares, colegas, ou outros ídolos dos meios de comunicação. Além disso, produziram indicadores sugestivos de elevado nível de egocentrismo, tendendo a relações afetivas bastante restritas. A autora discute seus resultados em consonância à caracterização do início da adolescência como um período marcado por fortes pressões internas e externas, sugerindo vivência de vulnerabilidade egóica em suas adolescentes. As evidências advindas deste trabalho apontaram a riqueza deste instrumento projetivo quando se pretende acessar aspectos do funcionamento mental de adolescentes, destacando-se a importância de se conhecer melhor as especificidades de desenvolvimento mental deste momento da vida.

Ainda na tentativa de ilustrar pesquisas relativas às aplicações clínicas do Método de Rorschach, encontra-se o estudo de Jordão e Ramires (2010). Investigaram características dos vínculos afetivos entre adolescentes com idades entre 16 e 17 anos, que apresentavam indicadores de organização de personalidade borderline, e seus pais. Esses adolescentes foram avaliados por meio do procedimento de estudo de casos múltiplos, utilizando-se dados dos seguintes instrumentos de avaliação psicológica: entrevistas, Rorschach, Teste do Desenho da Família e Inventário de Vínculos Parentais. De acordo com as autoras, os achados assinalaram vinculações afetivas fragilizadas, permeadas por representações de negligência, abandono, falta de amparo e proteção. Além disso, também foram encontradas histórias de vida com vivências traumáticas e de violência de diversas ordens. Jordão e Ramires (2010) destacaram a dimensão transgeracional no processo de interpretação dos casos avaliados. Por fim, elas reafirmaram a necessidade de ampliação dos estudos sobre a adolescência, mais especificamente no tocante às vivências dos adolescentes identificados como borderline.

Mais um estudo clínico utilizando o Rorschach em adolescentes foi o desenvolvido por Oliveira-Cardoso e Santos (2012) em pacientes com Anorexia Nervosa (AN) e Bulimia Nervosa (BN). Os autores buscaram avaliar o funcionamento lógico, afetivo e a adaptação social destes pacientes, a partir de amostra composta por 23 mulheres e quatro homens, totalizando 27 participantes que se inseriam na faixa etária dos 15 aos 23 anos de idade. Entretanto, grande parte da amostra (63\%) situava-se entre 15 e 18 anos de idade. O Método 
de Rorschach foi o instrumento utilizado para a coleta de dados, que foram codificados e interpretados seguindo os preceitos da Escola Francesa. Os resultados sugeriram que os participantes apresentam boa capacidade produtiva e desejo de estabelecer relacionamentos afetivos. Contudo, são invadidos, com certa facilidade, por intensa carga afetiva de difícil modulação, gerando acúmulo de inquietações e ansiedades, tornando-os predispostos ao isolamento social. Segundo os autores, a reduzida habilidade de elaboração dos conflitos internos tende a levar os pacientes à somatização. Os autores também puderam notar indicadores de comprometimento das funções psíquicas nestes pacientes, ressaltando a necessidade de acompanhamento psicoterapêutico específico associado ao amparo de uma equipe multiprofissional que aborde suas diferentes demandas de ajuda.

Juntamente à pesquisa voltada à aplicação clínica do Método de Rorschach, podem ser encontrados estudos relacionados à elaboração de padrões normativos para este método projetivo. Os profissionais envolvidos na área de avaliação psicológica no Brasil acompanham esta tendência mundial de busca de qualidade e atualização dos instrumentos utilizados. A partir de uma retrospectiva realizada por Lelé (2006) a respeito da produção científica com o Psicodiagnóstico de Rorschach no Brasil, pode-se ressaltar a variabilidade de sua aplicação e uma razoável quantidade de trabalhos realizados com o método desde sua inserção no Brasil na década de 1930, o que não descarta a necessidade de realização de estudos regionais contemporâneos.

O Psicodiagnóstico de Rorschach é utilizado com freqüência no Brasil e está necessitando de maior reflexão em várias regiões do país, devido, justamente, à enorme diversidade de paisagens humanas, sociais e culturais que pode trazer marcas significativas aos resultados desta prova projetiva. Como pode ser observado, a cultura influencia, de alguma forma, a percepção dos indivíduos. Daí a importância de ter dados normativos em diferentes regiões do país. (Lelé, 2006, p. 97)

Dentro desse contexto, Pasian (2002) realizou um levantamento dos estudos normativos do Rorschach que se encontravam acessíveis à consulta direta e que foram desenvolvidos no país no período de 1950 a 2000, envolvendo mais de seis décadas. Segundo a autora, foram encontrados 19 estudos normativos, dos quais cinco tinham seu enfoque em crianças de até 13 anos, três eram voltados para adolescentes (até 16-17), oito para adultos e outros três que incluíam diferentes faixas etárias (crianças e adolescentes, adolescentes e adultos e, um último, para idosos). A pesquisadora salienta que "a maioria desses estudos foi desenvolvida até a década de 70 ou pelo menos tiveram seus dados coletados nesse período" (p. 47). Estas evidências indicavam a necessidade de realização de novos estudos normativos 
do Rorschach no Brasil, uma vez que é premente a necessidade dos profissionais utilizarem dados atuais na avaliação e compreensão dos resultados de uma avaliação psicológica (CFP, 2003).

Em meio aos estudos normativos identificados por Pasian (2002) e voltados aos adolescentes, foco do presente estudo, encontram-se as produções de Ginsberg (1950), Adrados (1976) e Adrados (1985). Estes dois últimos consideraram as variáveis idade e gênero nas análises da produção no Método de Rorschach, sendo que o primeiro investigou 450 adolescentes de 14 a 18 anos de Guanabara (RJ) e o segundo focalizou a faixa etária de 7 a 14 anos. Já o trabalho de Ginsberg (1950) englobou amostra de 100 baianos de 10 a 16 anos de idade, examinando eventuais efeitos das variáveis gênero, idade e a cor de pele dos participantes (brancos versus negros).

No empenho de caracterizar a afetividade do adolescente no Rorschach, Japur (1982) investigou 180 estudantes de Ribeirão Preto (SP) na faixa entre 11 a 13 anos, com escolaridade correspondente à idade e de nível intelectual e socioeconômico médio ou médiosuperior. Ela buscou caracterizar a afetividade nesta fase do desenvolvimento utilizando o Psicodiagnoóstico de Rorschach recorrendo à análise das fórmulas vivenciais, dos índices de conflitos, de mecanismos de controle e adaptação intelectual e afetiva. A aplicação foi individual e os casos foram avaliados de acordo com a Escola Francesa. Este estudo preliminar de padronização foi desenvolvido, segundo Japur, com o intuito de suprir a ausência de dados normativos nacionais para a referida faixa etária. Os resultados mostraram a predominância da extratensividade aos 11 e 13 anos e da coartação aos 12 anos, bem como a presença marcada de conflitos atuais e de desenvolvimento em todo o período. Conclui-se que os indivíduos examinados apresentaram dificuldade no controle racional dos afetos e que sua adaptação sócio-intelectual mostrou-se superficial. Os achados também sinalizaram instabilidade emocional e imaturidade afetiva, mas com capacidade de expressão socializada dos afetos, apesar da crescente dificuldade de identificação com a figura humana, assim como dificuldade de contato humano. Enfim, este trabalho teve a intenção de sistematizar alguns parâmetros que contribuíssem para a compreensão da afetividade na pré-adolescência, tal como apreendida pelo Método de Rorschach.

Pasian (2002), em sua pesquisa bibliográfica, apreciou que esta amostra tinha seu enfoque na população infantil, contudo, a pesquisa de Japur se faz relevante por englobar grande parte das variáveis que se pretende averiguar no presente estudo, sendo utilizado como parâmetro inicial de referência para a classificação dos protocolos a serem obtidos, uma vez que Japur (1982) também seguiu a Escola Francesa do Rorschach, aqui adotada. Uma 
ressalva, porém, se faz importante: apesar da pesquisadora ter elaborado um atlas para a classificação das respostas obtidas no Rorschach para a referida faixa etária, Japur não teve o intuito específico de elaborar padrões normativos para o grupo estudado, focalizando a descrição da psicodinâmica dos adolescentes a partir dos indicadores técnicos da Escola Francesa do Rorschach.

Com o intuito de mapear o desenvolvimento de estudos normativos contemporâneos do Psicodiagnóstico de Rorschach na realidade brasileira, foi realizado um levantamento bibliográfico nos Livros de Resumos e de Anais dos últimos eventos científicos nacionais, da área de Avaliação Psicológica e realizados a partir de 2006. Assim, foram consultados os materiais relativos aos seguintes congressos: IV e V Encontros da Associação Brasileira de Rorschach e Métodos Projetivos - ASBRo (2006, 2008), IV Congresso de Brasileiro de Avaliação Psicológica - IBAP (2009), realizado conjuntamente com a XIV Conferência Internacional de Avaliação Psicológica: Formas e Contextos (2009), V Congresso Brasileiro de Rorschach e Outros Métodos Projetivos - ASBRo (2009) e, finalmente, o V Congresso Brasileiro de Avaliação Psicológica (2011). As pesquisas identificadas por tal levantamento encontram-se sinteticamente apresentadas na Tabela 1.

Tabela 1 - Estudos normativos do Rorschach apresentados nos últimos eventos científicos da área de Avaliação Psicológica e Métodos Projetivos no Brasil, ocorridos no período de 2006 a 2011.

\begin{tabular}{ccccc}
\hline Autores & Ano & Participantes & Faixa etária & Sistema \\
\hline Raspantini e Pasian & 2011 & 180 & 9 a 11 & Francês \\
\hline $\begin{array}{c}\text { Fernandes, Pasian e } \\
\text { Bordão-Alves }\end{array}$ & 2011 & 180 & 6 a 8 & Francês \\
\hline Nascimento & 2011 & 527 & $\begin{array}{c}\text { Adolescentes } \\
\text { e adultos }\end{array}$ & Compreensivo \\
\hline $\begin{array}{c}\text { Fernandes, Pasian, } \\
\text { Paula e Barrenha }\end{array}$ & 2009 & 70 & 6 a 8 & Francês \\
\hline $\begin{array}{c}\text { Nascimento, } \\
\text { Batistuzzo, Sato, } \\
\text { Brunoni, Bueno e } \\
\text { Marques }\end{array}$ & 2009 & 108 & Adolescentes & Compreensivo \\
\hline $\begin{array}{c}\text { Raspantini, Bordão- } \\
\text { Alves e Pasian }\end{array}$ & 2009 & 180 & 9 a 11 & Francês \\
\hline $\begin{array}{c}\text { Raspantini, Paula, } \\
\text { Barrenha e Pasian }\end{array}$ & 2009 & 180 & 9 a 11 & Francês \\
\hline $\begin{array}{c}\text { Ribeiro, Yazigi e } \\
\text { Semer }\end{array}$ & 2009 & 211 & 7 a 10 & Compreensivo \\
\hline
\end{tabular}


Conclusão

\begin{tabular}{ccccc}
\hline Autores & Ano & Participantes & Faixa etária & Sistema \\
\hline Fernandes e Pasian & 2008 & 35 & 6 a 8 & Francês \\
\hline Lelé & 2008 & 100 & 18 a 36 & Francês \\
\hline $\begin{array}{c}\text { Nascimento, } \\
\text { Russowskyi, Sasaki, } \\
\text { Bueno e Parsons }\end{array}$ & 2008 & 30 & 14 a 17 & Compreensivo \\
\hline $\begin{array}{c}\text { Pasian, Raspantini e } \\
\text { Fernandes }\end{array}$ & 2008 & 125 & 6 a 12 & Francês \\
\hline Raspantini e Pasian & 2008 & 90 & 9 a 11 & Francês \\
\hline $\begin{array}{c}\text { Ribeiro, Yazigi e } \\
\text { Semer }\end{array}$ & 2008 & 211 & 7 a 10 & Compreensivo \\
\hline Souza e Duarte Junior & 2008 & 506 & 18 a 50 & Francês \\
\hline Nascimento & 2007 & 409 & Adultos & Compreensivo \\
\hline $\begin{array}{c}\text { Yazigi, Villemor- } \\
\text { Amaral, Nascimento, } \\
\text { Semer e Primi }\end{array}$ & 2007 & 600 & Adultos & Compreensivo \\
\hline Lelé & 2006 & 100 & 18 a 36 & Francês \\
\hline Nascimento & 2006 & 409 & Adultos & Compreensivo \\
\hline $\begin{array}{c}\text { Resende, Rezende e } \\
\text { Martins }\end{array}$ & 2006 & 336 & 3 a 14 & Compreensivo \\
\hline $\begin{array}{c}\text { Villemor-Amaral, } \\
\text { Yazigi, Nascimento, } \\
\text { Primi e Semer }\end{array}$ & 2006 & - & Adultos & Compreensivo \\
\hline
\end{tabular}

O mapeamento dos estudos normativos nacionais do Rorschach, em desenvolvimento nos últimos cinco anos, permite reconhecer o empenho de vários centros de investigação científica em busca de qualificar e aprimorar o uso desta técnica projetiva no Brasil, acompanhando as exigências e as orientações do Conselho Federal de Psicologia. São pesquisas centradas em demonstrar parâmetros empíricos adequados para utilização do Método de Rorschach (a partir de diferentes sistemas avaliativos) no contexto brasileiro.

Um exame mais detalhado destes trabalhos permite identificar que, diferentemente do que ocorre internacionalmente, há uma relativa quantidade de estudos fundamentados na Escola Francesa do Rorschach desenvolvidos no Brasil. Dentre estes trabalhos, pode-se destacar: Raspantini e Pasian (2011); Fernandes, Pasian e Bordão-Alves (2011); Fernandes, Pasian, Paula e Barrenha (2009); Raspantini, Bordão-Alves e Pasian (2009); Raspantini, Paula, Barrenha e Pasian (2009); Fernandes e Pasian (2008); Lelé (2006, 2008b); Pasian, Raspantini e Fernandes (2008); Raspantini e Pasian (2008); Souza e Duarte Junior (2008). Em linhas gerais, estes trabalhos serão relatados a seguir.

Trabalhando com a população adulta, Lelé (2006, 2008b) avaliou 100 indivíduos advindos do Estado de Minas Gerais (MG), com idade variando entre 18 e 36 anos, de ambos 
os gêneros, de diversos níveis de escolaridade. Seus resultados mostraram significativas diferenças quando comparados com estudos normativos desenvolvidos em outras regiões do país, sinalizando influências culturais em diversos parâmetros referenciais do Rorschach, indicando, portanto, a necessidade de trabalhos de investigação específicos nesta área.

Os estudos de Raspantini e Pasian (2008, 2011); Fernandes, Pasian e Bordão-Alves (2011); Fernandes, Pasian, Paula e Barrenha (2009); Raspantini, Paula, Barrenha e Pasian (2009a); Raspantini, Bordão-Alves e Pasian (2009b) e Fernandes e Pasian (2008); e de Pasian, Raspantini e Fernandes (2008), todos pesquisadores integrantes do mesmo centro de investigações do presente estudo, desenvolveram estudos normativos com crianças do interior do Estado de São Paulo. Raspantini e Pasian (2008, 2011) e Raspantini et al. (2009a, 2009b) analisaram crianças de nove a 11 anos de idade, com desenvolvimento típico, distribuídas equitativamente em relação ao gênero, idade e origem escolar. Os protocolos foram avaliados por três juízes independentes e os resultados apontaram altos índices de acordo entre os avaliadores. Embora preliminares, os resultados indicaram sinais de maior investimento racional na interpretação da realidade por estudantes do ensino público. Por outro lado, as crianças procedentes da escola particular apresentaram índices maiores de qualidade formal e de integração entre elementos afetivos e racionais. Estes resultados evidenciaram a necessidade de atenção especial no processo de elaboração de referenciais normativos do Rorschach para crianças, de maneira a buscar garantir a realização de avaliações clínicas adequadas para as peculiaridades desta faixa etária. A conclusão deste estudo originou a dissertação de Mestrado de Raspantini (2010), onde podem ser encontrados os dados finais de sua pesquisa. Com relação à produtividade, os resultados encontrados, em termos medianos, junto às crianças analisadas foram: Número de respostas $\mathrm{R}=16,5$; Tempo de Latência médio=26,5 segundos; Tempo de Reação médio=32,8 segundos. Quanto aos modos de apreensão, obteve os seguintes dados médios: $\mathrm{G}=39,1 \%$; $\mathrm{D}=34,4 \%$; $\mathrm{Dd}=25,7 \%$. No que diz respeito aos índices formais, encontrou: $\mathrm{F} \%=63,1 \%$ e $\mathrm{F}+\%=73,3 \%$, enquanto os conteúdos mais presentes foram: $\mathrm{A} \%=58 \%$ e $\mathrm{H} \%=20,7 \%$. O estilo de vivência afetiva predominante foi o coartativo (denominado como "evitativo", no Sistema Compreensivo) e o índice de respostas banais $=20,4 \%$.

Por sua vez, Fernandes e Pasian (2008) e Fernandes et al. (2009, 2011) delinearam os dados normativos preliminares de crianças do interior do Estado de São Paulo, inseridas na faixa etária de seis a oito anos. Como aconteceu com Raspantini (2010), a conclusão deste estudo originou a Dissertação de Mestrado de Fernandes (2010), cujos resultados, em linhas gerais, foram: nos índices relativos à produtividade, $\mathrm{R}=14,5 ; \mathrm{TL}=14,2$ segundos e $\mathrm{TRm}=28,8$ 
segundos; Modos de apreensão: $\mathrm{G}=38,6 \%, \mathrm{D}=44,2 \%, \mathrm{Dd}=16,6 \%$ e $\mathrm{Dbl}=0,5 \%$; Determinantes e índices formais: $\mathrm{F} \%=66,4 \%, \mathrm{~F}+\%=68,8 \%$ e $\mathrm{F}+\mathrm{ext} \%=70,0 \%$; Estilo de vivência afetiva predominante: coartativo; Conteúdos predominantes: A\% $=64,5 \%$ e $\mathrm{H} \%=14,1 \%$; $\mathrm{Ban}=18,5 \%$.

Pautados também pela Escola Francesa do Rorschach, Souza e Duarte Junior (2008) avaliaram 506 adultos paraenses da cidade de Belém, de 18 e 50 anos de idade. Seu objetivo era examinar as respostas banais produzidas naquele contexto sociocultural da região Norte do Brasil. Seus achados foram comparados aos de estudos realizados em outras regiões do país, identificando diferenças estatisticamente significativas entre eles. Novamente, essa constatação ratificou a necessidade de se estabelecer normas regionais do Rorschach para a população brasileira, de modo a demonstrar, empiricamente, suas possibilidades de utilização nos diferentes contextos nacionais.

Ao retomar a análise da Tabela 1, cabe agora destacar os estudos normativos do Rorschach desenvolvidos com base no Sistema Compreensivo (CS). No período pesquisado, foram identificados os seguintes trabalhos apresentados em eventos científicos nacionais: Nascimento (2006, 2007, 2011); Nascimento et al. (2006, 2008a, 2009); Ribeiro et al. (2008, 2009); Villemor-Amaral et al. (2006); Resende et al. (2006) e Yazigi et al. (2006), que serão detalhados a seguir.

A equipe de pesquisadores coordenada por Nascimento $(2006,2007,2011)$ e Nascimento et al. (2006, 2008a, 2009) desenvolveram investigações na cidade de São Paulo, abarcando inicialmente adultos $(n=409)$ e depois adolescentes $(n=108)$, todos não pacientes. Compararam seus resultados normativos a estudos internacionais, apresentando e discutindo especificidades de produção no Rorschach destes grupos. Com relação ao estudo com os adolescentes, observaram algumas semelhanças em relação aos resultados encontrados em adolescentes italianos e americanos. No entanto, essas semelhanças ocorreram com maior frequência na análise comparativa de brasileiros e italianos. Ressaltaram também que não ocorreram diferenças importantes entre as três amostras em algumas das variáveis analisadas. Por outro lado, os achados apontaram para a necessidade de se utilizar parâmetros normativos distintos para adolescentes e adultos do contexto brasileiro, corroborando o que Meyer, Edberg e Shaffer (2007) assinalaram em relação às especificidades da avaliação psicológica de crianças e adolescentes a partir do Método de Rorschach.

Voltado à faixa etária infantil, Resende et al. (2006) estão realizando um trabalho cujo objetivo é apresentar resultados normativos do Rorschach de 336 crianças e adolescentes goianienses, provenientes de escolas públicas e de creches, englobando a faixa etária de três e 
14 anos. A partir de uma amostra parcial de 66 indivíduos, as autoras relataram dados preliminares referentes a algumas variáveis deste método projetivo. Seus resultados mostraram que o número de respostas aumentou com o avançar da idade, com exceção das crianças com dez e 11 anos de idade. Também observaram que a porcentagem média de respostas unicamente formais $(\mathrm{F} \%$ ) atingiu valores entre 66,7 a $80,2 \%$, apresentando-se superior ao índice encontrado em crianças e adolescentes norte-americanos.

Também com foco na investigação com crianças, Ribeiro, Yazigi e Semer (2008, 2009) avaliaram 211 estudantes cuiabanos, dentro da faixa etária de sete a dez anos. Para a constituição da amostra, foi aplicada aos pais das crianças a Child Behavior Checklist (CBCL), com o objetivo de avaliar a competência social e identificar problemas de comportamento dos possíveis participantes, os quais seriam eliminados, caso fossem identificados. Após essa seleção inicial, as crianças foram avaliadas pelo Teste das Matrizes Progressivas de Raven, buscando-se excluir aquelas que apresentassem baixo rendimento intelectual. Sua amostra, portanto, foi composta por crianças não pacientes, saudáveis. Na apresentação dos resultados, as crianças foram divididas de acordo com a idade, formando quatro grupos. Em relação aos índices médios de produtividade, as crianças de sete anos apresentaram $\mathrm{R}=15,9$ respostas ao Rorschach, as de oito, $\mathrm{R}=16,6$ respostas, as de nove, $\mathrm{R}=16,2$ respostas e, por fim, as de 10 alcançaram média $\mathrm{R}=16,7$ respostas. É importante ressaltar que este trabalho resultou no doutorado de Ribeiro (2010), onde podem ser encontrados os detalhados informes sobre o estudo realizado e seus significativos resultados.

Verifica-se, de tal modo, que a utilização adequada do Rorschach é dependente, como em qualquer técnica de avaliação psicológica, da existência de parâmetros de produção obtidos com grupos de referência, além da constante atualização dessas normas. Em outras palavras, faz-se necessária a elaboração de padrões de comportamento referentes às diversas variáveis do instrumento numa população específica para que novas produções possam ser comparadas de maneira apropriada, subsidiando adequadas hipóteses interpretativas sobre seus resultados (Pasian, 1998; Güntert, 2000). Assim sendo, os padrões normativos do Psicodiagnóstico de Rorschach devem ser desenvolvidos em diferentes condições socioculturais, nos diferentes contextos, sempre buscando acompanhar a contemporaneidade e suas especificidades (Weiner, 2000; Fensterseifer \& Werlang, 2008; Nascimento, 2010; CFP, 2010).

Diante dos elementos apresentados, notam-se esforços de muitos pesquisadores em atualizar os padrões normativos do Rorschach no Brasil, visando favorecer adequados processos de avaliação psicológica, consistentes com a realidade contemporânea. Todavia, 
sabe-se que as vivências do período da adolescência exigem atenção especial, pois, até o momento, mostra-se pouco investigada no Brasil a partir das evidências do Método de Rorschach. Além disso, os trabalhos realizados com adolescentes seguindo a Escola Francesa do Rorschach (Ginsberg, 1950; Adrados, 1976, 1985; Japur 1982) já possuem uma distância temporal que, por si só, justificaria a replicação técnica, de modo a testar a estabilidade dos resultados, sobretudo diante das rápidas mudanças socioculturais contemporâneas.

Neste contexto, uma proposta de elaboração de referenciais normativos do Rorschach para adolescentes se justifica pela possibilidade de contemplação, mais específica e atualizada socioculturalmente, do desenvolvimento afetivo-emocional da referida faixa etária. Esta meta será a diretriz assumida no presente trabalho, mais especificamente voltada à investigação da faixa etária de 12 a 14 anos de idade, favorecendo a adequação do trabalho clínico e científico com o Psicodiagnóstico de Rorschach no Brasil, a partir do referencial da Escola Francesa (Anzieu, 1986; Rausch de Traubenberg, 1998). 
2 OBJETIVOS 


\subsection{GERAL}

O presente estudo tem como objetivo geral elaborar padrões normativos do Psicodiagnóstico de Rorschach (Escola Francesa) para a faixa etária de 12 a 14 anos, no contexto do Brasil. Pretende-se, desta forma, identificar e sistematizar atualizados referenciais técnicos para subsidiar processos analítico-interpretativos deste instrumento projetivo para a avaliação de adolescentes da referida faixa etária, na realidade sociocultural contemporânea.

\subsection{ESPECÍFICOS}

A partir da delimitação do objetivo geral acima proposto, almeja-se alcançar, com maior especificidade, os seguintes aspectos no presente estudo:

2.2.1. Caracterizar o desempenho no Psicodiagnóstico de Rorschach do grupo total de indivíduos de 12 a 14 anos de idade, analisando-se a distribuição de frequência das diversas categorias de classificação das respostas, a saber: localizações, determinantes e conteúdos.

2.2.2. Analisar eventuais efeitos do gênero, da idade e da origem escolar sobre a produção no Rorschach dos adolescentes de 12 a 14 anos.

2.2.3. Examinar e descrever os recortes interpretativos nas pranchas do Rorschach, realizados pelo conjunto global de adolescentes avaliados, a fim de identificar as áreas detalhe (D) e pequeno detalhe $(\mathrm{Dd})$, a partir do critério de frequência de sua interpretação no total de respostas coletadas.

2.2.4. Examinar e descrever a qualidade formal (bem vistas, mal vistas e imprecisas) do conjunto de respostas obtidas no Rorschach com o grupo total de adolescentes.

2.2.5. Verificar a frequência específica de cada resposta do Psicodiagnóstico de Rorschach, em cada área circunscrita da prancha, para identificar as respostas banalidade (Ban).

2.2.6. Elaborar o atlas do Rorschach para adolescentes de 12 a 14 anos de idade, listando as áreas interpretadas e qualidade formal de suas respectivas respostas. 
3 MÉTODO 


\subsection{CARACTERÍSTICAS DA REGIÃO FONTE DO ESTUDO}

Este estudo foi efetivado na cidade de Ribeirão Preto, situada no interior do Estado de São Paulo, mais especificamente no nordeste do estado, a 319 km de distância da capital, com área territorial de $651 \mathrm{Km}^{2}$. Para se obter maiores informações a respeito desta cidade, foram consultados os endereços eletrônicos da Fundação Sistema Estadual de Análise de Dados (SEADE), do Instituto Brasileiro de Geografia e Estatística (IBGE) e da Prefeitura Municipal de Ribeirão Preto (SP).

A principal rodovia de acesso ao município é a Via Anhanguera (SP 330), que interliga Ribeirão Preto à capital do Estado, à cidade de Campinas e ao Triângulo Mineiro, além de outras cidades. Além desta, outras cinco rodovias permitem fácil acesso a várias regiões do estado e do país, estando relativamente próxima aos principais polos econômicos do interior de São Paulo e do Triângulo Mineiro. O solo fértil coloca esta região em evidência tanto no Estado de São Paulo quanto em todo país, com destaque no setor agropecuário e na agroindústria sucroalcooleira, sendo a maior produtora mundial de açúcar e álcool. A agropecuária é bastante diversificada, contando com a produção de amendoim, café, soja, milho, laranja e cana-de-açúcar, com predomínio desta última. Além disso, compõe também um dos principais centros universitários e de pesquisa do estado e do país, com destaque para a área médica.

Com relação aos índices demográficos e condições de vida, de acordo com o censo de 2010, possui uma estimativa populacional de 604.682 habitantes, com uma taxa de urbanização de 99,69\% e o crescimento populacional anual de 1,36. O Índice de Desenvolvimento Humano (IDM-H) é de 0,855, levemente superior ao índice de 0,814 do Estado de São Paulo. Cerca de 99,35\% da população tem acesso à coleta de lixo, 98,05\% tem acesso ao abastecimento de água e 95,77 à rede de esgoto. Ainda, segundo dados do IBGE (2005-2009), a renda per capita do ribeirão preto é de 24.898,11 reais. Em relação ao grau de escolaridade, mais de $45 \%$ da população economicamente ativa completou o Ensino Médio (FIESP, 2009). Em termos gerais, portanto, caracteriza-se uma cidade com bons indicadores de desenvolvimento humano, preservando marcas de uma cultura e de um padrão sociocultural ligado à agricultura e à prestação de serviços, tão comum em cidades de outras regiões do Brasil.

Esta breve contextualização do município de Ribeirão Preto (SP) foi realizada com o intuito de fornecer informações relevantes para auxiliar uma eventual transposição dos padrões normativos do Rorschach aqui encontrados, seguindo o referencial da Escola Francesa, para outros contextos e regiões do país que apresentem similaridades ao padrão 
sociocultural anteriormente descrito. Vale ressaltar, contudo, a importância de uma análise crítica desses resultados por parte dos psicólogos, de modo que possam levar em conta, em suas avaliações clínicas, a diversidade e as peculiaridades dos indivíduos e suas experiências socioculturais no contexto do Brasil.

É importante destacar também que este estudo integra projeto maior de um grupo de investigações científicas que vem sendo realizadas no Centro de Pesquisas em Psicodiagnóstico (CPP) do Departamento de Psicologia da Faculdade de Filosofia, Ciências e Letras de Ribeirão Preto da Universidade de São Paulo, visando a adaptação e a elaboração de referenciais normativos para métodos projetivos de avaliação psicológica para a região de Ribeirão Preto (SP) e contextos similares.

\subsection{PARTICIPANTES}

Diante dos objetivos propostos para o presente estudo, seria essencial a adequada seleção e composição da amostra, a fim de garantir a possibilidade de constituição final de dados representativos da população a ser estudada. Para tanto, foi realizado um levantamento preliminar de dados sócio demográficos característicos da população de estudantes do ensino fundamental da cidade em foco, universo a partir do qual se pretendia identificar os possíveis participantes do estudo (adolescentes de 12 a 14 anos).

No que tange à rede escolar de Ribeirão Preto, de acordo com dados do IBGE (2009) disponíveis em seu endereço eletrônico, 75.832 estudantes foram matriculados nas 168 escolas (82 particulares e 86 públicas) do ensino fundamental na cidade, dos quais 19.271 eram provenientes da escola privada. A partir destes dados, tem-se uma média de 658 alunos do ensino fundamental matriculados por escola pública e 235 por escola privada. Esta discrepância entre as duas redes de ensino reafirma os achados de Akkari (2001) em seu estudo sobre desigualdades educativas no Brasil. Segundo este autor, a grande maioria dos alunos brasileiros é acolhida pela rede pública de ensino, ao passo que o ensino particular, de acordo com ele, mais elitista, comporta as classes mais favorecidas. Akkari (2001) expõe que, em 1996, 88\% do total de alunos (29,4 milhões) frequentavam o ensino público fundamental, contra 3,7 milhões que estudavam na rede particular de ensino no Brasil.

Diante disso, a proposta de amostra deste trabalho, que focaliza a faixa de 12 a 14 anos de idade, foi composta por 174 estudantes (de escolas públicas e particulares de Ribeirão Preto, SP), correspondendo a aproximadamente $0,6 \%$ da população de estudantes de ensino fundamental da faixa etária em questão, distribuídos de forma equitativa em função das variáveis: idade, gênero e origem escolar (escola pública e particular). Esta decisão técnica, 
porém, não alcança a efetiva representação da diversidade socioeconômica e cultural dos estudantes desta faixa etária na cidade em questão, tratando-se apenas de uma forma de viabilização do presente trabalho. Contudo, o tamanho desta amostra $(n=174)$ oferece o devido suporte para se abarcar, em grau suficiente, uma diversidade de estilos individuais de estudantes, de modo a poder retratar o desempenho típico dos jovens de 12 a 14 anos no Psicodiagnóstico de Rorschach. A constituição desta amostra está descrita na Tabela 2, totalizando 174 participantes.

Tabela 2 - Caracterização da amostra deste estudo normativo do Rorschach, em função da idade, gênero e origem escolar $(n=174)$.

\begin{tabular}{cccccc}
\hline \multicolumn{6}{c}{ Origem Escolar } \\
\hline $\begin{array}{c}\text { Gênero } \\
\text { Idade }\end{array}$ & \multicolumn{2}{c}{ Pública } & \multicolumn{2}{c}{ Particular } \\
\cline { 2 - 6 } & Feminino & Masculino & Feminino & Masculino & Total \\
\hline 12 anos & 15 & 15 & 15 & 15 & 60 \\
\hline 13 anos & 14 & 15 & 15 & 13 & 57 \\
\hline 14 anos & 15 & 14 & 15 & 13 & 57 \\
\hline Total & 44 & 44 & 45 & 41 & 174 \\
\hline
\end{tabular}

Os participantes foram selecionados de maneira a não apresentarem história recente de desordem psicológica ou psiquiátrica, como tratamento psiquiátrico e/ou psicológico e/ou uso de medicação psicotrópica no último ano de vida, de acordo com os relatos dos pais ou responsáveis, fornecidos por suas respostas a um questionário informativo de história pessoal. Também não foram inclusos estudantes academicamente reprovados no ano anterior à coleta dos dados, nem aqueles com deficiências sensoriais impeditivas da aplicação dos instrumentos aqui propostos. Ainda na seleção dos participantes, levou-se em conta o nível de inteligência, conforme os resultados obtidos no Teste de Inteligência INV - Forma C (Weil \& Nick, 1971). Foram inclusos, neste estudo normativo, os adolescentes que atingiram desempenho igual ou superior ao percentil 25 nesta técnica de investigação intelectual, sinalizando potencial médio ou superior nessa área.

Considerando-se que a adolescência é uma fase do desenvolvimento humano na qual o indivíduo passa por grandes transformações, psíquicas e orgânicas, buscou-se, por meio dos critérios de inclusão anteriormente mencionados, selecionar participantes que, além de voluntários, devidamente autorizados ao estudo e disponíveis para a atividade, possuíssem 
indicadores de desenvolvimento típico para sua idade. Alcançou-se, assim, uma amostra suficiente grande de adolescentes, considerados não-pacientes, coerente com os objetivos de elaboração de um estudo normativo de instrumento projetivo de avaliação psicológica.

A coleta de dados dos adolescentes do ensino público foi realizada em duas escolas. A primeira instituição abordada contribuiu com a grande maioria dos participantes por contar com cerca de 1200 alunos matriculados, quase duas vezes a média de alunos por escola pública na cidade de Ribeirão Preto. Portanto, esta instituição foi selecionada por conveniência, uma vez que este estabelecimento de ensino contava com grande concentração de alunos na faixa etária em foco e situava-se numa região agregadora de bairros da cidade, facilitando o alcance da diversidade de indivíduos pretendida num estudo de natureza normativa. Além disso, outro critério de seleção das escolas colaboradoras foi o fácil acesso a todos os aplicadores, favorecendo o contato com os participantes e com o próprio processo de coleta de dados.

No que diz respeito à coleta de dados no âmbito do ensino particular, a pesquisadora encontrou maior dificuldade de inserção. Além do menor número de estudantes por escola nestas instituições de ensino, houve maior resistência à inserção da pesquisadora nestas escolas, sendo necessário o contato com maior número de estabelecimentos escolares para se tentar concluir a coleta de dados, o que causou lentidão para o desenvolvimento desta etapa da pesquisa, durando, ao todo, 15 meses. Ainda assim não foi possível completar a amostra dos adolescentes advindos do ensino particular apenas nas escolas, o que levou a pesquisadora a recorrer a indicações informais de possíveis participantes que se encaixassem nos critérios estabelecidos de seleção da amostra. Nestes casos, o primeiro contato com o participante e seus respectivos pais/responsáveis era realizado pela pesquisadora por meio de telefonema para, sucintamente, lhes explicar do que se tratava a pesquisa. Posteriormente, a pesquisadora entregava o envelope com o TCLE e o questionário informativo sobre histórico pessoal para que os pais/responsáveis avaliassem objetivamente a possibilidade de sua colaboração no estudo e, em caso positivo, preenchiam e assinavam os documentos entregues. Caso houvesse o assentimento de todos, era agendada a aplicação dos instrumentos de avaliação psicológica num ambiente propício e resguardado, que fosse conveniente às partes, podendo ser na escola do participante (quando esta concordasse - o que ocorreu em dois casos), na casa dele ou na residência da própria pesquisadora.

De modo a ilustrar o percurso amostral desta pesquisa, os contatos realizados para se chegar à amostra final foram sistematizados para compor a Tabela 3. Ela apresenta a quantidade de escolas procuradas pela pesquisadora e as que autorizaram o estudo, como 
também o número aproximado de adolescentes que foram contatados nos respectivos estabelecimentos de ensino. É possível também verificar o nível de adesão dos adolescentes ao estudo pela análise da frequência simples e a porcentagem de casos convidados e autorizados para participar da pesquisa.

Tabela 3 - Percurso amostral do estudo em função da origem escolar.

\begin{tabular}{lccccc}
\hline Instituição & $\begin{array}{c}\text { Escolas } \\
\text { contatadas }\end{array}$ & $\begin{array}{c}\text { Escolas } \\
\text { autorizadas }\end{array}$ & $\begin{array}{c}\text { Adolescentes } \\
\text { convidados* }^{*}\end{array}$ & $\begin{array}{c}\text { Adolescentes } \\
\text { autorizados }\end{array}$ & $\begin{array}{c}\text { Proporção } \\
\text { adolescentes } \\
\text { autorizados** }\end{array}$ \\
\hline Pública & 2 & 2 & 420 & 99 & $23,6 \%$ \\
\hline Particular & 5 & 2 & 380 & 100 & $26,3 \%$ \\
\hline Total & 7 & 4 & 800 & 199 & $24,9 \%$ \\
\hline $\begin{array}{l}\text { * Valores estimados, calculando-se, em média, 30 alunos por sala visitada. } \\
\text { **Proporção de adolescentes autorizados à pesquisa em relação ao total de estudantes convidados em cada } \\
\text { contexto escolar (público ou particular). }\end{array}$
\end{tabular}

Dentre os 199 adolescentes dispostos e autorizados a participar do estudo, foi preciso verificar, inicialmente, se os mesmos poderiam ser incluídos na amostra de acordo com as informações obtidas a partir do relato dos pais/responsáveis no questionário informativo sobre histórico pessoal. Nesta etapa, seis estudantes do ensino particular foram excluídos por apresentar histórico de tratamento psiquiátrico e/ou psicológico e/ou uso de medicação psicotrópica no último ano de vida. Em alguns destes casos, sempre visando o menor prejuízo ao adolescente, optou-se por aplicar os instrumentos, mesmo que estes protocolos fossem posteriormente descartados da amostra.

Por não se encaixarem na referida faixa etária, cinco voluntários não puderam participar do estudo, a saber: quatro alunos do ensino particular ainda estavam com onze anos quando a coleta do grupo dos 12 anos foi concluída e um adolescente da escola pública já estava com 15 anos quando entregou o Termo de Consentimento Livre e Esclarecido assinado. Além destes, outros cinco adolescentes não participaram (quatro do ensino público e um da rede particular), pois o subgrupo ao qual pertenciam já havia completado o total de participantes (inicialmente delineou-se incluir 15 estudantes para cada subgrupo de gênero e de idade, em cada escola).

Devido à mudança do estudante das escolas durante o processo de coleta de dados, não foi possível incluir dois alunos, um de escola particular e o outro de pública, já autorizados a participarem da pesquisa. Ainda, um adolescente do ensino particular já havia participado da 
pesquisa no ano anterior e não pôde participar novamente, apesar de apresentar um novo termo assinado. Por fim, um caso, advindo do ensino público, precisou ser desconsiderado por não atingir o percentil 25 no Teste INV - forma C.

Após o encerramento do processo de recolha dos dados, houve a necessidade de se incluir um novo critério de exclusão de casos: os protocolos do Rorschach que apresentassem quatro ou mais recusas não fariam parte da amostra. Considerou-se, nestes casos, que a produção ao Rorschach havia sofrido significativa interferência de fatores inibitórios, devendo ser excluída de um estudo normativo, mesmo dentro das diretrizes da Escola Francesa. A partir deste novo critério, outros cinco casos deixaram de ser incluídos, um representante da escola particular e outros quatro da pública.

Dessa maneira, vinte e cinco estudantes, do total de 199, não puderam fazer parte da amostra final deste estudo, representando uma perda de $12,6 \%$ do total de casos autorizados. Portanto, foi considerada a produção referente a 174 adolescentes para este estudo normativo do Rorschach, compondo, como acima descrito, a amostra efetivamente estudada no presente trabalho.

\subsection{MATERIAIS}

\subsubsection{Carta de Apresentação da pesquisa e Autorização da Instituição Escolar}

A Carta de Apresentação do projeto de pesquisa (APÊNDICE A) foi entregue aos diretores das escolas previamente selecionadas (por conveniência técnica e viabilidade operacional do estudo), juntamente à Autorização da Instituição Escolar, de modo a conseguir sua colaboração para o desenvolvimento do projeto, autorizando a inserção da pesquisadora no estabelecimento educacional sob sua responsabilidade. Na Carta de Apresentação estavam contidas informações a respeito dos objetivos do trabalho e de como a coleta de dados seria desenvolvida. A Autorização da Instituição Escolar, por sua vez, provia espaço adequado ao dirigente institucional atestar sua concordância com o presente projeto, autorizando-o em seu estabelecimento.

\subsubsection{Termo de Consentimento Livre e Esclarecido (TCLE)}

O Termo de Consentimento Livre e Esclarecido (APÊNDICE B) apresentava os objetivos da pesquisa aos pais ou responsáveis dos adolescentes convidados a participarem do estudo, bem como seus deveres e direitos, além do nome e o telefone de contato da pesquisadora responsável. O documento foi assinado em duas vias por aqueles que 
concordaram com a participação do(a) filho(a) no trabalho, permanecendo uma cópia com eles, para eventuais consultas, e outra com a pesquisadora.

\subsubsection{Questionário Informativo sobre histórico pessoal}

O Questionário apresentado no APÊNDICE C pretendeu caracterizar algumas variáveis da história do voluntário do estudo, investigando variáveis relacionadas ao seu desenvolvimento pessoal e acadêmico, segundo o relato fornecido pelos pais e/ou responsáveis. Este material foi entregue a todos os adolescentes que manifestaram interesse em participar do estudo e deveria ser entregue aos seus respectivos pais ou responsáveis. As informações relatadas pelos pais/responsáveis por meio deste Questionário Informativo foram utilizadas como critério de seleção dos participantes para o presente trabalho.

\subsubsection{Teste de Inteligência Não Verbal (INV) - forma C}

O Teste de Inteligência Não Verbal (INV), criado em 1951 por Pierre Weil e Eva Nick, para fins de pesquisa e também de diagnóstico, destina-se à avaliação do desenvolvimento intelectual. Em sua Forma C, o teste conta com 60 itens e mais quatro exemplos iniciais. Consiste num caderno de aplicação, a folha de rosto com os exemplos e o crivo de correção das respostas. Em cada uma das cinco páginas do caderno de aplicação, somam-se doze respostas menos os erros cometidos, a fim de se apurar o total de acertos. Sua aplicação, na Forma C, abrange todas as idades a partir do sexto ano de vida.

Para a interpretação dos resultados, são utilizadas escalas de percentis elaboradas sobre o resultado de uma pesquisa nacional da população brasileira e discriminadas por idade, nível de escolaridade, zona de habitação e atividade profissional. Dessa forma, cabe ao examinador escolher qual a escala mais adequada para o nível socioeconômico ou educacional do examinando (Weil \& Nick, 1971). Embora este instrumento encontre-se com normas desatualizadas, classicamente possui fortes evidências de validade, justificando-se sua atual utilização como critério de seleção dos possíveis participantes, bem como agregando valor a uma possível atualização normativa deste instrumento de avaliação cognitiva para o contexto brasileiro.

Assim sendo, mostra-se adequado aos propósitos de se conhecer o potencial cognitivo dos participantes deste trabalho. Foram inclusos neste estudo normativo os adolescentes que atingiram desempenho igual ou superior ao percentil 25 nesta técnica de investigação intelectual, sinalizando potencial médio ou superior nessa área. Esta técnica implica na utilização de seu respectivo manual, crivo de correção e caderno de aplicação. 
O Teste INV foi objeto do estudo de Lopes (2009), onde buscou atualizar os parâmetros psicométricos deste teste, investigando uma amostra de crianças da região de Belo Horizonte (MG). Conseguiu demonstrar adequados índices de validade e de precisão do instrumento no contexto brasileiro atual, reforçando as possibilidades de uso da técnica para avaliação intelectual em termos globais, como aqui proposto.

\subsubsection{Psicodiagnóstico de Rorschach}

O Psicodiagnóstico de Rorschach é uma prova de avaliação psicológica composta por um conjunto de dez pranchas com manchas de tinta, padronizadas (Rorschach, 1921), constituindo-se no material específico desta investigação normativa e permitindo avaliação de características da personalidade. A aplicação é individual e os cartões são apresentados um a um, sendo solicitado ao respondente que faça associações e diga o que podem parecer os estímulos apresentados. Frente às respostas obtidas, é possível desenhar um quadro amplo do funcionamento psicológico dos indivíduos, seguindo-se específicos sistemas avaliativos. Além das pranchas, este instrumento utiliza folhas para registro dos dados, folha padronizada de localização das respostas, folha para codificação das respostas e um cronômetro também se faz necessário para sua aplicação (registro do ritmo do trabalho associativo e interpretativo do respondente).

Este método projetivo de avaliação psicológica encontra, na literatura científica, diferentes bases teórico-metodológicas para sua sustentação, também conhecidas como as “escolas" do Rorschach. Para Pasian (2002):

Os diversos sistemas interpretativos do Rorschach apresentam peculiaridades no modo de codificação e análise das respostas, mas, no geral, preservam a mesma estrutura básica para a aplicação da técnica, procurando manter a proposição original do autor desse método. No entanto, essa diversidade de sistemas para o mesmo instrumento causa dificuldades na análise comparativa dos estudos, embora ao final, do ponto de vista das hipóteses interpretativas, todos tendam a chegar às mesmas conclusões, o que fortalece a própria técnica. (p. 48)

A autora assinala a necessidade de se optar por um sistema teórico para qualquer uso deste instrumento, levando-se em consideração as contribuições de cada escola do Rorschach. Pasian (2002) ainda argumenta sobre as dificuldades encontradas nesta escolha, quando afirma que:

No desenvolvimento histórico do Rorschach essas dificuldades acabaram gerando, em certos contextos, algumas indisposições e, até mesmo, rivalidades entre os diferentes sistemas teórico-interpretativos. Esta "concorrência" entre "escolas", muitas vezes decorrente do 
rígido apego ao conhecido pelo estudioso, por sua vez, pode comprometer a possibilidade de intercâmbio entre pesquisadores, este sim claramente prejudicial ao avanço científico na área. (p. 49)

Logo, a possibilidade de intercâmbio entre diferentes estudos normativos desenvolvidos por um mesmo centro de pesquisa, no qual a presente pesquisadora se faz inserida, foi o norte para se definir o sistema teórico-interpretativo a ser utilizado no presente trabalho. Sob esta ótica, a opção escolhida como referencial técnico-científico foi o sistema de Ombredane e Canivet do Rorschach, conhecido como a Escola Francesa, conforme proposições apresentadas por Rausch de Traubenberg (1998), Anzieu (1986) e, mais recentemente, por Azoulay et al. (2007). Um melhor detalhamento da codificação utilizada para o presente estudo encontra-se no Glossário (APÊNDICE D), ao final do trabalho.

\subsubsection{Recursos computacionais}

Foram utilizados recursos computacionais para registro e para análise de dados, tais como Microsoft Excel 2010, Microsoft Word 2010, o programa Statistical Package for the Social Sciences (SPSS) para Windows, versão 16.0, os programas estatísticos computacionais PROC NLMIXED e PROC LOGISTIC do software Statistical Analysis System (SAS), versão 9.1, e Adobe Fireworks CS4.

\subsection{PROCEDIMENTOS}

\subsubsection{Considerações éticas}

O presente projeto de pesquisa foi submetido à avaliação pelo Comitê de Ética em Pesquisa da Faculdade de Filosofia, Ciências e Letras de Ribeirão Preto da Universidade de São Paulo, conforme Resolução 196/96 do Conselho Nacional de Saúde (conselho.saude.gov/br/docs/ Resoluções/Reso196.doc) e Resolução 16/00 do Conselho Federal de Psicologia. Posteriormente à aprovação, iniciou-se o processo de coleta de dados.

Os devidos cuidados técnicos e éticos inerentes a qualquer avaliação psicológica foram tomados com participantes e responsáveis, os quais foram informados quanto aos objetivos da pesquisa e consultados sobre a possibilidade de participação neste trabalho. Desse modo, visou-se garantir-lhes o sigilo e a liberdade de participação nesta pesquisa, que se caracteriza por ser voluntária e não remunerada. Com o aceite, o Termo de Consentimento Livre e Esclarecido deveria ser assinado pelos pais e/ou responsáveis dos estudantes para, então, se efetivar a coleta de dados. 
Aos interessados e às escolas colaboradoras, ao final do projeto, poderiam ser agendadas palestras informativas da pesquisadora a respeito das características do desenvolvimento psíquico dos estudantes da respectiva faixa etária, como um meio de oferecer alguma contribuição aos participantes da pesquisa. Entretanto, nenhum dos estabelecimentos escolares manifestou interesse neste tipo de atividade, referindo dificuldades operacionais (de espaço físico e de agenda no calendário escolar) para implementar mais esta atividade na rotina acadêmica, preferindo encerrar os casos diretamente após a devida aplicação dos instrumentos com os participantes.

Cabe ainda ressaltar que, caso fossem identificados, nos resultados dos instrumentos de avaliação psicológica aplicados, indicadores de necessidades de auxílio profissional ao desenvolvimento dos adolescentes, estes poderiam ser encaminhados a serviços específicos de saúde em seus respectivos órgãos de referência de atendimento psicológico na cidade em estudo, por orientação da pesquisadora. Contudo, não houve necessidade de se efetivar nenhum encaminhamento formal dos voluntários ao estudo, talvez devido a pré-seleção criteriosa dos participantes, aderindo ao estudo provavelmente aqueles com adaptação social adequada a seu contexto de vida.

\subsubsection{Coleta de dados}

Um levantamento das escolas públicas e particulares de ensino fundamental da cidade de Ribeirão Preto (SP) foi realizado de início, a fim de apontar quais agregavam alunos situados dentro da faixa etária de 12 a 14 anos de idade, buscando-se conciliar as necessidades de buscar alguma representatividade populacional com a viabilidade do estudo. Para eleição das escolas potencialmente participantes, a priori, deu-se preferência àquelas que reuniam maior número de alunos da faixa etária pretendida, contribuindo para um bom andamento da coleta de dados.

Quando esta prévia identificação dos estabelecimentos de ensino foi efetivada, um contato com as respectivas coordenações foi realizado com o intuito de lhes entregar a Carta de Apresentação deste projeto, a qual explicitava os objetivos da pesquisa, como a coleta de dados seria desenvolvida e a importância da colaboração daquela instituição. Caso a coordenação fosse favorável ao desenvolvimento da pesquisa no estabelecimento sob sua responsabilidade, formalizava sua concordância assinando autorização para a pesquisa. A partir disso, a pesquisadora visitava as respectivas turmas de alunos, em suas salas específicas, a fim de estabelecer um primeiro contato com os alunos inseridos na faixa etária em questão. Esta visita teve por objetivo expor a proposta de pesquisa de forma sintética, 
assim como entregar o Termo de Consentimento Livre e Esclarecido (TCLE) e o Questionário Informativo sobre histórico pessoal aos possíveis participantes. Esses documentos deveriam ser entregues aos seus pais/responsáveis para que estes pudessem responder ao questionário informativo sobre histórico pessoal do adolescente e assinar o TCLE, de forma a autorizar a participação do aluno neste estudo.

Numa das escolas colaboradoras, tentou-se a princípio, a pedido da coordenação da instituição, fazer uma reunião com os pais/responsáveis para se explicar a pesquisa em linhas gerais. Devido à baixa adesão a esta estratégia (apenas três pais/responsáveis compareceram), voltou-se à estratégia anteriormente proposta, expondo a pesquisa primeiramente aos alunos para que estes levassem os documentos aos pais/responsáveis.

Posteriormente, numa segunda visita marcada dias depois, a pesquisadora passava novamente nas salas de aula das turmas contatadas para recolher os envelopes com os documentos assinados ou devolvidos em branco. A partir de então, eram avaliados e identificados os possíveis participantes do estudo, de acordo com os critérios de inclusão definidos previamente. Quando o número de adolescentes autorizados era inferior ao número de indivíduos pretendido na amostra, a pesquisadora voltava a entrar em contato com os alunos, lembrando-os da pesquisa, pois muitos argumentavam se esquecer de devolver os documentos. Quando este recurso se esgotava, entrava-se em contato com uma nova escola, repetindo-se o procedimento citado anteriormente até a efetivação do número de participantes almejado no estudo.

O amplo processo de coleta de dados foi realizado pela própria pesquisadora (aplicador 1), com a colaboração de outros três psicólogos com experiência prévia no Método de Rorschach e especificamente treinados na Escola Francesa, com o intuito de assegurar a homogeneidade de procedimentos de aplicação e de avaliação dos casos, fortalecendo a precisão do trabalho. O treinamento técnico foi realizado pela própria pesquisadora com seus colaboradores, tendo-se amplamente examinado e discutido os critérios para aplicação e codificação do Método de Rorschach, com posterior aplicação e codificação de casos-piloto, até se alcançar um nível de trabalho equivalente entre os colaboradores do estudo.

Apesar de se contar com auxiliares para a fase de coleta de dados, é importante ressaltar que o contato inicial com as escolas colaboradoras para a autorização da pesquisa nos estabelecimentos de ensino foi realizado exclusivamente pela autora do trabalho. Cada psicólogo ficou responsável por avaliar uma determinada quantidade de casos autorizados para o estudo, conforme suas possibilidades práticas. Desse modo, chegou-se, ao final do trabalho, com a seguinte distribuição dos casos entre os aplicadores: 
- Aplicador 1 (pesquisadora): 84 casos coletados.

- Aplicador 2: 63 casos coletados.

- Aplicador 3: 17 casos coletados.

- Aplicador 4: 10 casos coletados.

Uma vez realizada a seleção inicial dos participantes como descrita anteriormente, a pesquisadora ou seus colaboradores entravam em contato com os adolescentes durante o horário das aulas, convidando-os para a realização das tarefas implicadas na presente investigação científica. Sob o assentimento dos professores e em horários autorizados, previamente avisados pelos diretores ou coordenadores das escolas, o aluno era retirado da sala de aula para participar da pesquisa em sala reservada. O processo de coleta de dados foi efetivado no contexto escolar pela própria pesquisadora ou seus colaboradores, em aplicação individual. Realizava-se um breve rapport com a reapresentação dos objetivos da pesquisa. Em seqüência, dava-se início ao processo de aplicação dos instrumentos de avaliação psicológica, conforme o esquema: aplicação do INV - forma C, segundo as normas existentes em seu respectivo manual (Weil \& Nick, 1971), e do Psicodiagnóstico de Rorschach, respectivamente, seguindo-se as orientações da Escola Francesa (Rausch de Traubenberg, 1998).

De início, dizia-se ao participante que o trabalho se iniciaria com uma atividade de raciocínio, apresentando-se as instruções do Teste INV. Foi utilizada a seguinte proposição da atividade, em concordância com os padrões propostos por Weil e Nick (1971):

"A primeira atividade é composta por uma lista de exercícios, com alguns exemplos aqui na capa do caderno (apontar para os exemplos da capa do caderno do teste). Alguns serão mais fáceis e outros mais difíceis. Então, se encontrar dificuldades, não desanime, é quase impossivel acertar tudo. Você tem o tempo que precisar para o trabalho. Olhe para a primeira figura. Representa dois gatos. Porém, está faltando algo. Agora olhe abaixo da figura: é preciso procurar o que está faltando. O que está faltando no gato? Você pode apontar com o dedo? (segue-se pelos outros exemplos). Se não conseguir achar, pode passar para o desenho seguinte. Entendeu? Pode, então, começar."

Após a aplicação do INV - forma C, o Psicodiagnóstico de Rorschach era proposto. Neste momento, eram fornecidas as seguintes instruções, também elaborada pela pesquisadora visando a padronização da coleta de dados, baseada nas orientações de Jacquemin (1976) e Pasian (1998): 
“Agora vamos fazer uma atividade bastante diferente. Vou lhe apresentar alguns cartões onde existem manchas e queria que você me dissesse o que essas manchas podem ser. O que podem parecer? Elas podem se parecer com muitas coisas, então, aqui não existe resposta certa nem errada, é a sua opinião que importa, e você pode dizer tudo o que achar que parece. Enquanto você estiver respondendo, vou anotar suas respostas aqui, da forma como você me falar. Vou anotar o tempo, mas é apenas para registro, você tem o tempo que precisar. Quando você achar que não se parece com mais nada você me devolve o cartão, e eu lhe darei outro. Tem alguma dúvida? Podemos começar?"

Os participantes aparentaram apresentar boa compreensão das instruções dadas e pareciam motivados e dispostos para a realização das tarefas. Uma vez finalizada a etapa inicial de associação de respostas a partir da apresentação dos estímulos (cartões), passava-se ao processo de inquérito das respostas fornecidas e suas respectivas localizações. Dessa forma, os cartões eram novamente apresentados, um a um, segundo sua ordem numérica inicial, solicitando ao adolescente que localizasse cada uma das respostas dadas para cada cartão, contornando a área interpretada com o dedo indicador. Para finalizar o processo de inquérito das respostas, realizava-se a investigação de seus determinantes, isto é, pedia-se ao participante que explicasse porque lhe pareceu determinado conteúdo e o que havia no cartão que fez com que parecesse determinada resposta, procurando-se identificar as associações realizadas pelos adolescentes no processo de construção de suas respostas ao Rorschach.

Ao final das atividades, o aplicador perguntava ao respondente a respeito das impressões relativas às atividades realizadas, procurando acolher os comentários realizados e esclarecer eventuais dúvidas existentes. Antes, porém, de encerrar o contato com o estudante, agradecia-se a disponibilidade do adolescente em ajudar neste trabalho e lhe era explicado que estes materiais ficariam guardados com a pesquisadora responsável. Por fim, o aluno era dispensado para retornar à aula, sendo novamente acompanhado até a sala.

\subsubsection{Análise dos resultados}

\subsubsection{Sistematização dos dados}

A análise dos resultados foi pautada em várias etapas. De início, foi avaliado o desempenho cognitivo da amostra obtido a partir do INV - forma C, segundo seus referenciais técnicos, recorrendo-se aos padrões analíticos desenvolvidos por Weil e Nick (1971). Numa segunda etapa, o processo de codificação da produção no Psicodiagnóstico do 
Rorschach seguiu o referencial técnico-científico proposto pela Escola Francesa, nomeadamente Anzieu (1986) e Rausch de Traubenberg (1998), examinando-se possível influência das variáveis gênero e origem escolar nos resultados. O estudo de caracterização da afetividade de adolescentes a partir do Método de Rorschach, desenvolvido por Japur (1982) com crianças de 11 a 13 anos da região de Ribeirão Preto (SP), foi tomado como atlas básico de referência para a classificação das respostas presentemente obtidas neste trabalho. Isto porque, até o presente momento, constitui-se no atlas mais atual da Escola Francesa do Rorschach na faixa etária aqui estudada.

Cada protocolo do Rorschach foi classificado por três avaliadores, em atividades independentes, para posterior análise de sua precisão, na perspectiva da Escola Francesa do Rorschach. Esses juízes eram psicólogos que possuíam experiência prévia com o Psicodiagnóstico de Rorschach propriamente dito, mas que, ainda sim, receberam orientação específica para a realização das codificações do material coletado. A equipe de profissionais que participou deste processo de classificação dos resultados no Rorschach envolveu dez psicólogos, sendo um deles a própria pesquisadora (Examinador 1) e os demais foram colaboradores da pesquisa. Os casos avaliados foram distribuídos para classificação das respostas ao Rorschach conforme observado na Tabela 4.

Tabela 4 - Distribuição dos casos do Rorschach entre os examinadores independentes.

\begin{tabular}{ccccccccccc}
\hline Examinador & $\mathbf{1}$ & $\mathbf{2}$ & $\mathbf{3}$ & $\mathbf{4}$ & $\mathbf{5}$ & $\mathbf{6}$ & $\mathbf{7}$ & $\mathbf{8}$ & $\mathbf{9}$ & $\mathbf{1 0}$ \\
\hline $\begin{array}{c}\text { Número de casos } \\
\begin{array}{c}\text { avaliados } \\
\text { 150 }\end{array}\end{array}$ & 64 & 62 & 49 & 45 & 45 & 45 & 35 & 17 & 10 \\
\hline
\end{tabular}

Dessa forma, cada protocolo do Rorschach foi conferido, aleatoriamente, a três classificações independentes. Faz-se necessário ressaltar que no material atribuído a cada avaliador constou apenas o número de registro do protocolo do Rorschach e dados sobre idade, gênero e origem escolar do participante, encontrando-se isento de qualquer identificação pessoal, a fim de se evitar possíveis vieses no processo de codificação dos protocolos. Desta forma, pode-se apontar que os casos do Rorschach seguiram codificação às cegas. As classificações das respostas realizadas pela própria pesquisadora foram elaboradas após alguns meses do momento da aplicação, com o intuito de se buscar imparcialidade na codificação dos dados, visando fortalecer a precisão dessas análises. O índice de acordo entre as classificações realizadas pelos examinadores foi verificado posteriormente (índice de 
precisão entre examinadores), seguindo-se orientação de Weiner (1991) e Fensterseifer e Werlang (2008).

Dadas as três codificações independentes, uma folha final de codificação foi elaborada pela pesquisadora, para cada caso, composta a partir do consenso entre os julgamentos realizados. Considerou-se concordância entre os examinadores quando ao menos dois dos avaliadores independentes atribuíram a mesma codificação para cada parte (localização, determinante/qualidade formal, conteúdo e banalidades) das respostas do protocolo. Caso isto não ocorresse, a pesquisadora novamente codificaria a resposta em questão, buscando estabelecer uma classificação plausível para esta situação, considerando as diferentes avaliações prévias.

Completado o processo de codificação para cada protocolo do Rorschach, foi elaborado um banco de dados utilizando-se planilhas do Microsoft Office Excel 2010 com as codificações finais dos casos. Foi este material que serviu de base para o devido tratamento estatístico dos resultados, realizado por uma assessoria estatística especializada, com o intuito de realizar análises adequadas e consistentes do material produzido pelos participantes.

Desse modo, as principais variáveis deste banco de dados foram transpostas para planilhas específicas do programa estatístico computacional Statistical Package for the Social Sciences (SPSS) para Windows, versão 16.0. A assessoria estatística específica desta pesquisa também foi a responsável por desenvolver planilhas destes dados compatíveis aos aplicativos da análise estatística PROC NLMIXED e PROC LOGISTIC do software Statistical Analysis System (SAS), versão 9.1, possibilitando a realização das análises descritivas e inferenciais dos resultados, adotando-se como nível de significância o valor de $\mathrm{p} \leq 0,05$.

Os resultados das principais variáveis da Escola Francesa do Rorschach foram elaborados, primeiramente, em termos de estatísticas descritivas, calculando-se média, desvio-padrão, mediana, valor mínimo e máximo das 56 principais variáveis $^{(1+2)}$ do Rorschach, considerando-se o conjunto dos adolescentes avaliados $(n=174)$.

A fim de se verificar o possível efeito do gênero, da idade e origem escolar nos resultados dos adolescentes no Método de Rorschach, a assessoria estatística avaliou ser o modelo de regressão linear aquele que melhor se aplicava às variáveis relacionadas à produtividade e ao ritmo ${ }^{1}$. Pautada ainda pelas análises da assessoria estatística, as demais

\footnotetext{
${ }^{1}$ Variáveis relacionadas à produtividade e ao ritmo: R, RA, Recusa, Denegação, Tempo de Latência médio (TLm) e Tempo de Reação médio (TRm).
} 
variáveis da Escola Francesa do Rorschach ${ }^{2}$ assumiam uma distribuição binomial, compatível com apresentação em forma de proporções, isto é, frequências em relação ao total de ocorrências da variável. Especificamente no Rorschach, as variáveis associadas à localização, aos determinantes, aos conteúdos e às banalidades são examinadas em suas proporções relativas frente ao número total de respostas do protocolo (R), confirmando este tipo de distribuição binomial de seus resultados. Assim, foram efetuadas análises inferenciais simples (univariada) para cada uma das variáveis demográficas (gênero, idade e origem escolar), a fim de se investigar o efeito de cada um destes fatores sobre os resultados relativos aos dados do Rorschach (variáveis dependentes).

\subsubsection{Análise da precisão do Rorschach}

Uma vez concluído o processo de codificação final dos protocolos do Rorschach, foi calculado o índice de precisão entre os juízes independentes, fundamentado a partir das orientações de Weiner (1991) e Fernterseifer e Werlang (2008). Para esta análise, foram selecionados, aleatoriamente, 35 protocolos (cerca de $20 \%$ do total da amostra).

Cada resposta do Rorschach era dividida em quatro categorias de classificação: localização, determinante/qualidade formal, conteúdo e banalidade, elaborando-se a porcentagem de concordância entre as três codificações para cada protocolo do Rorschach. Vale salientar que, no índice geral de acordo entre avaliadores (expressos em porcentagem), contaram-se as concordâncias totais entre examinadores, bem como as concordâncias parciais (duas classificações iguais entre as três possíveis para cada variável do Rorschach). Desse modo, a "concordância parcial" também constituiu o índice global de acordo entre os psicólogos colaboradores.

\subsubsection{Elaboração do atlas do Rorschach}

Com o intuito de elaborar o atlas do Rorschach como havia sido proposto inicialmente nos objetivos deste estudo, organizou-se um banco de dados, utilizando-se de planilhas do Microsoft Office Excel 2010, com o conjunto de 3706 respostas dadas pelos 174 adolescentes participantes. Cada conteúdo interpretado foi relacionado a sua área específica de localização no cartão onde foi produzido. De tal modo, foi possível sistematizar todas as áreas

\footnotetext{
${ }^{2}$ Demais variáveis analisadas: G, D, Dd, Dbl, Do (modos de apreensão); F+, F+/-, F-, $\sum \mathrm{F}, \mathrm{F}+\%, \mathrm{~F}+\mathrm{ext} \%, \mathrm{~K}$,

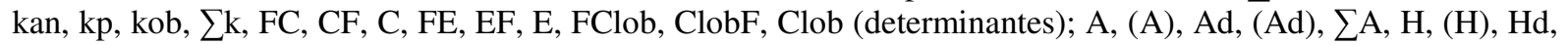
(Hd), $\sum H$, Anat, Sex, Sg, Bot, Geo, Nat, Pais, Obj, Arq, Art, Simb, Abst, Elem, Frag (conteúdos); Ban (banalidades).
} 
interpretadas, a frequência com que cada área foi evocada e sua respectiva resposta para cada cartão do Rorschach.

Devido ao elevado número de recortes feitos pelos participantes, adotou-se a decisão técnica de aglutinar alguns recortes que se assemelhassem, de modo a obter um conjunto de dados suficientemente integrado. Para tanto, a resposta enunciada em recortes interpretados com pouca frequência e com características muito semelhantes (tanto na pregnância do recorte como em seu conteúdo) a outra área evocada com maior frequência foi transposta para esta última. É imperativo ressaltar que todo o processo de vinculação das respostas às respectivas áreas foi realizado a partir do consenso entre a autora do presente trabalho e sua orientadora, examinando-se criteriosamente a pertinência e a relevância dessas transposições.

O passo seguinte foi definir as áreas que deveriam ser consideradas D (grande detalhe) e Dd (pequeno detalhe), de acordo com os padrões adotados por Jacquemin (1976) e Pasian (1998) no Brasil. Foram consideradas D as áreas interpretadas com frequência maior ou igual a $4 \%$ do total de respostas ao respectivo cartão. Por sua vez, os recortes que apresentassem frequência inferior a $4 \%$ das respostas emitidas ao cartão eram consideradas áreas Dd.

Uma vez definidas as áreas D e Dd, foi possível identificar quais áreas interpretadas seriam consideradas G amputado, seguindo-se as possibilidades de codificação da Escola Francesa do Rorschach. Foi classificada como G amputado a interpretação dada a uma área global da mancha que excluísse uma área Dd, ou também a uma resposta G que retirasse diminutas frações do seu contorno, ainda que mantivesse sua configuração de interpretação da totalidade da mancha. Esse modo de apreensão (G amputado) foi computado na categoria de respostas globais. Novamente, estas decisões metodológicas foram tomadas em conjunto com a autora e orientadora deste trabalho, tendo em vista as orientações técnicas de Rausch de Traubenberg (1998) e Jacquemin (1976).

Finalizado o processo de caracterização das áreas G, D e Dd, passou-se para a análise da qualidade formal das respostas (nível de precisão das interpretações). Neste momento, recorreu-se, inicialmente, à análise da frequência das interpretações, novamente segundo os procedimentos avaliativos propostos com Jacquemin (1976) e Pasian (1998). Dessa forma, uma resposta era classificada como tendo boa qualidade formal quando obtivesse, num mesmo recorte da mancha de um determinado cartão, ao menos uma frequência de $2 \%$ do total de indivíduos avaliados. Neste estudo, este percentual correspondeu a 4 ou mais verbalizações de uma mesma resposta para uma área circunscrita de cada um dos dez cartões do Rorschach. 
Concluída esta etapa, realizou-se a inspeção qualitativa do material, de modo a avaliar se as demais respostas que não atingiram o critério estatístico de frequência possuíam adequada constituição formal. Assim sendo, as respostas que não atingiram a frequência de $2 \%$ dos casos avaliados foram submetidas à apreciação de sua qualidade formal (bem vista, mal vista ou imprecisa) por três juízes independentes, sendo um deles a própria pesquisadora. Com isso, também se considerou uma resposta de boa qualidade formal aquela que foi classificada como adequada ao recorte interpretado da prancha por pelo menos dois dos três juízes independentes. Por sua vez, a resposta que não correspondeu formalmente à área interpretada, foi avaliada como sendo de má qualidade formal (mal vista).

Após a classificação da qualidade formal das respostas em suas respectivas áreas, foi preciso ainda identificar as respostas banalidade (Ban), verificando a frequência de cada resposta circunscrita a uma determinada área do cartão. Para tanto, novamente, o padrão técnico adotado por Jacquemin (1976) e Pasian (1998) foi seguido. Dessa forma, uma resposta foi considerada banal quando evocada uma vez a cada seis participantes, isto é, quando apresentava frequência igual ou superior a 16,7\% do total de indivíduos investigados. Em outras palavras, as respostas Ban consistiam, no presente estudo, àquelas que foram emitidas para uma mesma área de um cartão por, pelo menos, 29 adolescentes.

Enfim, paralelamente à realização das análises anteriormente mencionadas, recorreuse à assessoria digital e gráfica (por profissional qualificado nesta área), a fim de digitalizar os recortes interpretados para cada cartão pelos participantes do estudo, operacionalizando uma estratégia didática de representar e ilustrar o conjunto das produções alcançadas com o total de adolescentes avaliados. É importante ressaltar que este processo de digitalização e registro computacional das áreas interpretadas foi realizado sob acompanhamento e direta supervisão da pesquisadora, a fim de que os recortes pudessem ser registrados da forma mais fidedigna possível, preservando as produções originais.

Com base neste conjunto de procedimentos, resultou uma listagem didática das áreas de cada cartão do Rorschach interpretadas pelos adolescentes, com suas respectivas respostas, acompanhadas por sua frequência de casos e específica qualidade formal da resposta. Foi possível, portanto, elaborar um mapeamento completo dos recortes efetuados pelos estudantes de 12 a 14 anos, bem como sobre os conteúdos por eles interpretados, atribuindo-se a esta listagem uma análise de sua precisão formal em relação às áreas utilizadas dos cartões, material básico para futuras classificações da produção de adolescentes ao Método de Rorschach. 
4 RESULTADOS 


\subsection{PRECISÃO DO MÉTODO DE RORSCHACH}

Diante dos procedimentos utilizados, os valores de acordo entre examinadores (independentes e às cegas) obtidos nas quatro principais categorias de respostas da Escola Francesa do Rorschach foram: (a) Localizações $=97 \%$; (b) Determinantes $=90 \%$; (c) Conteúdos =95\%; (d) Banalidades $=90 \%$. Segundo a recomendação de Weiner (1991), o índice final de concordância deve ter valor superior a $80 \%$, logo, os valores aqui encontrados podem ser considerados satisfatórios.

Nota-se, ainda, que os índices são iguais ou superiores a 90\%, exceto na categoria dos determinantes. Cabe destacar que a classificação dos determinantes de uma resposta ao Rorschach está particularmente associada a sua qualidade formal. Visto que muitas das respostas obtidas neste estudo não estavam listadas no material de referência utilizado pelos avaliadores (Japur, 1982), a qualidade formal da atual produção precisou ser avaliada por semelhança a outras respostas ou por julgamento independente da sua adequação formal por parte do próprio examinador. Isso pode estar associado a esta maior variabilidade entre os juízes na codificação desta categoria dos determinantes das respostas ao Rorschach.

Com o objetivo de detalhar esta análise relativa aos determinantes das respostas ao Rorschach, pode-se verificar o índice de acordo entre examinadores independentes, alcançado em relação a cada classe possível de determinantes da Escola Francesa (forma, cor, sombreado ou movimento). Essa análise, em separado dos determinantes, apontou os seguintes índices de concordância entre os avaliadores: a) para determinantes formais $=95 \%$; b) para determinantes ligados à cor $=84 \%$; c) para determinantes ligados ao sombreado = $81 \%$; d) para determinantes ligados ao movimento $=90 \%$. Percebe-se, dessa forma, que as classes de determinantes Cor e Sombreado foram as que ocasionaram maiores inconsistências entre examinadores, talvez devido ao fato de que, em alguns casos, principalmente nos cartões acromáticos, a diferença entre cor e sombreado em certos protocolos torna-se um tanto tênue, dificultando sua classificação. Além disso, ainda que a resposta aglutinasse diferentes tipos de determinantes, na Escola Francesa do Rorschach codifica-se apenas um determinante para cada resposta apresentada. Os eventuais elementos complementares da resposta ficam classificados apenas como tendências (avaliadas qualitativamente), não aparecendo nas sínteses quantitativas dos resultados gerais. Nesse contexto é possível inferir que parte desta variabilidade entre examinadores, no tocante aos determinantes, tenha relação com o que cada juiz atribuiu como fator central de determinação da resposta, visto que, em muitos casos, o que um examinador considerou determinante de uma resposta foi avaliado como elemento secundário (tendência) por outro. Apesar desses limites técnicos, os resultados aqui 
encontrados podem ser considerados como satisfatórias demonstrações empíricas de precisão da Escola Francesa do Método de Rorschach, oferecendo confiança adicional aos próprios dados presentemente elaborados a respeito dos padrões de respostas de adolescentes a este método projetivo de avaliação psicológica.

\subsection{PERFIL GERAL DE RESULTADOS NO RORSCHACH}

Procurar-se-á, neste momento, caracterizar o perfil global dos resultados nas principais variáveis da Escola Francesa do Psicodiagnóstico de Rorschach alcançados com a amostra total de participantes $(n=174)$. Em sequência, será delineada a descrição e a análise comparativa dos resultados dos adolescentes em função das variáveis gênero, origem escolar e idade, averiguando possíveis efeitos destas sobre a produção neste método projetivo de avaliação psicológica.

Fundamentada nos pressupostos da Escola Francesa do Rorschach (Rausch de Traubenberg, 1998), a sistematização dos resultados aqui expostos será subdividida nos seguintes grupos de funções psíquicas: (a) produtividade e ritmo, (b) funcionamento lógico e (c) afetividade, controle de impulsos e adaptação social. Inicialmente, serão apresentados os índices relativos à produtividade da amostra composta por 174 adolescentes, conforme apresentado na Tabela 5.

Tabela 5 - Estatística descritiva da produtividade no Rorschach da amostra $(\mathrm{n}=174)$.

\begin{tabular}{cccccc}
\hline Variável & Média & DP & Mínimo & Mediana & Máximo \\
\hline R & 21,3 & 9,9 & 7 & 20 & 61 \\
\hline RA & 0,7 & 1,1 & 0 & 0 & 7 \\
\hline REC & 0,4 & 0,8 & 0 & 0 & 3 \\
\hline DEN & 0,2 & 0,5 & 0 & 0 & 5 \\
\hline TL médio & 17,6 & 15,6 & 3,4 & 12,9 & 113,4 \\
\hline TR médio & 29,6 & 19,6 & 9,6 & 24,5 & 128,5
\end{tabular}

$\mathrm{R}=$ número total de respostas; $\mathrm{RA}=$ número de respostas adicionais; $\mathrm{Rec}=$ número de recusas; Den $=$ número de respostas negadas durante o inquérito; TLm = tempo de latência médio (em segundos); TRm = tempo de reação médio (em segundos); DP = desvio-padrão; Mín. = mínimo; Med. = média; Máx. = máximo.

A análise dos achados relativos à produtividade no Rorschach permite identificar que os adolescentes apresentaram adequado número médio de respostas $(\mathrm{R}=21,3)$, pois, segundo Vaz (1997), o protocolo do Rorschach de um adolescente normal deve apresentar em torno de 15 a 24 respostas. Ao examinar a quantidade média de respostas juntamente ao tempo de 
latência médio (TLm) e ao tempo de resposta médio (TRm), observa-se boa capacidade associativo-interpretativa e agilidade nos processos de reação e de elaboração das respostas aos cartões. As respostas adicionais (RAs), recusas (REC) e denegações (DEN) ocorreram em frequência pouco expressiva, indicando que os adolescentes conseguiram processar os estímulos deste método projetivo sem a necessidade de recorrer a estratégias de maciça repressão ou até negação de seus processos associativos e interpretativos.

Ainda com foco na análise dos indicadores de produtividade no Rorschach, um exame complementar dos dados será apresentado, sistematizando-se o número de respostas, de respostas adicionais, de recusas e de denegações para cada prancha do conjunto total de participantes, com o intuito de retratar as diferenças de reação frente a cada estímulo específico do método. Tais resultados estão presentes na Tabela 6.

Tabela 6 - Resultados (frequência simples e porcentagem), para cada cartão, das variáveis associadas à produtividade no Rorschach.

\begin{tabular}{|c|c|c|c|c|c|c|c|c|}
\hline \multirow{2}{*}{ CARTÃO } & \multicolumn{2}{|c|}{$\mathbf{R}$} & \multicolumn{2}{|c|}{ RA } & \multicolumn{2}{|c|}{ Rec } & \multicolumn{2}{|c|}{ Den } \\
\hline & $\bar{f}$ & $\%$ & $\bar{f}$ & $\%$ & $\bar{f}$ & $\%$ & $\bar{f}$ & $\%$ \\
\hline $\mathrm{I}$ & 328 & 8,9 & 6 & 5,1 & 2 & 2,7 & 3 & 11,5 \\
\hline II & 336 & 9,1 & 22 & 18,8 & 9 & 12,2 & 2 & 7,7 \\
\hline III & 400 & 10,8 & 14 & 12 & 1 & 1,4 & 1 & 3,8 \\
\hline IV & 308 & 8,3 & 11 & 9,4 & 16 & 21,6 & 3 & 11,5 \\
\hline $\mathrm{V}$ & 323 & 8,7 & 9 & 7,7 & - & - & 2 & 7,7 \\
\hline VI & 311 & 8,4 & 9 & 7,7 & 16 & 21,6 & - & - \\
\hline$\overline{\text { VII }}$ & 341 & 9,2 & 11 & 9,4 & 7 & 9,5 & 1 & 3,8 \\
\hline VIII & 391 & 10,6 & 12 & 10,3 & - & - & 3 & 11,5 \\
\hline IX & 334 & 9,0 & 9 & 7,7 & 19 & 25,7 & 7 & 26,9 \\
\hline$X$ & 634 & 17,1 & 14 & 12 & 4 & 5,4 & 4 & 15,4 \\
\hline TOTAL & 3706 & 100,0 & 117 & 100,0 & 74 & 100,0 & 26 & 100,0 \\
\hline
\end{tabular}

$\mathrm{R}=$ Respostas $; \mathrm{RA}=$ Respostas adicionais $;$ Rec $=$ Recusas aos cartões $;$ Den $=$ Denegações.

Pode-se verificar, de acordo com a Tabela 6, que 3706 respostas foram coletadas no total de 174 protocolos examinados. Ainda, foram obtidas 117 respostas adicionais, 74 recusas e 26 denegações. $O$ cartão $X$ foi o que apresentou maior número de respostas $(17,1 \%)$, seguido do cartão III $(10,8 \%)$ e do cartão VIII (10,6\%). É notável a diferença entre o número 
de interpretações da prancha mais estimuladora (cartão X) e das pranchas com menor número de respostas (IV e VI), indicando considerável variação no potencial de estimulação peculiar de cada um dos cartões do Rorschach para os adolescentes avaliados.

Ressalta-se também a quantidade de respostas relacionadas às demais variáveis associadas à produtividade, como respostas adicionais, recusas e denegações, que, em termos psíquicos, representam sinais de impacto emocional diante dos estímulos. Nota-se que o cartão II apresentou um número elevado de respostas adicionais, somando 18,8\% do total de 117 respostas adicionais, seguindo-se dos cartões X e VIII, cada um representando, respectivamente, $12 \%$ e $10,3 \%$ do total de RA. Por outro lado, os cartões I, V, VI e IX foram observados como os que despertaram menor número de respostas adicionais. Essas evidências levam a pressupor possível influência das peculiaridades estruturais dos cartões na reatividade produtiva do indivíduo.

Ao focalizar a análise no tocante às recusas das pranchas, percebe-se o predomínio desta reação nos cartões IX $(25,7 \%)$, IV $(21,6 \%)$ e VI $(21,6 \%)$. Nota-se que o cartão IX também foi o que apresentou maior número de denegações (26,9\%), fazendo pensar que a prancha IX pode ter estimulado maior grau de mobilização emocional na amostra avaliada, favorecendo defesas de inibição e crítica da própria produção, caracterizando bloqueios associativos e denegações de respostas.

Em continuidade à caracterização dos padrões gerais de produção no Rorschach dos adolescentes avaliados, tem-se a Tabela 7. Ela traz a frequência simples e a porcentagem dos resultados das principais variáveis de codificação das respostas na amostra investigada. Vale lembrar que as codificações destas respostas foram baseadas no atlas elaborado por Japur (1982). No entanto, pretende-se, ao final deste estudo, reexaminar essas codificações a partir do novo atlas de classificação das respostas aqui elaborado, de modo a examinar, em trabalho futuro, possível efeito deste parâmetro técnico sobre os referenciais normativos aqui descritos.

Tabela 7 - Distribuição em frequência simples $(f)$ e porcentagem $(\%)$ do total de respostas $(\mathrm{R}=3706)$ nas diferentes categorias de classificação da Escola Francesa do Rorschach.

\begin{tabular}{lllc}
\hline $\begin{array}{c}\text { Categorias de } \\
\text { Classificação }\end{array}$ & Variáveis & $\boldsymbol{f}$ & $\boldsymbol{\%}$ \\
\hline \multirow{4}{*}{ Localização } & $\mathrm{G}$ & 954 & 25,7 \\
\cline { 2 - 4 } & $\mathrm{D}$ & $\mathbf{1 6 9 4}$ & $\mathbf{4 5 , 7}$ \\
\cline { 2 - 4 } & $\mathrm{Dd}$ & 1011 & 27,3 \\
\cline { 2 - 4 } & $\mathrm{Dbl}$ & 47 & 1,3 \\
\cline { 2 - 4 } & $\mathrm{Do}$ & - & - \\
\hline
\end{tabular}


Conclusão

\begin{tabular}{|c|c|c|c|c|}
\hline $\begin{array}{l}\text { Categorias de } \\
\text { Classificação }\end{array}$ & Variáveis & $f$ & $\%$ & \\
\hline \multirow{20}{*}{ Determinantes } & $\mathrm{F}+$ & 1142 & 30,8 & \multirow{6}{*}{$45,2 \%$} \\
\hline & $\mathrm{F}+-$ & 2 & 0,1 & \\
\hline & F- & 529 & 14,3 & \\
\hline & $\sum \mathrm{F}$ & 1673 & 45,2 & \\
\hline & $\mathrm{F}+\%$ & - & 68,3 & \\
\hline & $\mathrm{F}+\mathrm{ext} \%$ & - & 65,5 & \\
\hline & $\mathrm{K}$ & 235 & 6,3 & \multirow{5}{*}{$23,8 \%$} \\
\hline & kan & 538 & 14,5 & \\
\hline & kob & 31 & 0,8 & \\
\hline & $\mathrm{kp}$ & 82 & 2,2 & \\
\hline & $\sum \mathrm{k}$ & 651 & 17,6 & \\
\hline & $\mathrm{FC}$ & 354 & 9,6 & \multirow{3}{*}{$18,8 \%$} \\
\hline & $\mathrm{CF}$ & 324 & 8,7 & \\
\hline & $\mathrm{C}$ & 20 & 0,5 & \\
\hline & $\mathrm{FE}$ & 252 & 6,8 & \multirow{3}{*}{$12,1 \%$} \\
\hline & $\mathrm{EF}$ & 191 & 5,2 & \\
\hline & $\mathrm{E}$ & 3 & 0,1 & \\
\hline & FClob & 2 & 0,1 & \multirow{3}{*}{$0,1 \%$} \\
\hline & ClobF & - & - & \\
\hline & Clob & 1 & 0,0 & \\
\hline \multirow{25}{*}{ Conteúdos } & $\mathrm{A}$ & 1389 & 37,5 & \\
\hline & (A) & 124 & 3,3 & \\
\hline & Ad & 432 & 11,7 & \\
\hline & (Ad) & 47 & 1,3 & \\
\hline & $\sum \mathrm{A}$ & 1992 & 53,8 & \\
\hline & $\mathrm{H}$ & 331 & 8,9 & \\
\hline & $(\mathrm{H})$ & 143 & 3,9 & \\
\hline & $\mathrm{Hd}$ & 305 & 8,2 & \\
\hline & (Hd) & 61 & 1,6 & \\
\hline & $\sum \mathrm{H}$ & 840 & 22,7 & \\
\hline & Anat & 103 & 2,8 & \\
\hline & $\mathrm{Sg}$ & 8 & 0,2 & \\
\hline & Sex & 4 & 0,1 & \\
\hline & Obj & 309 & 8,3 & \\
\hline & Art & 26 & 0,7 & \\
\hline & Arq & 53 & 1,4 & \\
\hline & Simb & 60 & 1,6 & \\
\hline & Abs & 13 & 0,4 & \\
\hline & Bot & 117 & 3,2 & \\
\hline & Geo & 77 & 2,1 & \\
\hline & Nat & 16 & 0,4 & \\
\hline & Pais & 18 & 0,5 & \\
\hline & Elem & 10 & 0,3 & \\
\hline & Frag & 60 & 1,6 & \\
\hline & Ban & 547 & 14,8 & \\
\hline
\end{tabular}


Ao examinar a área eleita para interpretação, observa-se grande predomínio das respostas Detalhe $(45,7 \%)$, seguida pelas apreensões de pequeno detalhe $(\mathrm{Dd}=27,3 \%)$ e, por fim, as respostas globais $(\mathrm{G}=25,7 \%)$. A localização $\mathrm{Dbl}$ foi pouco utilizada pelos participantes $(1,3 \%)$ e a localização Do acabou não sendo atribuída a nenhuma das respostas analisadas. Tais índices sugerem, por parte dos adolescentes avaliados, adequada capacidade de diferenciação perceptiva e afetiva, bem como bom raciocínio prático e concreto, com atenção voltada a aspectos relevantes e significativos da realidade, incluindo também atenção a minúcias bem como apreensão da realidade como um todo.

Em relação aos determinantes, nota-se que grande parte das respostas emitidas pelos adolescentes foi determinada pela forma $\left(\sum \mathrm{F}=45,2 \%\right)$. Em seguida, observa-se que os determinantes encontram-se associados ao movimento (23,8\%), à cor $(18,8 \%)$ e ao sombreado $(12,1 \%)$. Esse resultado indica que os adolescentes, por meio de suas respostas, apresentaram razoável manifestação de elementos imaginativos e afetivos, embora estejam mais concentrados nos elementos formais dos estímulos, sugerindo acentuado investimento racional na interpretação da realidade nesta fase do desenvolvimento. Em outras palavras, sinalizaram empenho e esforço por apreender a realidade fazendo uso prioritário da razão e do pensamento.

A respeito das respostas unicamente determinadas pela forma, sob o que diz respeito à qualidade formal (F+, F-, F+/-), ainda considerando-se o total de respostas e não a proporção técnica do índice do Rorschach, ocorreu predomínio de respostas codificadas como F+ (30,8\%), seguido por F- (14,3\%) e reduzida porcentagem de F+/- (0,1\%). O cálculo específico do nível de precisão formal destas respostas (dimensionado na proporção de boas formas em relação ao total de respostas determinadas pela forma) apontou $\mathrm{F}+\%=68,3 \%$. Esse índice sugere adequado nível de precisão perceptiva da realidade por parte destes adolescentes.

Quanto aos determinantes associados ao movimento, houve predominância das pequenas cinestesias em relação às grandes cinestesias $(\mathrm{kan}+\mathrm{kob}+\mathrm{kp}=17,6 \%>\mathrm{K}=6,3 \%)$. Estes dados podem sinalizar que os recursos internos de dinamismo, voltados à imaginação e à criação, encontram-se ainda pouco amadurecidos (predomínio de pequenas cinestesias), o que pode condizer com o período de desenvolvimento em que se encontram os participantes da pesquisa.

Concernente aos determinantes associados à cor, novamente considerando o total de respostas, houve distribuição equivalente de $\mathrm{FC}(9,6 \%)$ e de $\mathrm{CF}(8,7 \%)$, com número bastante reduzido de respostas do tipo $\mathrm{C}(0,5 \%)$. Percebe-se, dessa forma, uma frequência considerável de respostas $\mathrm{CF}$ em relação às respostas $\mathrm{FC}$, sinalizando que os aspectos pertinentes à 
afetividade dos adolescentes podem vir a se manifestar com falhas no controle racional, embora não caracterize descontrole emocional.

Analisando-se, por fim, o determinante sombreado, novamente as respostas com codificação $\mathrm{FE}(6,8 \%)$ se sobrepuseram levemente às respostas $\mathrm{EF}$ (5,2\%), com uma porcentagem pouco significativa de respostas do tipo E puro $(0,1 \%)$. Esses elementos sugerem razoável habilidade para continência lógica de eventuais vivências de angústia por parte dos adolescentes.

Ao se examinar a distribuição dos conteúdos do conjunto das respostas, houve claro predomínio do conteúdo animal (53,8\%), seguido pelo conteúdo humano (22,7\%), ambos somando 76,5\% das respostas dos adolescentes no Rorschach. Percebe-se, portanto, concentração de interesses nos conteúdos teoricamente mais esperados, contudo, com espaço para diversificação de interpretações. Como pode ser depreendida, esta diversidade complementar de conteúdos associou-se às respostas de conteúdo objeto $(8,3 \%)$, incluindo as subcategorias alimento, máscara e vestimenta, botânico $(3,2 \%)$, conteúdo anatômico $(2,8 \%)$, geográfico $(2,1 \%)$, fragmento $(1,8 \%)$ e símbolo $(1,8 \%)$. Os demais conteúdos apresentaram frequência próxima ou inferior a 1,0\% do total de respostas, sendo, portanto, pouco expressivos.

Quanto às subclasses de conteúdo de resposta animal e humano, houve grande predomínio de perceptos íntegros [A, (A),H,(H)], em especial nas respostas de conteúdo animal. Cabe ainda destacar que o número de respostas de conteúdo animal mostrou-se bem acima do número de respostas de conteúdo humano, podendo-se inferir certa imaturidade no contato com a realidade, uma vez que o conteúdo animal está relacionado a uma percepção mais intuitiva e de menor elaboração cognitiva e emocional.

Uma última variável finaliza a análise das categorias descritivas do perfil geral de resultados do conjunto de adolescentes no Rorschach: a resposta do tipo banalidade. Foram obtidas 547 respostas banais $(14,8 \%$ do total de respostas da amostra avaliada), sugerindo adequado nível de participação no pensamento coletivo nesta amostra avaliada.

Ressalta-se que essa caracterização inicial dos resultados permite examinar, em linhas gerais, as marcas globais de produção dos adolescentes da faixa de 12 a 14 anos de idade perante o Método de Rorschach. No entanto, o aprofundamento da análise dos resultados alcançados com essa faixa do desenvolvimento humano é de grande relevância técnica e útil na prática clínica.

Em complementação a esta análise inicial dos resultados relacionados a localizações, determinantes e conteúdos, serão examinadas, neste momento, as variáveis do Método de 
Rorschach teoricamente representativas da vivência emocional. A Tabela 8 expõe esses dados, de acordo com as duas primeiras fórmulas afetivas consideradas na Escola Francesa, a saber: Tipo de Ressonância Íntimo (TRI) e Tendências Latentes (TL).

Tabela 8 - Distribuição dos adolescentes $(n=174)$ em frequência simples $(f)$ e porcentagem (\%), em função do Tipo de Vivência Afetiva (TRI) e da Fórmula das Tendências Latentes (TL).

\begin{tabular}{|c|c|c|c|c|c|c|c|}
\hline \multirow{2}{*}{$\begin{array}{c}\text { Tipo de } \\
\text { Vivência Afetiva }\end{array}$} & & \multicolumn{3}{|c|}{ TRI } & \multicolumn{3}{|c|}{ TL } \\
\hline & & $f$ & $f$ & $\%$ & $f$ & $f$ & $\%$ \\
\hline \multirow[t]{2}{*}{ Extratensivo } & Puro & 53 & \multirow{2}{*}{118} & \multirow{2}{*}{67,8} & 13 & \multirow{2}{*}{43} & \multirow{2}{*}{24,7} \\
\hline & Dilatado & 65 & & & 30 & & \\
\hline \multirow[t]{2}{*}{ Introversivo } & Puro & 5 & \multirow{2}{*}{42} & \multirow{2}{*}{24,1} & 18 & \multirow{2}{*}{116} & \multirow{2}{*}{66,7} \\
\hline & Dilatado & 37 & & & 98 & & \\
\hline Ambigual & & 7 & 7 & 4,0 & 7 & 7 & 4,0 \\
\hline Coartativo & & 2 & \multirow{2}{*}{7} & \multirow{2}{*}{4,0} & 3 & \multirow{2}{*}{8} & \multirow{2}{*}{4,6} \\
\hline Coartado & & 5 & & & 5 & & \\
\hline Total & & 174 & 174 & 100,0 & 174 & 174 & 100,0 \\
\hline
\end{tabular}

Os resultados do TRI assinalam que os adolescentes mostraram-se, predominantemente, extratensivos $(67,8 \%)$. Em outras palavras, eles apresentaram uma orientação afetiva com abertura para o ambiente, favorecendo a inteligência prática voltada para a realidade externa, bem como eventual instabilidade emocional, sobretudo nos tipos puros da extratensividade. Tais aspectos poderiam ser pensados como características teoricamente associadas às expectativas de funcionamento afetivo nesta fase do desenvolvimento, visto que os adolescentes tendem a sinalizar ardente necessidade de vínculo com outras pessoas, podendo experienciar importantes variações do humor e menor sinalização de vivências de natureza reflexiva (caracterizadoras do tipo introversivo de vivência afetiva).

$\mathrm{Na}$ sequência de análises do TRI, observa-se que o tipo de vivência afetiva introversivo mostrou-se de forma modesta na produção dos adolescentes (24,1\% da amostra), sinalizando que os movimentos reflexivos e o dobramento sobre si não pareceram caracterizar o funcionamento psíquico predominante nesta faixa etária. Quanto aos tipos coartadocoartativo, estes obtiveram uma proporção bastante restrita (4,0\% dos adolescentes), indicando que as marcas da restrição afetiva pareceram também não se sobressair neste 
momento de vida. Da mesma forma, o tipo de vivência ambigual atingiu resultados pouco expressivos, caracterizando apenas $4,0 \%$ da amostra analisada.

Voltando-se o foco para a análise da segunda Fórmula Afetiva do Rorschach, também conhecida como Fórmula das Tendências Latentes (TL), percebe-se, agora, o grande predomínio do tipo introversivo, presente em 66,7\% dos adolescentes. Ainda em relação às Tendências Latentes, o tipo extratensivo foi observado em 24,7\% dos adolescentes, enquanto que os tipos coartativo-coartado e ambigual estavam presentes em apenas 4,6\% e 4,0\% dos casos, respectivamente, sugerindo pouca influência destes no conjunto dos resultados dos estilos de vivência afetiva.

Desse modo, em termos gerais da amostra, pode-se detectar sinal de inconsistência entre as fórmulas e as vivências afetivas (advinda da contraposição de TRI e TL), o que pode evidenciar pistas de experiência interna de angústia e conflito psíquico. Os adolescentes, de modo global, apontaram predomínio de vivência afetiva habitual na linha extratensiva, porém com indícios de imaturidade psíquica, na medida em que seus recursos latentes sinalizaram-se como amplos e fortes, em direção inclusive complementar a sua expressão afetiva mais recorrente, marcando sinal de instabilidade emocional.

Em prosseguimento à descrição das características afetivas dos adolescentes a partir do Psicodiagnóstico de Rorschach, foram analisadas algumas variáveis relacionadas ao controle dos impulsos, de acordo com a orientação da Escola Francesa. Estes achados estão apresentados na Tabela 9, que traz a somatória e os dados médios da frequência das variáveis, considerando o total de 3706 respostas obtidas na amostra de 174 adolescentes.

Tabela 9 - Distribuição dos resultados globais (somatória e dados médios) da amostra em algumas variáveis do Rorschach associadas ao controle afetivo.

\begin{tabular}{ccc}
\hline Variáveis do Rorschach & $\begin{array}{c}\text { Frequência total } \\
\text { (somatória) }\end{array}$ & Proporção média \\
\hline $\mathrm{G}: \mathrm{K}$ & $954: 235$ & $4,1: 1,0$ \\
\hline $\mathrm{K}: \sum \mathrm{k}$ & $235: 651$ & $1,0: 2,8$ \\
\hline $\mathrm{FC}: \mathrm{CF}+\mathrm{C}$ & $354: 344$ & $1,0: 1,0$ \\
\hline $\mathrm{FE}: \mathrm{EF}+\mathrm{E}$ & $252: 194$ & $1,3: 1,0$ \\
\hline
\end{tabular}

A análise dessas evidências empíricas indicou maior frequência da resposta global (localização G) em relação ao total de respostas determinadas pela grande cinestesia 
(movimento K), denotando amplitude na captação dos elementos da realidade, ainda que com restrição em interpretações reflexivas e elaboradas. Esses resultados podem ser compreendidos como sinal de interpretação superficial do contexto por parte dos adolescentes avaliados, sugerindo imaturidade afetiva. Essa tendência se mostrou presente novamente na proporção entre grandes e pequenas cinestesias $\left(\mathrm{K}: \sum \mathrm{k}\right)$, evidenciando que os participantes sinalizaram bom potencial de dinamismo interno, embora parcialmente utilizado.

Com relação às proporções FC: $\mathrm{CF}+\mathrm{C}$ e de $\mathrm{FE}$ : EF + E, os adolescentes apresentaram sinais sugestivos de aparente controle racional das emoções, no entanto, suscetíveis de falhas, podendo caracterizar instabilidade afetiva. Mais uma vez, estes indícios podem ser percebidos como aspectos teoricamente característicos do funcionamento mental de adolescentes, já que flutuações do humor e do estado de ânimo podem estar presentes nesta fase do desenvolvimento.

Até aqui foram retratadas as evidências descritivas pertinentes ao padrão geral de produção diante do Método de Rorschach dos adolescentes avaliados neste estudo. A seguir, serão abordadas as análises estatísticas de natureza inferencial, examinando-se possível influência das variáveis gênero, idade e origem escolar nos resultados obtidos.

\subsection{RORSCHACH EM FUNÇÃO DO GÊNERO}

Com o intuito de efetuar a análise comparativa dos resultados no Rorschach de adolescentes em função do gênero (masculino versus feminino), foi utilizado o modelo de regressão linear para as variáveis associadas à produtividade e ao ritmo. Para as demais variáveis examinadas, o modelo de distribuição binomial foi o escolhido. Os dados referentes a essa comparação estatística em função do gênero de 89 adolescentes do grupo feminino e 85 do masculino nas principais variáveis de classificação das respostas da Escola Francesa do Rorschach encontram-se descritos nas Tabelas 10 e 11. As variáveis que apresentaram diferenças significativas foram destacadas em negrito.

Tabela 10 - Resultados da comparação estatística das variáveis relacionadas à produtividade e ritmo no Rorschach, em função do gênero.

\begin{tabular}{cccccc}
\hline Variável & Gênero & Média & DP & $\boldsymbol{p}$-valor & $\boldsymbol{p}$-valor ajustado \\
\hline \multirow{2}{*}{$\mathrm{R}$} & Feminino & 22,4 & 10,3 & \multirow{2}{*}{0,143} & \multirow{2}{*}{0,144} \\
& Masculino & 20,2 & 9,3 & & \multirow{2}{*}{0,089} \\
\hline \multirow{2}{*}{ RA } & Feminino & 0,8 & 1,2 & 0,092 & Continua
\end{tabular}


Conclusão

\begin{tabular}{|c|c|c|c|c|c|}
\hline Variável & Gênero & Média & DP & $p$-valor & $p$-valor ajustado \\
\hline \multirow{2}{*}{$\operatorname{Rec}$} & Feminino & 0,4 & 0,8 & \multirow{2}{*}{0,823} & \multirow{2}{*}{0,795} \\
\hline & Masculino & 0,4 & 0,8 & & \\
\hline \multirow{2}{*}{ Den } & Feminino & 0,2 & 0,7 & \multirow{2}{*}{0,298} & \multirow{2}{*}{0,313} \\
\hline & Masculino & 0,1 & 0,4 & & \\
\hline \multirow{2}{*}{ TLm } & Feminino & 16,5 & 12,7 & \multirow{2}{*}{0,317} & \multirow{2}{*}{0,293} \\
\hline & Masculino & 18,8 & 18,1 & & \\
\hline \multirow{2}{*}{ TRm } & Feminino & 28,1 & 16 & \multirow{2}{*}{0,320} & \multirow{2}{*}{0,310} \\
\hline & Masculino & 31,1 & 22,8 & & \\
\hline
\end{tabular}

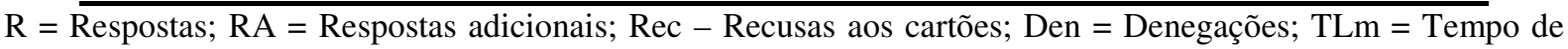
Latência médio (em segundos); TRm = Tempo de Reação médio (em segundos).

Nota-se a ausência de diferenças estatisticamente significativas entre os gêneros nos índices de produtividade da Escola Francesa do Rorschach. Não obstante, é possível observar que o grupo feminino apresentou, na média, maior número de respostas, assim como menores tempos médios de latência (TLm) e de reação (TRm). Dessa forma, embora sem diferença estatisticamente significativa, o grupo feminino produziu, em termos medianos, mais interpretações do que o grupo masculino e em menor tempo, sugerindo maior agilidade nos processos associativos.

Examinados os índices de produtividade em função do gênero, a Tabela 11, por sua vez, está composta pela análise das demais variáveis da Escola Francesa no Rorschach, também em função do gênero.

Tabela 11 - Resultados da comparação estatística das principais variáveis da Escola Francesa do Rorschach, em função do gênero.

\begin{tabular}{|c|c|c|c|c|c|}
\hline Variável & Gênero & Proporção & $\%$ & $p$-valor & $p$-valor ajustado \\
\hline \multirow{2}{*}{$\mathbf{G}$} & Feminino & $485 / 1991$ & 24,4 & \multirow{2}{*}{$\mathbf{0 , 0 3 8}$} & \multirow{2}{*}{$\mathbf{0 , 0 3 6}$} \\
\hline & Masculino & $469 / 1715$ & 27,4 & & \\
\hline \multirow{2}{*}{$\mathrm{D}$} & Feminino & $909 / 1991$ & 45,7 & \multirow{2}{*}{0,943} & \multirow{2}{*}{0,978} \\
\hline & Masculino & $785 / 1715$ & 45,8 & & \\
\hline \multirow{2}{*}{ Dd } & Feminino & $574 / 1991$ & 28,8 & \multirow{2}{*}{$\mathbf{0 , 0 2 3}$} & \multirow{2}{*}{$\mathbf{0 , 0 2 2}$} \\
\hline & Masculino & $437 / 1715$ & 25,5 & & \\
\hline \multirow{2}{*}{ Dbl } & Feminino & $23 / 1991$ & 1,2 & \multirow{2}{*}{0,508} & \multirow{2}{*}{0,436} \\
\hline & Masculino & $24 / 1715$ & 1,4 & & \\
\hline \multirow{2}{*}{ Do } & Feminino & $0 / 1991$ & 0,0 & \multirow[b]{2}{*}{ - } & \multirow[b]{2}{*}{-} \\
\hline & Masculino & $0 / 1715$ & 0,0 & & \\
\hline \multirow{2}{*}{$\mathrm{F}+$} & Feminino & $602 / 1991$ & 30,2 & \multirow{2}{*}{0,411} & \multirow{2}{*}{0,486} \\
\hline & Masculino & $540 / 1715$ & 31,5 & & \\
\hline \multirow{2}{*}{$\mathrm{F}+-$} & Feminino & $0 / 1991$ & 0,0 & \multirow{2}{*}{0,940} & \multirow{2}{*}{0,940} \\
\hline & Masculino & $2 / 1715$ & 0,1 & & \\
\hline
\end{tabular}


Continuação

\begin{tabular}{|c|c|c|c|c|c|}
\hline Variável & Gênero & Proporção & $\%$ & $p$-valor & $p$-valor ajustado \\
\hline \multirow{2}{*}{ F- } & Feminino & $274 / 1991$ & 13,8 & \multirow{2}{*}{0,337} & \multirow{2}{*}{0,349} \\
\hline & Masculino & $255 / 1715$ & 14,9 & & \\
\hline \multirow{2}{*}{$\sum \mathrm{F}$} & Feminino & $876 / 1991$ & 44,0 & \multirow{2}{*}{0,131} & \multirow{2}{*}{0,168} \\
\hline & Masculino & 1715 & 46,5 & & \\
\hline \multirow{2}{*}{$\mathrm{F}+\%$} & Feminino & $602 / 876$ & 68,7 & \multirow{2}{*}{0,712} & \multirow{2}{*}{0,729} \\
\hline & Masculino & $541 / 797$ & 67,9 & & \\
\hline \multirow{2}{*}{$\mathrm{F}+\mathrm{ext} \%$} & Feminino & $1299 / 1991$ & 65,2 & \multirow{2}{*}{0,736} & \multirow{2}{*}{0,787} \\
\hline & Masculino & $1128 / 1715$ & 65,8 & & \\
\hline \multirow{2}{*}{$\mathrm{K}$} & Feminino & $132 / 1991$ & 6,6 & \multirow{2}{*}{0,437} & \multirow{2}{*}{0,470} \\
\hline & Masculino & 103 / 715 & 6,0 & & \\
\hline \multirow{2}{*}{ kan } & Feminino & $303 / 1991$ & 15,2 & \multirow{2}{*}{0,192} & \multirow{2}{*}{0,179} \\
\hline & Masculino & $235 / 1715$ & 13,7 & & \\
\hline \multirow{2}{*}{ kob } & Feminino & $9 / 1991$ & 0,5 & \multirow{2}{*}{0,008} & \multirow{2}{*}{0,009} \\
\hline & Masculino & $22 / 1715$ & 1,3 & & \\
\hline \multirow{2}{*}{$\mathrm{Kp}$} & Feminino & $51 / 1991$ & 2,6 & \multirow{2}{*}{0,122} & \multirow{2}{*}{0,106} \\
\hline & Masculino & $31 / 1715$ & 1,8 & & \\
\hline & Feminino & $363 / 1991$ & 18,2 & (A) 251 & 0226 \\
\hline $2 \mathrm{k}$ & Masculino & $288 / 1715$ & 16,8 & 0,251 & 0,226 \\
\hline & Feminino & $182 / 1991$ & 9,1 & & \\
\hline $\mathrm{FC}$ & Masculino & $172 / 1715$ & 10,0 & 0,359 & 0,355 \\
\hline CE & Feminino & $170 / 1991$ & 8,5 & 0626 & 0571 \\
\hline $\mathrm{CF}$ & Masculino & $154 / 1715$ & 9,0 & 0,036 & $0, \mathrm{~J} / 1$ \\
\hline & Feminino & $11 / 1991$ & 0,6 & & \\
\hline $\mathrm{C}$ & Masculino & $9 / 1715$ & 0,5 & 0,909 & 0,862 \\
\hline ББ & Feminino & $132 / 1991$ & 6,6 & 0650 & 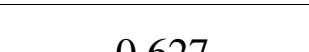 \\
\hline $\mathrm{FE}$ & Masculino & $120 / 1715$ & 7,0 & 0,058 & $0,0<1$ \\
\hline FF & Feminino & $119 / 1991$ & 6,0 & 0015 & 0022 \\
\hline & Masculino & $72 / 1715$ & 4,2 & & \\
\hline $\mathrm{E}$ & Feminino & $3 / 1991$ & 0,2 & 0.055 & 0042 \\
\hline $\mathrm{E}$ & Masculino & $0 / 1715$ & 0,0 & 0,95د & 0,942 \\
\hline ECloh & Feminino & $2 / 1991$ & 0,0 & 0045 & 010 \\
\hline FClob & Masculino & $0 / 1715$ & 0,0 & 0,945 & 0,919 \\
\hline & Feminino & $0 / 1991$ & 0,0 & & \\
\hline ClobF & Masculino & $0 / 1715$ & 0,0 & - & - \\
\hline Cloh & Feminino & $1 / 1991$ & 0,1 & 0961 & 0026 \\
\hline Clob & Masculino & $0 / 1715$ & 0,0 & 0,961 & 0,936 \\
\hline $\mathrm{A}$ & Feminino & $750 / 1991$ & 37,7 & O 707 & 0783 \\
\hline A & Masculino & $639 / 1715$ & 37,3 & 0,797 & 0,783 \\
\hline (A) & Feminino & $66 / 1991$ & 3,3 & 0010 & 0.068 \\
\hline (A) & Masculino & $58 / 1715$ & 3,4 & 0,910 & 0,908 \\
\hline Ad & Feminino & $227 / 1991$ & 11,4 & 0607 & 0696 \\
\hline Ad & Masculino & $205 / 1715$ & 12,0 & 0,602 & 0,696 \\
\hline$(\Delta d)$ & Feminino & $22 / 1991$ & 1,1 & 0340 & 0371 \\
\hline (Ad) & Masculino & $25 / 1715$ & 1,5 & 0,340 & $0,3 / 1$ \\
\hline
\end{tabular}


Conclusão

\begin{tabular}{|c|c|c|c|c|c|}
\hline Variável & Gênero & Proporção & $\%$ & $p$-valor & $p$-valor ajustado \\
\hline \multirow{2}{*}{$\sum \mathrm{A}$} & Feminino & $1065 / 1991$ & 53,5 & \multirow{2}{*}{0,732} & \multirow{2}{*}{0,840} \\
\hline & Masculino & $927 / 1715$ & 54,1 & & \\
\hline \multirow{2}{*}{$\mathrm{H}$} & Feminino & $188 / 1991$ & 9,4 & \multirow{2}{*}{0,240} & \multirow{2}{*}{0,235} \\
\hline & Masculino & $143 / 1715$ & 8,3 & & \\
\hline \multirow{2}{*}{$(\mathrm{H})$} & Feminino & $78 / 1991$ & 3,9 & \multirow{2}{*}{0,841} & \multirow{2}{*}{0,761} \\
\hline & Masculino & $65 / 1715$ & 3,8 & & \\
\hline \multirow{2}{*}{$\mathrm{Hd}$} & Feminino & $174 / 1991$ & 8, & \multirow{2}{*}{0,224} & \multirow{2}{*}{0,202} \\
\hline & Masculino & $131 / 17 \quad 5$ & 7,6 & & \\
\hline \multirow{2}{*}{ (Hd) } & Feminino & $41 / 1991$ & 2,1 & \multirow{2}{*}{$\mathbf{0 , 0 3 6}$} & \multirow{2}{*}{0,040} \\
\hline & Masculino & $20 / 1715$ & 1,2 & & \\
\hline \multirow{2}{*}{$\sum \mathbf{H}$} & Feminino & $481 / 1991$ & 24,2 & \multirow{2}{*}{$\mathbf{0 , 0 1 9}$} & \multirow{2}{*}{$\mathbf{0 , 0 1 6}$} \\
\hline & Masculino & $359 / 1715$ & 20,9 & & \\
\hline \multirow{2}{*}{ Anat } & Feminino & $62 / 1991$ & 3,1 & \multirow{2}{*}{0,183} & \multirow{2}{*}{0,245} \\
\hline & Masculino & $41 / 1715$ & 2,4 & & \\
\hline \multirow{2}{*}{$\mathrm{Sg}$} & Feminino & $4 / 1991$ & 0,2 & \multirow{2}{*}{0,833} & \multirow{2}{*}{0,788} \\
\hline & Masculino & $4 / 1715$ & 0,2 & & \\
\hline \multirow{2}{*}{ Sex } & Feminino & $4 / 1991$ & 0,2 & 0940 & 0936 \\
\hline & Masculino & $0 / 1715$ & 0,0 & 0,949 & 0 \\
\hline Ohi & Feminino & $148 / 1991$ & 7,4 & 0032 & 0026 \\
\hline U10J & Masculino & $161 / 1715$ & 9,4 & 0,0 & $0,0<0$ \\
\hline Art & Feminino & $19 / 1991$ & 1,0 & 0.054 & 0.053 \\
\hline & Masculino & $7 / 1715$ & 0,4 & & \\
\hline Arg & Feminino & $30 / 1991$ & 1,5 & 0.672 & 0.714 \\
\hline Arq & Masculino & $23 / 1715$ & 1,3 & $0,0 / 2$ & $0, / 14$ \\
\hline Simb & Feminino & $34 / 1991$ & 1,7 & 0645 & O 700 \\
\hline गा1ाए & Masculino & $26 / 1715$ & 1,5 & $0,04 J$ & 0,193 \\
\hline Ahs & Feminino & $4 / 1991$ & 0,2 & 0109 & 0107 \\
\hline & Masculino & $9 / 1715$ & 0,5 & & \\
\hline Bot & Feminino & $66 / 1991$ & 3,3 & 0.554 & 0.627 \\
\hline Dot & Masculino & $51 / 1715$ & 3,0 & 0,534 & $0,0<1$ \\
\hline Geo & Feminino & $33 / 1991$ & 1,7 & 0055 & 0056 \\
\hline Ued & Masculino & $44 / 1715$ & 2,6 & $0,0 J 3$ & 0,050 \\
\hline Nat & Feminino & $5 / 1991$ & 0,3 & 0081 & 0 ר9 \\
\hline I Nal & Masculino & $11 / 1715$ & 0,6 & 0,001 & 0,092 \\
\hline Pais & Feminino & $8 / 1991$ & 0,4 & 0.431 & 0.419 \\
\hline & Masculino & $10 / 1715$ & 0,6 & & \\
\hline Flem & Feminino & $2 / 1991$ & 0,1 & & 0060 \\
\hline Elem & Masculino & $8 / 1715$ & 0,5 & 0,052 & 0,000 \\
\hline Frro & Feminino & $26 / 1991$ & 1,3 & 0106 & 0115 \\
\hline Hiag & Masculino & $34 / 1715$ & 2,0 & 0,100 & $0,11 J$ \\
\hline Ban & Feminino & $286 / 1991$ & 14,4 & 0.465 & 0.438 \\
\hline & Masculino & $261 / 1715$ & 15,2 & & \\
\hline
\end{tabular}


Inicialmente, torna-se imperativo esclarecer que as proporções aqui apresentadas em relação à qualidade formal das respostas, isto é, as porcentagens ilustradas para F+, F+- e Fcorrespondem à proporção geral com que estas ocorreram nos protocolos avaliados. Portanto, não se referem, especificamente, ao cálculo do índice de precisão formal das respostas $(\mathrm{F}+\%)$ da Escola Francesa do Rorschach.

A análise estatística de comparação do conjunto destas variáveis do Rorschach em função do gênero possibilitou a identificação de diferenças significativas em oito das 49 variáveis examinadas. São elas: Global (G), Pequeno detalhe (Dd), Movimento de objeto (kob), Sombreado com má qualidade formal (EF), Parte de conteúdo humano fantasiado [(Hd)], Somatória de conteúdo humano $\left(\sum \mathrm{H}\right)$, Objeto $(\mathrm{Obj})$ e Arte (Art). Estas diferenças nas referidas variáveis serão comentadas a seguir.

Em se tratando de modos de apreensão dos estímulos, foram observadas diferenças estatisticamente significativas em duas $(G$ e $D d)$ das cinco variáveis analisadas $(G, D, D d$, Dbl e Do). O grupo masculino apresentou maior frequência de respostas globais em relação ao grupo feminino, que, por sua vez, produziu maior proporção de respostas de pequeno detalhe. Esses resultados sugerem indicadores de que os adolescentes do sexo masculino da faixa de 12 a 14 anos se ativeram aos aspectos gerais dos estímulos, enquanto que o sexo feminino tendeu a focar numa análise minuciosa dos fatos e situações, alusivo a uma abordagem mais detalhista da realidade.

Concernente ao grupo dos determinantes das respostas ao Rorschach, em comparação com o grupo feminino, os adolescentes do sexo masculino produziram maior frequência de conteúdos de movimento de objeto, sendo sugestivo de vivência psíquica mais marcada pela impulsividade. Ainda, as adolescentes se diferenciaram do gênero oposto proporcionando maior quantidade de respostas determinadas pelo sombreado de má qualidade formal (EF), sinalizando maior nível de angústia vivenciado por elas.

Já em relação aos conteúdos das respostas, o grupo feminino foi o que produziu, significativamente, maior número de respostas de conteúdo humano [H e (Hd)] e arte (Art), sinalizando maior interesse pelo contato humano [H e (Hd)], assim como maior sensibilidade e canalização das emoções para vias abstratas (Art). Já os adolescentes do sexo masculino apresentaram maior produção de respostas de conteúdo objeto, sugerindo possível maior pragmatismo por parte dos participantes deste gênero.

Novamente há que ressaltar que estas diferenças devem ser cuidadosamente ponderadas frente à proporção geral do conjunto dos dados, uma vez que correspondem a variáveis pouco frequentes. Esses achados, dessa forma, podem conferir a estas peculiaridades 
encontradas na produção um caráter de possível aleatoriedade e pouca relevância do ponto de vista clínico nos resultados.

Diante do que foi mostrado, considerando-se o conjunto das 56 variáveis da Escola Francesa do Rorschach aqui analisadas, pode-se verificar que o padrão de respostas dos adolescentes de ambos os gêneros foi bastante semelhante, diferindo apenas em algumas particularidades produtivas, as quais se apreciam como pouco expressivas de significativo conteúdo clínico. A partir disso, a elaboração de referenciais normativos do Rorschach específicos para adolescentes de 12 a 14 anos de idade não se mostrou necessária em função do gênero.

\subsection{RORSCHACH EM FUNÇÃO DA ORIGEM ESCOLAR}

Tendo em vista que a literatura científica sobre o Método de Rorschach versa sobre a possibilidade de influência da cultura na estruturação e no desenvolvimento da personalidade dos indivíduos, procurou-se focalizar uma investigação deste tipo de variável no presente estudo. Dentro da faixa etária aqui focalizada, considerou-se que uma representação viável do contexto sociocultural seriam as experiências acadêmicas vivenciadas pelos adolescentes, tendo em vista a heterogeneidade de estímulos socioculturais no ambiente das escolas públicas e particulares no Brasil. Desse modo, foram realizados procedimentos para exame de eventual efeito da procedência escolar sobre as variáveis do Rorschach.

A mesma estratégia técnica anteriormente proposta para comparação dos resultados dos adolescentes em função do gênero foi aqui seguida na análise comparativa entre origens escolares. Foram estatisticamente comparados os resultados nas 56 variáveis do Rorschach dos adolescentes oriundos da rede particular $(n=86)$ e pública de ensino $(n=88)$. Os dados estão sistematizados nas Tabelas 12 e13.

Tabela 12 - Resultados da comparação estatística das variáveis relacionadas a produtividade e ritmo no Rorschach, em função da origem escolar.

\begin{tabular}{|c|c|c|c|c|c|}
\hline Variável & $\begin{array}{l}\text { Origem } \\
\text { Escolar }\end{array}$ & Média & DP & $p$-valor & $p$-valor ajustado \\
\hline $\mathbf{R}$ & $\begin{array}{l}\text { Particular } \\
\text { Pública }\end{array}$ & $\begin{array}{l}23,6 \\
19,0\end{array}$ & $\begin{array}{c}10,0 \\
9,3\end{array}$ & 0,002 & 0,002 \\
\hline RA & $\begin{array}{l}\text { Particular } \\
\text { Pública }\end{array}$ & $\begin{array}{l}0,6 \\
0,8\end{array}$ & $\begin{array}{l}1,1 \\
1,1\end{array}$ & 0,345 & 0,324 \\
\hline $\operatorname{Rec}$ & $\begin{array}{l}\text { Particular } \\
\text { Pública }\end{array}$ & $\begin{array}{l}0,3 \\
0,6\end{array}$ & $\begin{array}{l}0,6 \\
0,9\end{array}$ & 0,004 & 0,004 \\
\hline
\end{tabular}


Conclusão

\begin{tabular}{|c|c|c|c|c|c|}
\hline Variável & $\begin{array}{l}\text { Origem } \\
\text { Escolar }\end{array}$ & Média & DP & $p$-valor & $p$-valor ajustado \\
\hline Den & $\begin{array}{l}\text { Particular } \\
\text { Pública }\end{array}$ & $\begin{array}{l}0,2 \\
0,1\end{array}$ & $\begin{array}{l}0,7 \\
0,4\end{array}$ & 0,244 & 0,254 \\
\hline TLm & $\begin{array}{l}\text { Particular } \\
\text { Pública }\end{array}$ & $\begin{array}{l}17,8 \\
17,4\end{array}$ & $\begin{array}{l}14,1 \\
17,1\end{array}$ & 0,849 & 0,818 \\
\hline $\mathrm{TRm}$ & $\begin{array}{l}\text { Particular } \\
\text { Pública }\end{array}$ & $\begin{array}{l}28,9 \\
30,2\end{array}$ & $\begin{array}{l}18,7 \\
20,6\end{array}$ & 0,673 & 0,697 \\
\hline
\end{tabular}

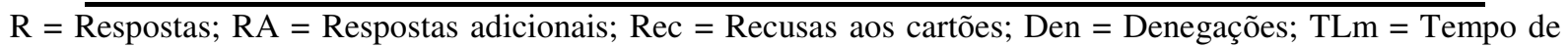
Latência médio (em segundos); TRm = Tempo de Reação médio (em segundos).

Os resultados apontaram existência de diferença estatisticamente significativa em duas das seis variáveis relacionadas à produtividade e ao ritmo de produção no Rorschach entre os adolescentes de escolas públicas e particulares de ensino. Uma das variáveis é o número de respostas $(\mathrm{R})$ e a outra é a quantidade de recusas $(\mathrm{Rec})$. Embora a quantidade de recusas tenha valor pouco expressivo na produção total dos protocolos, o número de respostas é um dado bastante significativo, requerendo atenção especial a este achado referente ao potencial de associações realizado pelos adolescentes, sinalizado como maior entre estudantes de escolas particulares.

A seguir, foram comparados, estatisticamente, os resultados médios dos adolescentes da escola pública e particular nas demais variáveis da Escola Francesa do Rorschach. Estes dados compõem a Tabela 13.

Tabela 13 - Resultados da comparação estatística das principais variáveis do Rorschach, em função da origem escolar.

\begin{tabular}{|c|c|c|c|c|c|}
\hline Variável & $\begin{array}{l}\text { Origem } \\
\text { Escolar }\end{array}$ & Proporção & $\%$ & $p$-valor & $\begin{array}{c}p \text {-valor } \\
\text { ajustado }\end{array}$ \\
\hline \multirow{2}{*}{$\mathrm{G}$} & Particular & $519 / 2031$ & 25,6 & \multirow{2}{*}{0,773} & \multirow{2}{*}{0,772} \\
\hline & Pública & $435 / 1675$ & 26.0 & & \\
\hline \multirow{2}{*}{$\mathrm{D}$} & Particular & $921 / 2031$ & 45,4 & \multirow{2}{*}{0,626} & \multirow{2}{*}{0,574} \\
\hline & Pública & $773 / 1675$ & 46,2 & & \\
\hline \multirow{2}{*}{$\mathrm{Dd}$} & Particular & $562 / 2031$ & 27,7 & \multirow{2}{*}{0,557} & \multirow{2}{*}{0,506} \\
\hline & Pública & $449 / 1675$ & 26,8 & & \\
\hline \multirow{2}{*}{ Dbl } & Particular & $29 / 2031$ & 1,4 & \multirow{2}{*}{0,341} & \multirow{2}{*}{0,313} \\
\hline & Pública & $18 / 1675$ & 1,1 & & \\
\hline \multirow{2}{*}{ Do } & Particular & $0 / 2031$ & 0,0 & & \multirow[b]{2}{*}{-} \\
\hline & Pública & $0 / 1675$ & 0,0 & & \\
\hline \multirow{2}{*}{$\mathbf{F}+$} & Particular & $672 / 2031$ & 33,1 & \multirow{2}{*}{0,001} & \multirow{2}{*}{0,001} \\
\hline & Pública & $470 / 1675$ & 28,1 & & \\
\hline
\end{tabular}


Continuação

\begin{tabular}{|c|c|c|c|c|c|}
\hline Variável & $\begin{array}{l}\text { Origem } \\
\text { Escolar }\end{array}$ & Proporção & $\%$ & $p$-valor & $\begin{array}{c}p \text {-valor } \\
\text { ajustado }\end{array}$ \\
\hline $\mathrm{F}+-$ & Particular & $\begin{array}{l}2 / 2031 \\
0 / 1675\end{array}$ & 0,1 & 0,946 & 0,943 \\
\hline F- & $\begin{array}{l}\text { Particular } \\
\text { Pública }\end{array}$ & $\begin{array}{l}288 / 2031 \\
241 / 1675\end{array}$ & $\begin{array}{l}0.0 \\
14,2 \\
14,4\end{array}$ & 0,857 & 0,860 \\
\hline$\sum \mathbf{F}$ & $\begin{array}{l}\text { Particular } \\
\text { Pública }\end{array}$ & $\begin{array}{l}962 / 2031 \\
711 / 1675\end{array}$ & $\begin{array}{l}47,4 \\
42,5\end{array}$ & 0,003 & 0,003 \\
\hline $\mathrm{F}+\%$ & $\begin{array}{l}\text { Particular } \\
\text { Pública }\end{array}$ & $\begin{array}{l}673 / 962 \\
470 / 711\end{array}$ & $\begin{array}{l}70,0 \\
66,1\end{array}$ & 0,094 & 0,091 \\
\hline $\mathrm{F}+\mathrm{ext} \%$ & $\begin{array}{l}\text { Particular } \\
\text { Pública }\end{array}$ & $\begin{array}{l}1354 / 2031 \\
1073 / 1675\end{array}$ & $\begin{array}{l}66,7 \\
64,1\end{array}$ & 0,097 & 0,094 \\
\hline $\mathrm{K}$ & $\begin{array}{l}\text { Particular } \\
\text { Pública }\end{array}$ & $\begin{array}{l}123 / 2031 \\
112 / 1675\end{array}$ & $\begin{array}{l}6,1 \\
67\end{array}$ & 0,433 & 0,513 \\
\hline kan & $\begin{array}{l}\text { Particular } \\
\text { Pública }\end{array}$ & $\begin{array}{l}256 / 2031 \\
282 / 1675\end{array}$ & $\begin{array}{l}12,6 \\
16,8\end{array}$ & $<0,001$ & $<0,001$ \\
\hline kob & $\begin{array}{l}\text { Particular } \\
\text { Pública }\end{array}$ & $\begin{array}{l}19 / 2031 \\
12 / 1675\end{array}$ & $\begin{array}{l}0,9 \\
0,7\end{array}$ & 0,468 & 0,484 \\
\hline $\mathrm{Kp}$ & $\begin{array}{l}\text { Particular } \\
\text { Pública }\end{array}$ & $\begin{array}{l}46 / 2031 \\
36 / 1675\end{array}$ & $\begin{array}{l}2,3 \\
2,2\end{array}$ & 0,812 & 0,876 \\
\hline$\sum \mathbf{k}$ & $\begin{array}{l}\text { Particular } \\
\text { Pública }\end{array}$ & $\begin{array}{l}321 / 2031 \\
330 / 1675 \\
\end{array}$ & $\begin{array}{l}15,8 \\
19,7 \\
\end{array}$ & 0,002 & 0,001 \\
\hline $\mathrm{FC}$ & $\begin{array}{l}\text { Particular } \\
\text { Pública }\end{array}$ & $\begin{array}{l}210 / 2031 \\
144 / 1675\end{array}$ & $\begin{array}{c}10,3 \\
8,6\end{array}$ & 0,073 & 0,083 \\
\hline $\mathrm{CF}$ & $\begin{array}{l}\text { Particular } \\
\text { Pública }\end{array}$ & $\begin{array}{l}170 / 2031 \\
154 / 1675\end{array}$ & $\begin{array}{l}8,4 \\
9,2\end{array}$ & 0,377 & 0,371 \\
\hline $\mathrm{C}$ & $\begin{array}{l}\text { Particular } \\
\text { Pública }\end{array}$ & $\begin{array}{c}9 / 2031 \\
11 / 1675\end{array}$ & $\begin{array}{l}0,4 \\
0,7\end{array}$ & 0,380 & 0,329 \\
\hline $\mathrm{FE}$ & $\begin{array}{l}\text { Particular } \\
\text { Pública }\end{array}$ & $\begin{array}{l}139 / 2031 \\
113 / 1675\end{array}$ & $\begin{array}{l}6,8 \\
6,7\end{array}$ & 0,907 & 0,849 \\
\hline $\mathrm{EF}$ & $\begin{array}{l}\text { Particular } \\
\text { Pública }\end{array}$ & $\begin{array}{l}94 / 2031 \\
97 / 1675\end{array}$ & $\begin{array}{l}4,6 \\
5,8\end{array}$ & 0,112 & 0,118 \\
\hline $\mathrm{E}$ & $\begin{array}{l}\text { Particular } \\
\text { Pública }\end{array}$ & $\begin{array}{l}1 / 2031 \\
2 / 1675\end{array}$ & $\begin{array}{l}0,1 \\
0,1\end{array}$ & 0,469 & 0,367 \\
\hline FClob & $\begin{array}{l}\text { Particular } \\
\text { Pública }\end{array}$ & $\begin{array}{l}1 / 2031 \\
1 / 1675\end{array}$ & $\begin{array}{l}0,0 \\
0,0\end{array}$ & 0,892 & 0,968 \\
\hline ClobF & $\begin{array}{l}\text { Particular } \\
\text { Pública }\end{array}$ & $\begin{array}{l}0 / 2031 \\
0 / 1675\end{array}$ & $\begin{array}{l}0,0 \\
0,0\end{array}$ & - & - \\
\hline Clob & $\begin{array}{l}\text { Particular } \\
\text { Pública }\end{array}$ & $\begin{array}{l}1 / 2031 \\
0 / 1675\end{array}$ & $\begin{array}{l}0,1 \\
0,0\end{array}$ & 0,962 & 0,934 \\
\hline $\mathbf{A}$ & $\begin{array}{l}\text { Particular } \\
\text { Pública }\end{array}$ & $\begin{array}{l}732 / 2031 \\
657 / 1675\end{array}$ & $\begin{array}{l}36,0 \\
39,2\end{array}$ & 0,046 & 0,035 \\
\hline (A) & $\begin{array}{l}\text { Particular } \\
\text { Pública }\end{array}$ & $\begin{array}{l}69 / 2031 \\
55 / 1675\end{array}$ & $\begin{array}{l}3,4 \\
3,3\end{array}$ & 0,848 & 0,914 \\
\hline
\end{tabular}


Continuação

\begin{tabular}{|c|c|c|c|c|c|}
\hline Variável & $\begin{array}{l}\text { Origem } \\
\text { Escolar }\end{array}$ & Proporção & $\%$ & $p$-valor & $\begin{array}{c}p \text {-valor } \\
\text { ajustado }\end{array}$ \\
\hline \multirow{2}{*}{ Ad } & Particular & $254 / 2031$ & 12,5 & \multirow{2}{*}{0,076} & \multirow{2}{*}{0,095} \\
\hline & Pública & $178 / 1675$ & 10.6 & & \\
\hline \multirow{2}{*}{ (Ad) } & Particular & $23 / 2031$ & 1,1 & \multirow{2}{*}{0,417} & \multirow{2}{*}{0,398} \\
\hline & Pública & $24 / 1675$ & 1,4 & & \\
\hline \multirow{2}{*}{$\sum \mathrm{A}$} & Particular & $1078 / 2031$ & 53,1 & \multirow{2}{*}{0,365} & \multirow{2}{*}{0,260} \\
\hline & Pública & $914 / 1675$ & 54,6 & & \\
\hline \multirow{2}{*}{$\mathrm{H}$} & Particular & $175 / 2031$ & 8,6 & \multirow{2}{*}{0,459} & \multirow{2}{*}{0,507} \\
\hline & Pública & $156 / 1675$ & 9,3 & & \\
\hline \multirow{2}{*}{$(\mathrm{H})$} & Particular & $72 / 2031$ & 3,6 & \multirow{2}{*}{0,276} & \multirow{2}{*}{0,257} \\
\hline & Pública & $71 / 1675$ & 4,2 & & \\
\hline \multirow{2}{*}{$\mathrm{Hd}$} & Particular & $175 / 2031$ & 8,6 & \multirow{2}{*}{0,346} & \multirow{2}{*}{0,332} \\
\hline & Pública & $130 / 1675$ & 7,8 & & \\
\hline \multirow{2}{*}{$(\mathrm{Hd})$} & Particular & $26 / 2031$ & 1,3 & \multirow{2}{*}{0,056} & \multirow{2}{*}{0,064} \\
\hline & Pública & $35 / 1675$ & 2,1 & & \\
\hline \multirow{2}{*}{$\sum \mathrm{H}$} & Particular & $448 / 2031$ & 22,1 & \multirow{2}{*}{0,331} & \multirow{2}{*}{0,364} \\
\hline & Pública & $392 / 1675$ & 23,4 & & \\
\hline \multirow{2}{*}{ Anat } & Particular & $51 / 2031$ & 2,5 & & \\
\hline & Pública & $52 / 1675$ & 3,1 & $0,2 / 5$ & 0,302 \\
\hline $\mathrm{So}$ & Particular & $5 / 2031$ & 0,3 & 0663 & 0638 \\
\hline sg & Pública & $3 / 1675$ & 0,2 & 0,003 & 0,058 \\
\hline & Particular & $1 / 2031$ & 0,1 & & \\
\hline Sex & Pública & $3 / 1675$ & 0,2 & 0,203 & 0,210 \\
\hline & Particular & $192 / 2031$ & 9,5 & & \\
\hline ODJ & Pública & $117 / 1675$ & 7,0 & $0,00 /$ & 0,005 \\
\hline & Particular & $13 / 2031$ & 0,6 & & \\
\hline Art & Pública & $13 / 1675$ & 0,8 & $0,0<2$ & $0,0<2$ \\
\hline Arg & Particular & $30 / 2031$ & 1,5 & 0791 & 0741 \\
\hline Arq & Pública & $23 / 1675$ & 1,4 & 0,191 & 0,141 \\
\hline & Particular & $33 / 2031$ & 1,6 & & \\
\hline Simb & Pública & $27 / 1675$ & 1,6 & 0,915 & $0,8<0$ \\
\hline & Particular & $9 / 2031$ & 0,4 & & \\
\hline Abs & Pública & $4 / 1675$ & 0,2 & 0,503 & 0,299 \\
\hline Bot & Particular & $66 / 2031$ & 3,3 & 0723 & 0682 \\
\hline DOL & Pública & $51 / 1675$ & 3,0 & $0, / 23$ & 0,002 \\
\hline Geo & Particular & $40 / 2031$ & 2,0 & 0.611 & 0.590 \\
\hline Geo & Pública & $37 / 1675$ & 2,2 & 0,011 & 0,590 \\
\hline & Particular & $10 / 2031$ & 0,5 & & \\
\hline Nat & Pública & $6 / 1675$ & 0,4 & ( & 0,כ50 \\
\hline & Particular & $15 / 2031$ & 0,7 & 0025 & 0090 \\
\hline Pals & Pública & $3 / 1675$ & 0,2 & $\mathbf{0 , 0}<5$ & $\mathbf{0 , 0}<0$ \\
\hline Elem & Particular & $6 / 2031$ & 0,3 & 0741 & 0802 \\
\hline Elem & Pública & $4 / 1675$ & 0,2 & 0,141 & 0,002 \\
\hline
\end{tabular}


Conclusão

\begin{tabular}{|c|c|c|c|c|c|}
\hline Variável & $\begin{array}{l}\text { Origem } \\
\text { Escolar }\end{array}$ & Proporção & $\%$ & $p$-valor & $\begin{array}{c}p \text {-valor } \\
\text { ajustado }\end{array}$ \\
\hline Frag & $\begin{array}{l}\text { Particular } \\
\text { Pública }\end{array}$ & $\begin{array}{l}34 / 2031 \\
26 / 1675\end{array}$ & 1,7 & 0,770 & 0,829 \\
\hline Ban & $\begin{array}{l}\text { Particular } \\
\text { Pública }\end{array}$ & $\begin{array}{l}278 / 2031 \\
269 / 1675\end{array}$ & $\begin{array}{l}13,7 \\
16,1\end{array}$ & 0,043 & $\mathbf{0 , 0 3 9}$ \\
\hline
\end{tabular}

Primeiramente, como esclarecido anteriormente em relação à comparação entre os gêneros, as proporções aqui apresentadas em relação à qualidade formal das respostas, isto é, as porcentagens ilustradas para F+, F+- e F- correspondem à proporção com que estas ocorreram no conjunto de respostas gerais dos protocolos avaliados. Portanto, não se referem, especificamente, ao cálculo do índice de precisão formal das respostas $(\mathrm{F}+\%)$, exigindo atenção especial para sua interpretação.

Os dados da Tabela 13 permitem observar diferenças estatisticamente significativas em oito das 50 principais variáveis do Rorschach examinadas. Essas diferenças foram encontradas nas seguintes variáveis distribuídas pelas categorias: Determinante: boa qualidade formal $(\mathrm{F}+)$, somatória das respostas formais $\left(\sum \mathrm{F}\right)$, movimento animal (kan), somatória das respostas de pequenas cinestesias ( $\left.\sum \mathrm{k}\right)$; Conteúdo: animal (A), objeto (Obj), paisagem (Pais) e banalidades (Ban).

A respeito do determinante das respostas, ressalta-se que os adolescentes da rede particular de ensino empregaram mais os elementos formais dos cartões (maior $\sum F$ ) que os demais provenientes da escola pública. Além disso, sinalizaram maior precisão lógica em suas análises formais dos estímulos, isto é, os adolescentes do ensino particular apresentaram número significativamente maior de respostas de boa qualidade formal. Por sua vez, os adolescentes do ensino público revelaram índices estatisticamente superiores em relação aos determinantes: movimento animal (kan) e em relação ao somatório das pequenas cinestesias $\left(\sum \mathrm{k}\right)$. Esses dados permitem inferir que os adolescentes da rede pública sinalizaram maior elaboração e maior envolvimento emocional na interpretação das pranchas, enquanto que os aqueles de escolas particulares demonstraram maior investimento racional na tarefa.

No tocante aos conteúdos identificados nas respostas ao Rorschach, os adolescentes se diferenciaram estatisticamente de modo significativo em algumas variáveis, a saber: A, Obj, Pais e Ban. Os adolescentes provenientes da escola pública apresentaram maior proporção das respostas de conteúdo animal, todavia, a comparação da somatória dos conteúdos animais, 
que representa mais da metade do conjunto de respostas para cada grupo examinado, não apresentou diferenças significativas.

Ainda em relação aos conteúdos, outras três diferenças, significativas estatisticamente, foram constatadas entre os grupos de adolescentes examinados. A variável objeto (Obj) ocorreu em maior frequência nos adolescentes do ensino particular, que também tenderam a apresentar mais respostas de conteúdo paisagem (Pais), comparados aos advindos do ensino público. Estes, por sua vez, expuseram maior quantidade de respostas banais (Ban) em relação aos estudantes de escola particular, despontando sinal de maior compartilhamento do pensamento coletivo.

É importante destacar novamente que os resultados aqui apresentados devem ser devidamente ponderados no conjunto das variáveis do Rorschach. Assim sendo, pode-se considerar que o contexto ambiental sinalizou-se como passível de influenciar o desenvolvimento dos adolescentes analisados e, logo, interferir igualmente na forma de produção e de interpretação dos estímulos propostos pelo Método de Rorschach. No entanto, aprofundando-se nesta questão e suas implicações práticas e considerando o conjunto das 56 variáveis da Escola Francesa do Rorschach, na análise global da distribuição dos dados, há que se relativizar estas especificidades de produção identificadas, visto que não foram consistentes em todos os aspectos examinados. Desse modo, pode-se depreender que as evidências ainda são insuficientes para justificar a elaboração de normas avaliativas específicas para os adolescentes de 12 a 14 anos de idade em função da origem escolar. Apesar disso, certamente, os atuais achados apontam para a necessidade de se levar em consideração componentes do contexto sociocultural dos indivíduos como variáveis influentes em processos clínicos de avaliação psicológica por meio do Método de Rorschach.

\subsection{RORSCHACH EM FUNÇÃO DA IDADE}

Em continuidade às análises das possíveis influências de determinadas variáveis sócio demográficas sobre a produção dos adolescentes de 12 a 14 anos no Psicodiagnóstico de Rorschach, foram realizadas comparações estatísticas dos resultados médios em função da idade dos jovens, mesmo tendo-se avaliado uma faixa etária reduzida. Para tanto, os seguintes subgrupos foram arranjados: 12 anos $(\mathrm{n}=60), 13$ anos $(\mathrm{n}=57)$ e 14 anos $(\mathrm{n}=57)$. Os procedimentos adotados foram os mesmos anteriormente descritos, sendo que os resultados encontrados encontram-se nas Tabelas 14 e 15. 
Tabela 14 - Resultados da análise estatística das variáveis relacionadas a produtividade e ritmo no Rorschach, em função da idade (em anos).

\begin{tabular}{|c|c|c|c|c|c|}
\hline Variável & Idade & Média & DP & $p$-valor & $p$-valor ajustado \\
\hline \multirow{3}{*}{$\mathrm{R}$} & 12 & 23,5 & 10,52 & \multirow{3}{*}{0,210} & \multirow{3}{*}{0,194} \\
\hline & 13 & 19,02 & 8,18 & & \\
\hline & 14 & 21,26 & 10,33 & & \\
\hline \multirow{3}{*}{ RA } & 12 & 0,72 & 1,25 & \multirow{3}{*}{0,932} & \multirow{3}{*}{0,966} \\
\hline & 13 & 0,56 & 0,87 & & \\
\hline & 14 & 0,74 & 1,13 & & \\
\hline \multirow{3}{*}{ Rec } & 12 & 0,2 & 0,44 & \multirow{3}{*}{0,090} & \multirow{3}{*}{0,089} \\
\hline & 13 & 0,65 & 0,95 & & \\
\hline & 14 & 0,44 & 0,8 & & \\
\hline \multirow{3}{*}{ Den } & 12 & 0,13 & 0,43 & \multirow{3}{*}{0,939} & \multirow{3}{*}{0,950} \\
\hline & 13 & 0,18 & 0,73 & & \\
\hline & 14 & 0,14 & 0,4 & & \\
\hline \multirow{3}{*}{ TLm } & 12 & 16,3 & 16,14 & \multirow{3}{*}{$\mathbf{0 , 0 5 7}$} & \multirow{3}{*}{0,054} \\
\hline & 13 & 14,72 & 6,84 & & \\
\hline & 14 & 21,87 & 20,04 & & \\
\hline \multirow{3}{*}{$\mathrm{TRm}$} & 12 & 28,15 & 20,14 & \multirow{3}{*}{0,153} & \multirow{3}{*}{0,148} \\
\hline & 13 & 27,22 & 12,8 & & \\
\hline & 14 & 33,41 & 24,01 & & \\
\hline
\end{tabular}

$\mathrm{R}=$ Respostas; RA $=$ Respostas adicionais; Rec $=$ Recusas aos cartões; Den $=$ Denegações; TLm $=$ Tempo de Latência médio (em segundos); TRm = Tempo de Reação médio (em segundos).

Em relação às variáveis associadas à produtividade, dentre os subgrupos avaliados, foi constatada diferença estatisticamente significativa somente na variável relativa ao tempo médio de latência de resposta (TLm). Pode-se notar que os adolescentes de 14 anos apresentaram maior tempo médio de latência quando comparados aos de outras idades (12 e 13 anos), ou seja, os adolescentes do subgrupo mais velho processaram sua primeira resposta ao Rorschach após maior tempo de exposição aos estímulos. Esse dado pode indicar que esses adolescentes podem ter apresentado uma postura mais reflexiva diante dos cartões do Rorschach, talvez menos impulsiva. Vale ressaltar que, ainda que os adolescentes de 14 anos também tenham mostrado um ritmo de trabalho (TRm) discretamente mais lento que os demais, não houve, estatisticamente, diferença significativa no tempo total despendido para associar os estímulos e produzir suas interpretações ao Rorschach. 
Tabela 15 - Resultados da análise estatística das principais variáveis do Rorschach, em função da idade (em anos).

\begin{tabular}{|c|c|c|c|c|c|c|c|}
\hline \multirow{4}{*}{$\begin{array}{c}\text { Variável } \\
\text { G }\end{array}$} & \multirow{2}{*}{$\frac{\text { Idade * }}{12}$} & \multicolumn{2}{|c|}{ Proporção } & \multirow{2}{*}{$\frac{\%}{25,5}$} & \multirow[t]{2}{*}{$\begin{array}{c}p \text { - } \\
\text { valor }\end{array}$} & \multirow[t]{2}{*}{$\begin{array}{c}p \text {-valor } \\
\text { ajustado }\end{array}$} & \multirow[t]{2}{*}{ Diferença } \\
\hline & & 360 & $/ 1410$ & & & & \\
\hline & 13 & 277 & $/ 1084$ & 25,6 & 0,922 & 0,879 & - \\
\hline & 14 & 317 & $/ 1212$ & 26,2 & & & \\
\hline \multirow{3}{*}{$\mathrm{D}$} & 12 & 641 & $/ 1410$ & 45,5 & \multirow{3}{*}{0,494} & \multirow{3}{*}{0,476} & \multirow{3}{*}{-} \\
\hline & 13 & 511 & $/ 1084$ & 47,1 & & & \\
\hline & 14 & 542 & $/ 1212$ & 44,7 & & & \\
\hline \multirow{3}{*}{$\mathrm{Dd}$} & 12 & 397 & $/ 1410$ & 28,2 & \multirow{3}{*}{0,523} & \multirow{3}{*}{0,505} & \multirow{3}{*}{ - } \\
\hline & 13 & 283 & $/ 1084$ & 26,1 & & & \\
\hline & 14 & 331 & $/ 1212$ & 27,3 & & & \\
\hline \multirow{3}{*}{ Dbl } & 12 & 12 & $/ 1410$ & 0,9 & \multirow{3}{*}{0,094} & \multirow{3}{*}{0,081} & \multirow{3}{*}{-} \\
\hline & 13 & 13 & $/ 1084$ & 1,2 & & & \\
\hline & 14 & 22 & $/ 1212$ & 1,8 & & & \\
\hline \multirow{3}{*}{ Do } & 12 & 0 & $/ 1410$ & 0,0 & \multirow{3}{*}{-} & \multirow{3}{*}{-} & \multirow{3}{*}{-} \\
\hline & 13 & 0 & $/ 1084$ & 0,0 & & & \\
\hline & 14 & 0 & $/ 1212$ & 0,0 & & & \\
\hline \multirow{3}{*}{$\mathbf{F}+$} & 12 & 468 & $/ 1410$ & 33,2 & \multirow{3}{*}{0,045} & & \\
\hline & 13 & 323 & $/ 1084$ & 29,8 & & 0,045 & $\begin{array}{l}12 \neq 13 \\
12 \neq 14\end{array}$ \\
\hline & 14 & 351 & $/ 1212$ & 29,0 & & & \\
\hline & 12 & 2 & $/ 1410$ & 0,1 & & & \\
\hline $\mathrm{F}+-$ & 13 & 0 & $/ 1084$ & 0,0 & 0,997 & 0,997 & \\
\hline & 14 & 0 & $/ 1212$ & 0,0 & & & \\
\hline & 12 & 211 & $/ 1410$ & 15,0 & & & \\
\hline F- & 13 & 150 & $/ 1084$ & 13,8 & 0,642 & 0,660 & \\
\hline & 14 & 168 & $/ 1212$ & 13,9 & & & \\
\hline & 12 & 681 & $/ 1410$ & 48,3 & & & $12 \neq 13$ \\
\hline$\sum \mathbf{F}$ & 13 & 473 & $/ 1084$ & 43,6 & 0,010 & 0,010 & $\begin{array}{l}12 \neq 13 \\
12 \neq 14\end{array}$ \\
\hline & 14 & 519 & $/ 1212$ & 42,8 & & & \\
\hline & 12 & 469 & $/ 681$ & 68,87 & & & \\
\hline $\mathrm{F}+\%$ & 13 & 323 & $/ 473$ & 68,29 & 0,900 & 0,878 & \\
\hline & 14 & 351 & 1519 & 67,63 & & & \\
\hline & 12 & 946 & $/ 1410$ & 67,1 & & & \\
\hline $\mathrm{F}+\mathrm{ext} \%$ & 13 & 701 & $/ 1084$ & 64,7 & 0,271 & 0,267 & \\
\hline & 14 & 780 & $/ 1212$ & 64,4 & & & \\
\hline & 12 & 98 & $/ 1410$ & 7,0 & & & \\
\hline $\mathrm{K}$ & 13 & 55 & $/ 1084$ & 5,1 & 0,126 & 0,140 & \\
\hline & 14 & 82 & $/ 1212$ & 6,8 & & & \\
\hline & 12 & 199 & $/ 1410$ & 14,1 & & & \\
\hline kan & 13 & 172 & $/ 1084$ & 15,9 & 0,316 & 0,194 & \\
\hline & 14 & 167 & $/ 1212$ & 13,8 & & & \\
\hline
\end{tabular}




\begin{tabular}{|c|c|c|c|c|c|c|c|}
\hline \multirow{4}{*}{$\begin{array}{c}\text { Variável } \\
\text { kob }\end{array}$} & \multirow{2}{*}{$\frac{\text { Idade * }}{12}$} & \multicolumn{2}{|c|}{ Proporção } & \multirow{2}{*}{$\frac{\%}{1,1}$} & \multirow[t]{2}{*}{$\begin{array}{c}p- \\
\text { valor }\end{array}$} & \multirow[t]{2}{*}{$\begin{array}{c}p \text {-valor } \\
\text { ajustado }\end{array}$} & \multirow[t]{2}{*}{ Diferença } \\
\hline & & 16 & $/ 1410$ & & & & \\
\hline & 13 & 6 & $/ 1084$ & 0,6 & 0,272 & 0,292 & \\
\hline & 14 & 9 & $/ 1212$ & 0,7 & & & \\
\hline \multirow{3}{*}{$\mathrm{Kp}$} & 12 & 31 & $/ 1410$ & 2,2 & & & \\
\hline & 13 & 29 & $/ 1084$ & 2,7 & 0,379 & 0,348 & \\
\hline & 14 & 22 & $/ 1212$ & 1,8 & & & \\
\hline \multirow{3}{*}{$\sum \mathrm{k}$} & 12 & 246 & $/ 1410$ & 17,5 & & & \\
\hline & 13 & 207 & $/ 1084$ & 19,1 & 0,220 & 0,136 & \\
\hline & 14 & 198 & $/ 1212$ & 16,3 & & & \\
\hline \multirow{3}{*}{$\mathrm{FC}$} & 12 & 122 & $/ 1410$ & 8,7 & & & \\
\hline & 13 & 114 & $/ 1084$ & 10,5 & 0,282 & 0,305 & \\
\hline & 14 & 118 & $/ 1212$ & 9,7 & & & \\
\hline \multirow{3}{*}{$\mathrm{CF}$} & 12 & 104 & $/ 1410$ & 7,4 & & & \\
\hline & 13 & 101 & $/ 1084$ & 9,3 & 0,065 & 0,062 & \\
\hline & 14 & 119 & $/ 1212$ & 9,8 & & & \\
\hline \multirow{3}{*}{$\mathrm{C}$} & 12 & 6 & $/ 1410$ & 0,4 & & & \\
\hline & 13 & 9 & $/ 1084$ & 0,8 & 0,313 & 0,282 & \\
\hline & 14 & 5 & $/ 1212$ & 0,4 & & & \\
\hline \multirow{3}{*}{$\mathrm{FE}$} & 12 & 99 & $/ 1410$ & 7,0 & & & \\
\hline & 13 & 65 & $/ 1084$ & 6,0 & 0,446 & 0,432 & \\
\hline & 14 & 88 & $/ 1212$ & 7,3 & & & \\
\hline \multirow{3}{*}{$\mathbf{E F}$} & 12 & 54 & $/ 1410$ & 3,8 & & & \\
\hline & 13 & 58 & $/ 1084$ & 5,4 & 0,008 & 0,012 & $12 \neq 14$ \\
\hline & 14 & 79 & $/ 1212$ & 6,5 & & & \\
\hline \multirow{3}{*}{$\mathrm{E}$} & 12 & 0 & $/ 1410$ & 0,0 & & & \\
\hline & 13 & 2 & $/ 1084$ & 0,2 & 0,803 & 0,691 & \\
\hline & 14 & 1 & $/ 1212$ & 0,1 & & & \\
\hline \multirow{3}{*}{ FClob } & 12 & 0 & $/ 1410$ & 0,0 & & & \\
\hline & 13 & 0 & $/ 1084$ & 0,0 & 0,996 & 0,995 & \\
\hline & 14 & 2 & $/ 1212$ & 0,0 & & & \\
\hline \multirow{3}{*}{ ClobF } & 12 & 0 & $/ 1410$ & 0,0 & & & \\
\hline & 13 & 0 & $/ 1084$ & 0,0 & - & - & \\
\hline & 14 & 0 & $/ 1212$ & 0,0 & & & \\
\hline \multirow{3}{*}{ Clob } & 12 & 0 & $/ 1410$ & 0,0 & & & \\
\hline & 13 & 0 & $/ 1084$ & 0,0 & 0,996 & 0,997 & \\
\hline & 14 & 1 & $/ 1212$ & 0,1 & & & \\
\hline \multirow{3}{*}{ A } & 12 & 507 & $/ 1410$ & 36,0 & & & \\
\hline & 13 & 435 & $/ 1084$ & 40,1 & 0,090 & 0,069 & \\
\hline & 14 & 447 & $/ 1212$ & 36,9 & & & \\
\hline
\end{tabular}


Continuação

\begin{tabular}{|c|c|c|c|c|c|c|c|}
\hline \multirow{4}{*}{$\begin{array}{c}\text { Variável } \\
\text { (A) }\end{array}$} & \multirow{2}{*}{$\frac{\text { Idade * }}{12}$} & \multicolumn{2}{|c|}{ Proporção } & \multirow{2}{*}{$\frac{\%}{3,4}$} & \multirow[t]{2}{*}{$\begin{array}{c}p \text { - } \\
\text { valor }\end{array}$} & \multirow[t]{2}{*}{$\begin{array}{c}p \text {-valor } \\
\text { ajustado }\end{array}$} & \multirow[t]{2}{*}{ Diferença } \\
\hline & & 48 & $/ 1410$ & & & & \\
\hline & 13 & 42 & /1084 & 3,9 & 0,362 & 0,368 & \\
\hline & 14 & 34 & $/ 1212$ & 2.8 & & & \\
\hline \multirow{3}{*}{ Ad } & 12 & 173 & $/ 1410$ & 12,3 & \multirow{3}{*}{0,106} & \multirow{3}{*}{0,131} & \\
\hline & 13 & 137 & $/ 1084$ & 12,6 & & & \\
\hline & 14 & 122 & $/ 1212$ & 10,1 & & & \\
\hline \multirow{3}{*}{ (Ad) } & 12 & 23 & $/ 1410$ & 1,6 & \multirow{3}{*}{0,256} & \multirow{3}{*}{0,269} & \\
\hline & 13 & 13 & $/ 1084$ & 1,2 & & & \\
\hline & 14 & 11 & $/ 1212$ & 0,9 & & & \\
\hline \multirow{3}{*}{$\sum \mathbf{A}$} & 12 & 751 & $/ 1410$ & 53,3 & \multirow{3}{*}{0,002} & \multirow{3}{*}{0,002} & \\
\hline & 13 & 627 & $/ 1084$ & 57,8 & & & $\begin{array}{l}12 \neq 13 \\
13 \neq 14\end{array}$ \\
\hline & 14 & 614 & $/ 1212$ & 50,7 & & & \\
\hline \multirow{3}{*}{$\mathrm{H}$} & 12 & 140 & $/ 1410$ & 9,9 & \multirow{3}{*}{0,207} & \multirow{3}{*}{0,210} & \\
\hline & 13 & 86 & /1084 & 7,9 & & & \\
\hline & 14 & 105 & $/ 1212$ & 8,7 & & & \\
\hline \multirow{3}{*}{$(\mathrm{H})$} & 12 & 66 & $/ 1410$ & 4,7 & \multirow{3}{*}{0,062} & \multirow{3}{*}{0,058} & \\
\hline & 13 & 42 & $/ 1084$ & 3,9 & & & \\
\hline & 14 & 35 & $/ 1212$ & 2,9 & & & \\
\hline \multirow{3}{*}{$\mathrm{Hd}$} & 12 & 127 & $/ 1410$ & 9,0 & \multirow{3}{*}{0,399} & \multirow{3}{*}{0,369} & \\
\hline & 13 & 85 & $/ 1084$ & 7,8 & & & \\
\hline & 14 & 93 & $/ 1212$ & 7,7 & & & \\
\hline & 12 & 23 & $/ 1410$ & 1,6 & & & \\
\hline (Hd) & 13 & 16 & $/ 1084$ & 1,5 & 0,815 & 0,921 & \\
\hline & 14 & 22 & $/ 1212$ & 1,8 & & & \\
\hline & 12 & 356 & $/ 1410$ & 25,3 & & & \\
\hline$\sum \mathbf{H}$ & 13 & 229 & $/ 1084$ & 21,1 & 0,013 & 0,011 & $\begin{array}{l}12 \neq 13 \\
12+14\end{array}$ \\
\hline & 14 & 255 & $/ 1212$ & 21,0 & & & \\
\hline & 12 & 24 & $/ 1410$ & 1,7 & & & \\
\hline Anat & 13 & 3 & $/ 1084$ & 2,8 & 0,002 & 0,003 & $12 \neq 14$ \\
\hline & 14 & 49 & $/ 1212$ & 4,0 & & & \\
\hline & 12 & 2 & $/ 1410$ & 0,1 & & & \\
\hline $\mathrm{Sg}$ & 13 & 2 & $/ 1084$ & 0,2 & 0,580 & 0,561 & \\
\hline & 14 & 4 & $/ 1212$ & 0,3 & & & \\
\hline & 12 & 0 & $/ 1410$ & 0,0 & & & \\
\hline Sex & 13 & 2 & $/ 1084$ & 0,2 & 0,992 & 0,923 & \\
\hline & 14 & 2 & $/ 1212$ & 0,2 & & & \\
\hline & 12 & 118 & $/ 1410$ & 8,4 & & & \\
\hline Obj & 13 & 73 & $/ 1084$ & 6,7 & $\mathbf{0 , 0 3 5}$ & $\mathbf{0 , 0 1 7}$ & $13 \neq 14$ \\
\hline & 14 & 118 & $/ 1212$ & 9,7 & & & \\
\hline
\end{tabular}


Conclusão

\begin{tabular}{|c|c|c|c|c|c|c|c|}
\hline \multirow{4}{*}{$\begin{array}{c}\text { Variável } \\
\text { Art }\end{array}$} & \multirow{2}{*}{$\frac{\text { Idade }^{*}}{12}$} & \multicolumn{2}{|c|}{ Proporção } & \multirow{2}{*}{$\begin{array}{c}\% \\
0,7\end{array}$} & \multirow{4}{*}{$\begin{array}{c}\begin{array}{c}p- \\
\text { valor }\end{array} \\
0,974\end{array}$} & \multirow{4}{*}{$\begin{array}{c}\begin{array}{c}\boldsymbol{p} \text {-valor } \\
\text { ajustado }\end{array} \\
0,936\end{array}$} & \multirow[t]{4}{*}{ Diferença } \\
\hline & & 10 & $/ 1410$ & & & & \\
\hline & 13 & 8 & $/ 1084$ & 0,7 & & & \\
\hline & 14 & 8 & $/ 1212$ & 0.7 & & & \\
\hline \multirow{3}{*}{ Arq } & 12 & 19 & $/ 1410$ & 1,4 & \multirow{3}{*}{0,534} & \multirow{3}{*}{0,537} & \\
\hline & 13 & 13 & $/ 1084$ & 1,2 & & & \\
\hline & 14 & 21 & $/ 1212$ & 1,7 & & & \\
\hline \multirow{3}{*}{ Simb } & 12 & 17 & $/ 1410$ & 1,2 & \multirow{3}{*}{0,001} & \multirow{3}{*}{0,002} & \\
\hline & 13 & 10 & $/ 1084$ & 0,9 & & & $12 \neq 13$ \\
\hline & 14 & 33 & $/ 1212$ & 2,7 & & & \\
\hline \multirow{3}{*}{ Abs } & 12 & 5 & $/ 1410$ & 0,4 & \multirow{3}{*}{0,861} & \multirow{3}{*}{0,797} & \\
\hline & 13 & 3 & $/ 1084$ & 0,3 & & & \\
\hline & 14 & 5 & $/ 1212$ & 0,4 & & & \\
\hline \multirow{3}{*}{ Bot } & 12 & 36 & $/ 1410$ & 2,6 & \multirow{3}{*}{0,121} & \multirow{3}{*}{0,125} & \\
\hline & 13 & 33 & /1084 & 3,0 & & & \\
\hline & 14 & 48 & $/ 1212$ & $\begin{array}{l}5,0 \\
4,0\end{array}$ & & & \\
\hline \multirow{3}{*}{ Geo } & 12 & 30 & $/ 1410$ & 2,1 & \multirow{3}{*}{0,959} & \multirow{3}{*}{0,979} & \\
\hline & 13 & 23 & $/ 1084$ & 2,1 & & & \\
\hline & 14 & 24 & $/ 1212$ & 2,0 & & & \\
\hline \multirow{3}{*}{ Nat } & 12 & 10 & $/ 1410$ & 0,7 & \multirow{3}{*}{0,141} & \multirow{3}{*}{0,154} & \\
\hline & 13 & 2 & $/ 1084$ & 0,2 & & & \\
\hline & 14 & 4 & $/ 1212$ & 0,3 & & & \\
\hline \multirow{3}{*}{ Pais } & 12 & 7 & $/ 1410$ & 0,5 & \multirow{3}{*}{0,194} & \multirow{3}{*}{0,148} & \\
\hline & 13 & 2 & $/ 1084$ & 0,2 & & & \\
\hline & 14 & 9 & $/ 1212$ & 0,7 & & & \\
\hline & 12 & 4 & $/ 1410$ & 0,3 & & & \\
\hline Elem & 13 & 5 & $/ 1084$ & 0,5 & 0,277 & 0,311 & \\
\hline & 14 & 1 & $/ 1212$ & 0,1 & & & \\
\hline & 12 & 21 & $/ 1410$ & 1,5 & & & \\
\hline Frag & 13 & 22 & $/ 1084$ & 2,0 & 0,441 & 0,478 & \\
\hline & 14 & 17 & $/ 1212$ & 1,4 & & & \\
\hline & 12 & 194 & $/ 1410$ & 13,8 & & & \\
\hline Ban & 13 & 168 & $/ 1084$ & 15,5 & 0,399 & 0,367 & \\
\hline & 14 & 185 & $/ 1212$ & 15,3 & & & \\
\hline
\end{tabular}

Os resultados dispostos na Tabela 15 acima, referentes à comparação dos adolescentes divididos em subgrupos em função da idade, marcaram diferenças estatisticamente significativas em oito variáveis do total de 50 analisadas. Não foram constatadas diferenças no modo de apreensão do estímulo, assim sendo, todas estão distribuídas nas categorias dos determinantes e conteúdos das interpretações. Dentre os determinantes, tem-se: boa qualidade formal $(\mathrm{F}+)$, somatória das respostas formais $\left(\sum \mathrm{F}\right)$ e sombreado de má qualidade formal $(\mathrm{EF})$. 
Nos conteúdos estão as outras cinco diferenças encontradas: somatória de conteúdo animal $\left(\sum \mathrm{A}\right)$, somatória de conteúdo humano $\left(\sum \mathrm{H}\right)$, anatômico (Anat), objeto (Obj) e símbolo (Simb). Faz-se importante destacar que algumas destas variáveis ocorreram em reduzida proporção relativamente às demais, de tal modo que estas diferenças detectadas perdem em força interpretativa no conjunto das evidências encontradas.

Em relação aos determinantes das respostas que diferiram estatisticamente entre os subgrupos, nota-se um destaque para aqueles relativos ao componente formal $\left(\mathrm{F}+\mathrm{e} \sum \mathrm{F}\right)$ dos adolescentes de 12 anos. Eles diferiram, de maneira significativa, das outras idades tanto em relação à boa qualidade formal das respostas quanto na somatória das respostas determinadas pela forma. Entretanto, é imperativo afirmar que, ao se comparar a qualidade formal relacionada às demais variáveis do conjunto $(\mathrm{F}+\mathrm{ext} \%)$, não foram detectadas diferenças estatisticamente significativas entre os subgrupos de idades, sugerindo que esta peculiaridade no modo de responder ao Rorschach dos adolescentes mais novos se deve à intensidade com que recorrem aos elementos formais dos estímulos e não em sua precisão lógica nas análises formais dos mesmos. Há que se destacar também que os adolescentes de 14 anos apresentaram número significativamente maior de respostas determinadas pelo $\mathrm{EF}$, sugerindo maior nível de angústia nos adolescentes de mais idade dessa amostra avaliada no presente trabalho.

Em se tratando dos conteúdos das respostas, os adolescentes de 13 anos se distinguiram significativamente dos de 12 e dos de 14 anos no que diz respeito à somatória do conteúdo animal das respostas. Cabe ressaltar que esta diferença ocorreu apenas na somatória das variáveis de conteúdo animal e não nas variáveis tomadas individualmente $[\mathrm{A},(\mathrm{A}), \mathrm{Ad}$ e (Ad)]. O mesmo ocorre com a variável $\sum \mathrm{H}$, mas, neste caso, são os mais novos (12 anos) que se destacam das demais idades pelo maior número de respostas de conteúdo humano (na somatória das variáveis). Embora detectadas essas peculiaridades na produção dos adolescentes, fica difícil hipotetizar explicações plausíveis para este tipo de achados, visto que não sinalizaram direção consistente em termos etários. Neste momento ficam destacados como variáveis relevantes do Rorschach a serem exploradas nos processos de interpretação clínica dos casos examinados por meio deste método projetivo de avaliação psicológica e como ponto de pauta para investigações futuras.

Nos demais conteúdos de respostas ao Rorschach foram verificadas diferenças estatisticamente significativas nas variáveis Anat, Obj e Simb. Em relação à primeira variável citada, o subgrupo de 12 anos revelou índices significativamente inferiores aos estudantes de 13 e 14 anos, podendo indicar maior angústia em relação ao corpo e às mudanças corporais no 
subgrupo de maior idade dessa amostra. As respostas de conteúdo Obj e Símb foram mais relatadas pelos adolescentes de 14 anos, sugestivo de maior uso da racionalização e dos processos de simbolização entre os estudantes de maior idade presentemente avaliados. Estas evidências empíricas, embora reduzidas numericamente, apontam para sinais de sensibilidade do Método de Rorschach ao processo de desenvolvimento das funções psíquicas entre os indivíduos, sugerindo variáveis sensíveis à evolução do funcionamento lógico e afetivo.

Frente aos achados atuais referentes às diferenças estatisticamente significativas entre variáveis do Rorschach, quer por sua frequência ou por sua especificidade técnica, tornam-se insuficientes para justificar a elaboração de parâmetros normativos do Método de Rorschach específicos para cada ano de idade presentemente avaliado. No entanto, estas pistas técnicas deverão ser obrigatoriamente levadas em consideração em elaborações psicodiagnósticas, pois, como comentado, sugerem especificidades ligadas ao desenvolvimento humano que devem ser ponderadas para garantir a adequada análise interpretativa do conjunto de indicadores deste método projetivo de avaliação psicológica.

\subsection{SÍNTESE GERAL DO RORSCHACH}

Finalizadas as análises estatísticas elaboradas com o intuito de verificar as possíveis influências do gênero, da origem escolar e da idade sobre as variáveis codificadas no Método de Rorschach, considerou-se sensato sistematizar uma tabela descritiva e analítica para vislumbrar o conjunto total de dados, considerando-se onde foram constatadas as diferenças significativas. A Tabela 16 delineia uma síntese quantitativa dos resultados médios gerais da amostra no Psicodiagnóstico de Rorschach, de acordo com as 56 variáveis consideradas. Estes dados podem auxiliar as análises interpretativas e clínicas por parte dos profissionais que porventura vierem a fazer uso do material para os adolescentes de 12 a 14 anos de idade em regiões com características sócio-demográficas e culturais similares às do presente estudo.

Tabela 16 - Resultados médios descritivos e inferenciais das variáveis do Rorschach na $\operatorname{amostra}(\mathrm{n}=174)$.

\begin{tabular}{cccccccc}
\hline Variáveis & Mediana & Média & $\begin{array}{c}\text { Desvio- } \\
\text { padrão }\end{array}$ & $\begin{array}{c}\text { Média } \\
(\%)\end{array}$ & Mínimo & Máximo & $\begin{array}{c}\text { Diferenças } \\
\text { estatisticamente } \\
\text { significativas } \\
\text { entre subgrupos }\end{array}$ \\
\hline R & 20 & 21,3 & 9,9 & - & 7 & 61 & Part > Pub \\
\hline RA & 0 & 0,7 & 1,1 & - & 0 & 7 & - \\
\hline Rec & 0 & 0,4 & 0,8 & - & - & 3 & Pub > Part \\
\hline Den & 0 & 0,2 & 0,5 & - & 0 & 5 & - \\
\hline & & & & & & & Continua
\end{tabular}


Continuação

\section{Variáveis Mediana Média \\ Desvio-
padrão $\quad \begin{aligned} & \text { Média } \\ & \text { (\%) }\end{aligned}$ Mínimo Máximo}

Diferenças estatisticamente

significativas entre subgrupos

\begin{tabular}{|c|c|c|c|c|c|c|c|}
\hline TLm & 12,9 & 17,6 & 15,6 & - & 3,4 & 113,4 & $14>12$ e 13 \\
\hline $\mathrm{TRm}$ & 24,5 & 29,6 & 19,6 & - & 9,6 & 128,5 & - \\
\hline $\mathrm{G}$ & 5 & 5,5 & 3,5 & 25,7 & 0 & 18 & $M>F$ \\
\hline $\mathrm{D}$ & 8,5 & 9,7 & 5,8 & 45,7 & 0 & 30 & - \\
\hline $\mathrm{Dd}$ & 4 & 5,8 & 5,4 & 27,3 & 0 & 26 & $\mathrm{~F}>\mathrm{M}$ \\
\hline Dbl & 0 & 0,3 & 0,6 & 1,3 & 0 & 4 & - \\
\hline Do & 0 & 0 & 0 & 0 & 0 & 0 & - \\
\hline $\mathrm{F}+$ & 6 & 6,6 & 4,7 & 30,8 & 0 & 24 & $\begin{array}{c}12>13 \text { e } 14 \\
\text { Part }>\text { Pub }\end{array}$ \\
\hline $\mathrm{F}+-$ & 0 & 0,0 & 0,2 & 0,1 & 0 & 2 & - \\
\hline F- & 2 & 3,0 & 3,0 & 14,3 & 0 & 14 & - \\
\hline$\sum F$ & 9 & 9,6 & 6,6 & 45,1 & 0 & 38 & $\begin{array}{c}12>13 \text { e } 14 \\
\text { Part }>\text { Pub }\end{array}$ \\
\hline $\mathrm{F}+\%$ & 70,3 & 70,0 & 22,9 & 68,3 & 0 & 100,0 & - \\
\hline $\mathrm{F}+\mathrm{ext} \%$ & 66,7 & 68,1 & 15,5 & 65,5 & 26,3 & 100,0 & - \\
\hline $\mathrm{K}$ & 1 & 1,4 & 1,5 & 6,3 & 0 & 8 & - \\
\hline kan & 2 & 3,1 & 2,9 & 14,5 & 0 & 16 & Pub > Part \\
\hline kob & 0 & 0,2 & 0,5 & 0,8 & 0 & 3 & $\mathrm{M}>\mathrm{F}$ \\
\hline $\mathrm{kp}$ & 0 & 0,5 & 0,9 & 2,2 & 0 & 5 & - \\
\hline$\sum \mathrm{k}$ & 3 & 3,7 & 3,3 & 17,6 & 0 & 19 & Pub > Part \\
\hline $\mathrm{FC}$ & 2 & 2,0 & 1,9 & 9,6 & 0 & 10 & - \\
\hline $\mathrm{CF}$ & 1 & 1,9 & 1,9 & 8,7 & 0 & 13 & - \\
\hline $\mathrm{C}$ & 0 & 0,1 & 0,4 & 0,5 & 0 & 3 & - \\
\hline $\mathrm{FE}$ & 1 & 1,4 & 1,4 & 6,8 & 0 & 9 & - \\
\hline $\mathrm{EF}$ & 1 & 1,1 & 1,7 & 5,2 & 0 & 12 & $\mathrm{~F}>\mathrm{M}, 12<14$ \\
\hline $\mathrm{E}$ & 0 & 0,0 & 0,1 & 0,1 & 0 & 1 & - \\
\hline FClob & 0 & 0,0 & 0,1 & 0,1 & 0 & 1 & - \\
\hline ClobF & 0 & 0 & 0 & 0 & 0 & 0 & - \\
\hline Clob & 0 & 0,0 & 0,1 & 0,0 & 0 & 1 & - \\
\hline $\mathrm{A}$ & 7,5 & 8,0 & 4,0 & 37,5 & 0 & 23 & Pub > Part \\
\hline (A) & 0 & 0,7 & 1,1 & 3,3 & 0 & 5 & - \\
\hline Ad & 2 & 2,5 & 2,6 & 11,7 & 0 & 13 & - \\
\hline$(\mathrm{Ad})$ & 0 & 0,3 & 0,5 & 1,3 & 0 & 3 & - \\
\hline$\sum \mathrm{A}$ & 10 & 11,4 & 5,5 & 53,8 & 3 & 36 & $13>12$ e 14 \\
\hline $\mathrm{H}$ & 2 & 1,9 & 1,5 & 8,9 & 0 & 7 & - \\
\hline$(\mathrm{H})$ & 0 & 0,8 & 1,2 & 3,9 & 0 & 7 & - \\
\hline $\mathrm{Hd}$ & 1 & 1,8 & 2,0 & 8,2 & 0 & 11 & - \\
\hline$(\mathrm{Hd})$ & 0 & 0,4 & 0,7 & 1,6 & 0 & 5 & $\mathrm{~F}>\mathrm{M}$ \\
\hline$\sum \mathrm{H}$ & 4 & 4,8 & 3,4 & 22,7 & 0 & 21 & $\begin{array}{c}12>13 \text { e } 14 \\
F>M\end{array}$ \\
\hline Anat & 0 & 0,6 & 1,0 & 2,8 & 0 & 6 & $14>12$ \\
\hline $\mathrm{Sg}$ & 0 & 0,0 & 0,2 & 0,2 & 0 & 1 & - \\
\hline
\end{tabular}


Conclusão

\begin{tabular}{cccccccc}
\hline Variáveis & Mediana & Média & $\begin{array}{c}\text { Desvio- } \\
\text { padrão }\end{array}$ & $\begin{array}{c}\text { Média } \\
(\boldsymbol{\%})\end{array}$ & Mínimo & Máximo & $\begin{array}{c}\text { Diferenças } \\
\text { estatisticamente } \\
\text { significativas } \\
\text { entre subgrupos }\end{array}$ \\
\hline Sex & 0 & 0,0 & 0,2 & 0,1 & 0 & 1 & - \\
\hline Obj & 1 & 1,8 & 2,3 & 8,3 & 0 & 14 & $13<14$ \\
\hline Art & 0 & 0,1 & 0,4 & 0,7 & 0 & 3 & F > M \\
\hline Arq & 0 & 0,3 & 0,6 & 1,4 & 0 & 3 & - \\
\hline Simb & 0 & 0,3 & 0,7 & 1,6 & 0 & 4 & $14>12$ e 13 \\
\hline Abs & 0 & 0,1 & 0,3 & 0,4 & 0 & 2 & - \\
\hline Bot & 0 & 0,7 & 1,0 & 3,2 & 0 & 5 & - \\
\hline Geo & 0 & 0,4 & 0,8 & 2,1 & 0 & 5 & - \\
\hline Nat & 0 & 0,1 & 0,3 & 0,4 & 0 & 2 & - \\
\hline Pais & 0 & 0,1 & 0,4 & 0,5 & 0 & 3 & Part > Pub \\
\hline Elem & 0 & 0,1 & 0,2 & 0,3 & 0 & 1 & - \\
\hline Frag & 0 & 0,3 & 0,8 & 1,6 & 0 & 4 & - \\
\hline Ban & 3 & 3,1 & 1,4 & 14,8 & 0 & 8 & Pub Part \\
\hline
\end{tabular}

Part = Escolas particulares; Pub = Escolas públicas; $\mathrm{M}=$ gênero masculino; $\mathrm{F}=$ gênero feminino.

A descrição geral dos resultados presente na Tabela 16 expõe algumas particularidades encontradas no conjunto dos adolescentes de 12 a 14 anos. Observa-se uma média de respostas bastante satisfatória, o predomínio de respostas $\mathrm{D}$ sobre $\mathrm{G}$ e $\mathrm{Dd}$, elevado número de respostas exclusivamente determinadas pela forma $(\mathrm{F}=45,1 \%)$ e adequado índice de precisão formal em suas análises dos estímulos do ambiente $(\mathrm{F}+\%=68,3 \%$ e $\mathrm{F}+\mathrm{ext} \%=65,5 \%)$. Dentre os conteúdos que despontaram com maior frequência nas respostas estão o animal $(53,8 \%)$ e o humano $(22,7 \%)$, com destaque para o primeiro. Estes dados combinam com o teoricamente previsto para o desenvolvimento psíquico da referida faixa etária, levando em consideração a identificação com elementos vivos e dinâmicos da realidade.

A análise estatística inferencial realizada apontou peculiaridades em função do gênero, da origem escolar ou da idade em 21 das 56 variáveis avaliadas na Escola Francesa do Rorschach, devidamente registradas na Tabela 16. Como dito anteriormente, tais dados podem auxiliar as análises interpretativas e clínicas por parte dos profissionais que porventura vierem a fazer uso do material para os adolescentes de 12 a 14 anos de idade em regiões com características sócio demográficas e culturais similares as do presente estudo. Contudo, é importante novamente ressaltar que esses referenciais normativos do Rorschach devem ser examinados com o devido cuidado, a fim de permitir interpretações válidas e consistentes, orientadas para o conjunto da produção e não apenas em variáveis isoladas. 


\subsection{ATLAS DO RORSCHACH}

Concluída a etapa relativa à análise estatística dos dados encontrados a partir do conjunto de adolescentes avaliados, realizou-se a sistematização dos resultados relativos às áreas interpretadas, as respostas nela identificadas, bem como seu respectivo nível de qualidade formal. Em síntese, passou-se a compor um Atlas do Rorschach (Escola Francesa) para adolescentes de 12 a 14 anos, conforme descrito anteriormente no capítulo que se destinou ao método empregado neste estudo. Não obstante as respostas produzidas pelos 174 adolescentes, assim como seus respectivos recortes interpretativos, componha conteúdo central neste trabalho, dada sua extensão, este material será apresentado na seção de apêndices (APÊNDICE E).

Este Atlas comporta a classificação atualizada dos recortes interpretativos das respostas, bem como sua respectiva classificação como área G, D, Dd ou Dbl. É importante salientar que o número atribuído a cada área $\mathrm{D}, \mathrm{Dd}$ ou $\mathrm{Dbl}$ seguiu a frequência de interpretações atribuídas a cada uma delas, adotando-se a ordem decrescente para apresentação de cada recorte aqui utilizado pelos adolescentes. Portanto, uma área nomeada D1 obteve uma frequência maior de respostas que a área D2 subsequente, e assim sucessivamente. Quando não se podiam diferenciar as áreas em relação ao número de respostas de cada uma (por possuírem a mesma frequência), deu-se preferência à área de maior pregnância, ou seja, aquela que possuísse o recorte de maior tamanho.

Além disso, também foi analisado o nível de precisão formal das respostas emitidas pelos participantes, as quais eram assinaladas como sendo de boa qualidade formal (+), má qualidade formal (-), ou imprecisa ( \pm ). Para a determinação da precisão formal das respostas foram utilizados critérios quantitativos e qualitativos, a partir da análise dos três avaliadores independentes. Estes procedimentos já foram relatados anteriormente no capítulo referente ao percurso metodológico deste estudo.

Ainda concernente ao Atlas do Rorschach, foi realizada uma análise para averiguar quais respostas atingiriam o critério para corresponder a uma resposta banal (Ban) a partir do padrão técnico adotado por Jacquemin (1976), já previamente apresentado. Dessa forma, para ser uma resposta banal (Ban), ela precisaria incidir em uma mesma área de um cartão por, pelo menos, 29 adolescentes (16,7\% do total de indivíduos investigados). A listagem das 13 respostas Ban encontradas está descrita na Tabela 17. 
Tabela 17 - Lista das respostas banais ao Rorschach, identificadas a partir do conjunto de respostas emitidas $(\mathrm{R}=3706)$ pela amostra total $(\mathrm{n}=174)$.

\begin{tabular}{ccccc}
\hline Cartão & Localização & Conteúdo & $f$ & $\%$ \\
\hline I & G & Borboleta (com ou sem Dbl) & 36 & 20,7 \\
\hline I & G & Cara de animal (com ou sem Dbl) & 33 & 19,0 \\
\hline I & G & Morcego (com ou sem Dbl) & 41 & 23,6 \\
\hline II & D2 & Coração & 29 & 16,7 \\
\hline III & D1 & Figuras humanas (duas) e objeto & 34 & 19,5 \\
\hline III & D1 & Borboleta (^ ou $\vee$ ) & 30 & 17,2 \\
\hline III & D2 & Borboleta & 65 & 37,4 \\
\hline V & G & Morcego & 62 & 35,6 \\
\hline V & G & Figuras humanas (duas) & 35 & 20,1 \\
\hline VII & G & Animais quadrúpedes (dois - em D1) acrescido & & 16,7 \\
\hline & & de conteúdo adicional do tipo botânico, & 32 & 18,4 \\
VIII & G & geográfico, natureza ou paisagem & & \\
\hline VIII & D1 & Animais quadrúpedes (dois) & 105 & 60,3 \\
\hline X & Aranha $(\wedge$ ou $\vee$ ) & 31 & 17,8 \\
\hline
\end{tabular}

Nota-se na Tabela 17 que as respostas Ban aparecem com proporções de ocorrência muito variadas, embora todas possam ser classificadas como banais. Nesse sentido, respostas como borboleta e morcego no cartão V e animais quadrúpedes no cartão VIII foram muito mais aludidas que outras, indicando maior popularidade destas sobre as demais respostas Ban. Diante disso, destaca-se que determinados perceptos são muito esperados em um protocolo e, portanto, do ponto de vista qualitativo, a eventual ausência desta interpretação no conjunto de respostas de um protocolo se faz mais relevante que sua própria presença.

Por fim, vale ressaltar que muitas das respostas Ban aqui encontradas foram também percebidas em adolescentes avaliados nos estudos de Jardim-Maran (2011), Ikiz et al. (2010) e de Azoulay et al. (2008). As comparações entre estes trabalhos e o atual serão exploradas mais adiante. 
5 DISCUSSÃO 
Dado o objetivo proposto para a presente investigação, voltado à caracterização do padrão de respostas ao Método de Rorschach de adolescentes de 12 a 14 anos, pode-se inicialmente apontar que esta meta foi alcançada a partir de uma amostra de 174 adolescentes. Torna-se possível neste momento, portanto, apresentar referenciais normativos atualizados do Método de Rorschach (Escola Francesa) para os adolescentes do interior paulista inseridos na referida faixa etária. Dessa forma, este estudo está em concordância com as orientações do Conselho Federal de Psicologia (CFP, 2011), que prevê o desenvolvimento de padrões normativos para os instrumentos de avaliação psicológica, que abarquem os diferentes contextos e idades, a cada 15 anos (prazo máximo).

Versando, agora, sobre alguns aspectos metodológicos aqui adotados, focalizaremos inicialmente os indicadores relativos à fidedignidade do Método de Rorschach. De acordo com Urbina (2007) e Fernsterseifer e Werlang (2008), a avaliação dos casos por juízes independentes consiste em procedimento comumente empregado para avaliar a precisão dos resultados no Rorschach. Diferentes estudos realizados com este instrumento de avaliação da personalidade, tanto sob o referencial da Escola Francesa quanto aqueles desenvolvidos no Sistema Compreensivo, elegeram o acordo entre examinadores (independente e às cegas) como o método para cálculo do índice de fidedignidade dos dados.

Assim como em estudos normativos internacionais do Rorschach identificados anteriormente (Hansen, 2007; Lis, Salcuni \& Parolin, 2007; Matsumoto et al., 2007; Salcuni et al., 2007; Van Patten et al., 2007), alguns protocolos foram selecionados aleatoriamente para se calcular o índice de concordância entre juízes. Os índices foram apresentados em porcentagens e variavam de 70 a 100\% de acordo. Desse modo, os índices de concordância presentemente encontrados (Localizações $=97 \%$; Determinantes $=90 \%$; Conteúdos $=95 \%$; Banalidades $=90 \%$ ) podem ser considerados altamente satisfatórios, fortalecendo a qualidade dos achados com a Escola Francesa do Rorschach utilizado no contexto do Brasil.

Diante destas evidências empíricas de precisão do método projetivo estudado, pode-se seguir para a análise dos dados normativos propriamente ditos. Será realizada, neste momento, uma comparação entre os dados aqui encontrados em relação aos referenciais normativos desenvolvidos por Azoulay et al. (2007 - amostra francesa de adolescentes e jovens adultos), por Ikiz et al. (2010 - adolescentes turcos de 13 a 19 anos de idade) e por Jardim-Maran (2011 - estudantes brasileiros de 15 a 17 anos), todos sob os preceitos da Escola Francesa do Rorschach. Vale ressaltar que estes três estudos normativos com adolescentes na Escola Francesa foram os mais recentes encontrados e, por isso, justifica-se o presente foco analítico centrado na comparação destes com os resultados aqui encontrados. 
Para dar início à análise comparativa entre os citados estudos, será abordada a produtividade no Método do Rorschach específica para cada um dos cartões, exemplificandose essa variável pelo último estímulo deste instrumento de avaliação psicológica. Desse modo, pode-se notar que, em todos os estudos comparados, o cartão $\mathrm{X}$ foi o que provocou maior número de interpretações. Os autores do estudo francês argumentam que esta maior atividade perceptiva pode estar associada tanto à multiplicidade de cores quanto à dispersão da mancha, exemplificando que características sensoriais dos estímulos devem ser consideradas nos processos de interpretação das respostas ao Método de Rorschach, paralelamente ao significado simbólico eventual atribuído às variáveis técnicas de classificação das respostas em si. Rausch de Traubenberg (1998) apontava, classicamente, a importância da integração dos elementos perceptuais aos vivenciais na compreensão do psicodinamismo humano, a partir dos indicadores técnicos do Método de Rorschach.

Entretanto, não somente similaridades quanto à reatividade específica diante de estímulos do Rorschach foram identificadas entre os referidos estudos, podendo-se explorar variáveis gerais diante deste método projetivo. Nesse sentido, podem-se notar, numa exploração de natureza comparativa destes achados, outros elementos de similaridade entre as normas do Rorschach desenvolvidas com adolescentes e jovens adultos na França e aquelas aqui elaboradas para adolescentes do interior paulista. No estudo francês, os adolescentes avaliados forneceram um número médio de respostas igual a $25,8(\mathrm{R}=25,8)$, superior ao presentemente encontrado, já que o número médio de respostas aqui identificado assumiu o valor de 21,3 $(\mathrm{R}=21,3)$. Por outro lado, o resultado do presente estudo foi superior ao encontrado por Jardim-Maran (2011) ao avaliar adolescentes do mesmo contexto, cuja média de respostas alcançou o valor de 17,7. Com relação ao tempo médio de resposta (TRm), verificou-se que os adolescentes da amostra atual foram consideravelmente mais ágeis em seus processos associativos (TRm $=29,6$ segundos) do que os adolescentes de Jardim-Maran (2011), uma vez que o TRm deste estudo atingiu 45,3 segundos.

As demais variáveis relacionadas à produtividade no Rorschach (respostas adicionais, recusas e denegações), que podem ser indicativas de impacto emocional frente os estímulos desta técnica projetiva, ocorreram em proporções bastante reduzidas nos protocolos das pesquisas presentemente comparadas. Os adolescentes aqui avaliados obtiveram média de 0,40 recusas, mesmo valor encontrado por Jardim-Maran (2011), enquanto os adolescentes e jovens adultos franceses (Azoulay et al., 2007) alcançaram média de 0,18 recusas e os turcos (Ikiz et al., 2010) apresentaram uma média de 0,59 recusas. A prancha que apresentou maior número de recusas, tanto no atual estudo quanto no francês e no turco, foi a IX, sendo que 
nestes últimos estudos o cartão II também recebeu destaque juntamente ao IX. Já na pesquisa de Jardim-Maran (2011), foram os cartões IV e VI os responsáveis por suscitar maior número de recusas. Estes achados estão congruentes com as considerações clássicas de Anzieu (1986) e Rausch de Traubenberg (1998), seguindo-se o referencial da Escola Francesa do Rorschach, que distinguem as pranchas VI e IX como os cartões mais favorecedores deste tipo de reação.

É válido destacar que a prancha IX, além de ser a que apresentou maior quantidade de recusas entre os adolescentes do atual estudo, foi também o que mais provocou denegações de respostas, sendo, portanto, um cartão de impacto emocional para a população investigada. Por outro lado, levando-se em consideração a adequada média de respostas e o reduzido valor dos índices de recusa, respostas adicionais e denegações, pode-se inferir que os adolescentes brasileiros, tanto quanto os franceses, puderam responder ao Psicodiagnóstico de Rorschach sem grandes implicações emocionais e resistências, oferecendo confiança adicional aos próprios dados.

Ao se considerar os modos de apreensão, o estudo de Azoulay et al. (2007) constatou que a média de respostas globais $(\mathrm{G})$ assumiu a proporção de 43,3\%, muito próxima à média de respostas localizadas em áreas detalhe $(\mathrm{D}=43,6 \%)$, enquanto os índices médios para $\mathrm{Dd}$ (área pequeno detalhe) e Dbl (detalhe branco) foram de 10,2\% e 2,9\%, respectivamente. Em contrapartida, os resultados aqui alcançados, em termos médios, mostraram prevalência das respostas detalhe $(\mathrm{D}=45,7 \%)$ sobre as respostas globais $(\mathrm{G}=25,7 \%)$ e pequeno detalhe ( $\mathrm{Dd}$ $=27,3 \%)$. Por sua vez, os achados de Jardim-Maran (2011) apontaram para um destaque da área G $(35,0 \%)$ sobre as áreas D $(33,4 \%)$ e Dd $(30,3 \%)$.

Dessa forma, enquanto que no estudo realizado na França (Azoulay et al., 2007) as respostas Dd são pouco relevantes em comparação às respostas $\mathrm{G}$ (maior frequência) e $\mathrm{D}$, na presente investigação esse modo de apreensão (Dd) encontra-se superior às respostas globais. Esses resultados demonstraram predomínio, por parte da amostra francesa, de associações realizadas a partir de uma apreensão geral do estímulo (respostas G), da mesma forma como ocorreu com os adolescentes brasileiros analisados por Jardim-Maran (2011), enquanto que os adolescentes brasileiros da atual pesquisa (e mais novos que as outras amostras citadas) se ativeram mais aos aspectos pregnantes e relevantes da realidade (respostas D), com acentuado interesse pelas particularidades do meio (respostas Dd). Nesse sentido, os adolescentes de 12 a 14 anos mostraram que, por vezes, podem estar mais focados em minúcias do que na realidade como um todo, podendo marcar especificidade em seu modo de abordagem dos estímulos ambientais. 
Ainda no tocante aos modos de apreensão, percebe-se uma similaridade entre os adolescentes da presente amostra com os turcos do estudo de Ikiz et al. (2010), uma vez que estes mostraram um $\mathrm{D}=66,0 \%$, bem superior as respostas $\mathrm{G}(28,1 \%)$ e Dd $(3,4 \%)$. Estes resultados podem indicar maior apego ao concreto e ao imediato do ambiente por parte desses adolescentes (tanto os brasileiros do presente estudo quanto os turcos), oferecendo análises menos generalistas e, porventura, menos abstratas da realidade, compatível com seu nível de desenvolvimento cognitivo, ainda fortemente associado a elementos operatório-concretos.

Nas demais localizações das respostas ao Rorschach, os adolescentes da atual amostra apresentaram média igual a 1,3\% de respostas Dbl, bem similar ao encontrado no outro estudo brasileiro (Jardim-Maran, 2011), com Dbl =1,1\%, e de Ikiz et al. (2010), que atingiu um índice de 2,0\%. Por sua vez, os adolescentes franceses proporcionaram valores um pouco mais elevados $(\mathrm{Dbl}=9,2 \%)$, mas, ainda assim, este modo de apreensão é pouco expressivo frente ao conjunto de dados, limitando seu valor interpretativo. Porém, pode-se observar uma tendência mais oposicionista por parte dos adolescentes franceses que dos brasileiros e turcos.

Ao analisar a distribuição dos determinantes das respostas ao Método de Rorschach, encontra-se para o determinante unicamente formal $(\mathrm{F} \%)$ deste estudo um valor médio de 45,2\%, enquanto que os dados dos estudos de Jardim-Maran (2011), Ikiz et al. (2010) e de Azoulay et al. (2007) mostraram valores médios correspondentes a 54,5\%,62,0\% e 61,3\%, respectivamente. Essa diferença entre os trabalhos aponta níveis de investimento lógico diferenciados entre os indivíduos avaliados, parecendo que, com o crescimento etário, haveria maior investimento em respostas unicamente determinadas por aspectos formais dos cartões do Rorschach. No entanto, há que se relativizar estas comparações globais visto que os indivíduos advinham de ambientes muito diversos, servindo apenas como hipótese preliminar exploratória sobre esta diversidade de achados.

Outro resultado que condiz com estes achados empíricos do presente estudo foi o observado por Japur (1982), no qual 42\% da amostra apresentou F\% em proporção equivalente ao intervalo entre 50 a $70 \%$ do total do conjunto de respostas. Adrados (1976), que investigou adolescentes brasileiros de 14 a 18 anos, também registrou uma média em torno de $45 \%$ para o F\%. Pode-se depreender, desse modo, que os atuais adolescentes, bem como os de Adrados (1976), indicaram vivência dos afetos de uma maneira um pouco mais intensa que os indivíduos descritos nas outras investigações (Azoulay et al., 2007; Ikiz et al., 2010; Jardim-Maran, 2011). Esses dados sinalizam que os adolescentes, de maneira geral, buscaram manter o controle dos elementos afetivos recorrendo aos elementos formais dos 
estímulos, embora em proporções um pouco menores no contexto do atual estudo comparado aos demais trabalhos citados.

Cabe destacar também que, no tocante à precisão formal das respostas $(\mathrm{F}+\% \mathrm{e}$ $\mathrm{F}+\mathrm{ext} \%$ ), o resultado médio encontrado na presente amostra foi, respectivamente, $68,3 \%$ e de $65,5 \%$, ou seja, indicadores de adequada discriminação da realidade no funcionamento lógico, inclusive ao integrar componentes afetivos e imaginativos na elaboração das respostas $(\mathrm{F}+\mathrm{ext} \%)$. Nos outros estudos aqui usados para comparação geral, temos os seguintes índices de F+\% e F+ext\%: 55,6\% e 57,3\% para os demais adolescentes brasileiros (Jardim-Maran, 2011); 76,5\% e 77,2\% para os turcos (Ikiz et al., 2010) e, para a amostra de Azoulay et al. (2007), os valores médios foram, respectivamente, $65 \%$ e 66,0\%. Há que se destacar que os índices dos atuais adolescentes foram praticamente os mesmos dos estudantes franceses, inferiores aos valores apresentados pelos turcos e superiores aos adolescentes brasileiros de mais idade. Aqui não fica evidente uma direção única para os valores assumidos por estas variáveis entre as amostras, sinalizando possíveis especificidades nestes indicadores do Rorschach. Contudo, o mais relevante parece ser o indicador geral de que os índices de precisão formal na análise do Rorschach de todas as amostras foram superiores ao investimento específico em determinantes formais das respostas (valores maiores do que F\%), além do que assumiram expressão quantitativa suficiente para garantir a interpretação de adequada captação dos estímulos da realidade, sugestivo de boa discriminação lógica, como seria esperado para amostras de caráter normativo como estas aqui comparadas.

No que se refere ao conteúdo das respostas fornecidas ao Rorschach, os resultados encontrados no presente trabalho foram semelhantes aos apresentados por Jardim-Maran (2011), Azoulay et al. (2007) e Ikiz (2010), além similares também ao identificado com adultos não pacientes do interior paulista em estudo de Pasian (2000). Em todas estas investigações, houve predomínio majoritário dos conteúdos animal e humano sobre os demais. Na presente amostra, os índices médios desses conteúdos foram de $\mathrm{A}=53,3 \%$ e $\mathrm{H}=$ 24,3\%. Os resultados médios encontrados por Jardim-Maran (2011) alcançaram valores de A $=51,0 \%$ e $\mathrm{H}=20,9 \%$, enquanto Azoulay et al. (2007) encontraram índices de $\mathrm{A}=44,5 \%$ e $\mathrm{H}$ $=16,0 \%$. Por sua vez, os adolescentes turcos do estudo de Ikiz et al. (2010) obtiveram $\mathrm{A}=$ $41 \%$ e $\mathrm{H}=13,7 \%$.

Afora estes conteúdos representarem grande parte da produção no Rorschach, ainda houve margem para que outros conteúdos emergissem entre os adolescentes presentemente avaliados, indicando diversificação de interesses e no contato com o ambiente. Assim como relatado por Jardim-Maran (2011), os adolescentes presentemente avaliados deram destaque 
para outras quatro categorias de conteúdos, a saber: Obj $(8,3 \%)$, Bot $(3,2 \%)$, Anat $(2,8 \%)$ e Geo $(2,1 \%)$. Esta variação nos conteúdos interpretados, portanto, aponta para diversidade de interesses e, ainda, para possível projeção de conteúdos objetais classicamente representativos de vivências de ansiedade (conteúdos Anat, Geo e Bot), além de movimentos de racionalização (conteúdos Obj), segundo Rausch de Traubenberg (1998).

Merece um destaque especial neste momento o exame específico dos conteúdos anatômicos (Anat). Percebe-se que estes foram mais expressivos no estudo com os adolescentes brasileiros de maior idade (Jardim-Maran, 2011), onde Anat atingiu valor médio de 5,2\%. Ao se tomar esta tendência aos dados atuais apontando que, nos adolescentes de 12 anos, o índice médio de Anat foi de 1,7\% e, para os adolescentes de 14 anos, o valor de Anat atingiu 4,0\%, parece existir uma tendência à expressão de maior frequência de conteúdos do tipo anatômico com o passar dos anos de idade entre adolescentes brasileiros. Talvez possa se associar este indicador específico como movimento projetivo sinalizador da busca da identidade psíquica e corporal dos adolescentes frente às grandes transformações físicas vivenciadas neste período do desenvolvimento, como classicamente apontado pela literatura científica da área (Erikson, 1976; Aberastury \& Knobel, 1981; Outeiral, 1994; Paladino, 2005; Levisky, 2009).

Em relação à fórmula vivencial de Tipo de Ressonância Íntima (TRI), 68\% da atual amostra e 79,4\% dos adolescentes do estudo de Jardim-Maran (2011) caracterizaram-se como tipo extratensivo. Em outras palavras, grande parte dos adolescentes do interior paulista evidenciou tendência à abertura psíquica, expressando mais diretamente suas necessidades afetivas. Essa tendência geral de natureza extratensiva também foi encontrada nos estudos de Adrados (1976), que analisou adolescentes de 14 a 18 anos, e de Japur (1982), avaliando respondentes de 11 a 13 anos de idade. Os estudos de Azoulay et al. (2007) e de Ikiz et al. (2010) não apresentaram resultados referentes a esta variável técnica da Escola Francesa do Rorschach.

Por outro lado, em relação à fórmula das Tendências Latentes (TL), percebeu-se, no atual trabalho, grande predomínio do tipo introversivo, presente em 66,7\% dos adolescentes. Já nos adolescentes do estudo de Jardim-Maran (2011) se apresentaram, novamente, de maneira extratensiva, assim como no TRI. Desse modo, em termos gerais da amostra, pode-se detectar sinal de inconsistência entre as fórmulas e as vivências afetivas dos adolescentes presentemente avaliados, o que pode evidenciar pistas de experiência interna de angústia e conflito psíquico. Os adolescentes, de modo global, apontaram predomínio de vivência afetiva habitual na linha extratensiva, porém com indícios de imaturidade psíquica, na medida em 
que seus recursos latentes sinalizaram-se como amplos e fortes, em direção inclusive complementar a sua expressão afetiva mais recorrente, marcando sinal de instabilidade emocional em seu atual funcionamento psíquico.

A divergência presentemente encontrada entre as duas primeiras fórmulas vivenciais (TRI e TL) da Escola Francesa do Rorschach também foi identificada nos adolescentes avaliados por Japur (1982). Segundo esta pesquisadora, a discrepância entre a direção das vivências afetivas predominantes (TRI) e das tendências latentes (TL) poderia ser compreendida como sinal de inadaptação afetiva do grupo pré-adolescente, associando estes resultados à possível presença de conflitos afetivos, por ela reconhecidos como típicos da referida faixa etária. Dessa forma, ambas as evidências empíricas, embora colhidas em épocas diferentes, sugerem presença de conflitos emocionais no processo da adolescência, reafirmando pressupostos teóricos.

Ainda na perspectiva de comparação entre o presente estudo, o francês de Azoulay et al. (2007), o desenvolvido na Turquia por Ikiz et al. (2010) e o de Jardim-Maran (2011) com adolescentes brasileiros, é importante observar também as respostas banais originadas nestes quatro estudos. As respostas identificadas como banais (Ban) nestes vários trabalhos investigativos são as seguintes:

Cartão I - morcego ou borboleta na área G. Identificadas nos trabalhos brasileiros e no francês.

Cartão III - figuras humanas no preto, presente em todos os estudos; e borboleta no D central, encontrada no presente trabalho e também nos adolescentes franceses e turcos.

Cartão $V$ - morcego ou borboleta na área G. Identificadas em todos os trabalhos.

Cartão VII - figuras humanas na área G. Dada como resposta banal pelos adolescentes brasileiros e turcos.

Cartão VIII - Animais na área D lateral. Resposta banal encontrada como pelos adolescentes brasileiros e franceses.

Cartão $X$ - Aranhas na área D lateral azul. Considerada como resposta banal no atual estudo, no francês e também no turco.

As semelhanças entre as respostas banais encontradas nestes estudos, os quais envolveram adolescentes de diferentes idades e nacionalidades, fortalece o próprio conceito de banalidade nesta técnica de investigação da personalidade. De tal modo, em função de suas características estruturais, é possível perceber a pregnância formal de algumas áreas dos cartões, o que favorece a percepção e interpretação de conteúdos socialmente compartilhados, dando sentido à resposta banal (denominada "popular" em outros sistemas avaliativos do 
Rorschach). Logo, emergem novas evidências empíricas relacionadas à sensibilidade do Método de Rorschach em poder apreender este tipo de indicador do funcionamento lógico coletivamente compartilhado, ainda que em contextos socioculturais diversos.

Procurou-se, também neste momento, realizar análises comparativas entre o atual estudo e demais trabalhos desenvolvidos internacionalmente com adolescentes em contextos distintos e outras perspectivas teóricas do Método de Rorschach. Destacou-se, para tanto, os estudos realizados por Lis et al. (2007), na Itália, e Van Patten et al. (2007), nos Estados Unidos, ambos fundamentados no referencial teórico-científico do Sistema Compreensivo do Rorschach. Iniciando-se a comparação a partir do número médio de respostas encontrado em cada um dos estudos citados, percebe-se grande semelhança entre os adolescentes brasileiros presentemente examinados $(R=21,3)$ e os italianos $(R=21,7)$. Por outro lado, os jovens americanos apresentaram valor médio para o número de respostas bastante diferenciado, igual a 15,8. A despeito desta diferença entre os adolescentes americanos com os brasileiros e italianos, é possível notar indicadores técnicos de boa capacidade associativa e interpretativa nesta faixa etária, mesmo que recorrendo a diferentes sistemas do Rorschach. Mesmo que considerado a partir de um indicador específico, trata-se de evidência empírica relevante a respeito da própria validade dos achados com este método de investigação psicológica.

Outro ponto de intersecção apresentado pelos atuais adolescentes brasileiros e os italianos (Lis et al., 2007) refere-se aos modos de apreensão. Em ambos os estudos, houve predomínio das áreas $\mathrm{D}$, com média de 9,74 respostas $\mathrm{D}$ por protocolo no presente estudo e 9,44 para os adolescentes italianos. Porém, Lis et al. (2007) encontraram valores mais altos de respostas globais $(\mathrm{W}=10,14)$ em comparação às respostas de pequeno detalhe $(\mathrm{Dd}=4,20)$. Como discutido anteriormente, os jovens presentemente avaliados mostraram pequena superioridade das respostas Dd (média de 5,81 respostas por protocolo) sobre as G $(5,48$ respostas por protocolo). Como nos estudos de Jardim-Maran (2011) e Azoulay et al. (2007), os norte-americanos avaliados por Van Patten et al. (2007) apresentaram predomínio das respostas globais sobre as demais, sendo as respostas $\mathrm{Dd}$ as menos interpretadas $(\mathrm{W}=10,14$; $\mathrm{D}=7,73$ e $\mathrm{Dd}=6,78$ respostas por protocolo). Mais uma vez, verificam-se indicadores técnicos de especificidades no processamento das informações advindas dos estímulos do Método de Rorschach em adolescentes de diferentes contextos socioculturais, fortalecendo esta linha de investigação com variados grupos de indivíduos, sobretudo nesta faixa etária, como apontado por Meyer et al. (2007).

Vale ressaltar que as atuais análises comparativas de valores médios dos indicadores técnicos do Rorschach anteriormente apresentadas devem ser devidamente ponderadas como 
estratégias exploratórias e explanações sobre dados empíricos, devidamente interpretados em seus alcances e limitações informativas. Abordaram adolescentes de nacionalidades distintas, não sendo estudos com objetivo e métodos específicos para comparações transculturais. Assim, estes trabalhos apresentavam diferentes delineamentos, como: o sistema avaliativo utilizado (Compreensivo ou Francês), o número de participantes e o critério de seleção destes, entre outros, inibindo considerações mais extensas acerca das comparações realizadas devido às variações técnicas encontradas. Dessa forma, como apontaram Pasian e Loureiro (2010), a multiplicidade de sistemas do Rorschach pode limitar as possibilidades de comparação entre os achados de pesquisas devido aos diversos modos de definição operacional das variáveis, relacionadas tanto à coleta quanto à análise dos dados de cada estudo.

Contudo, buscou-se explorar esses estudos com o intuito de averiguação de possíveis tendências e perspectivas compreensivas para os resultados do Método de Rorschach. Nesse sentido, Exner (2005) e Weiner (2000), entre tantos outros autores, assinalaram que diversos trabalhos encontrados na literatura versavam extensamente sobre as comparações realizadas em diferentes sistemas interpretativos do Rorschach. Para este último, a integração de estudos desenvolvidos em aspectos metodológicas distintos é de muita valia para a compreensão da personalidade humana como um todo.

Considerando-se as análises aqui realizadas e as peculiaridades encontradas nos estudos desenvolvidos em diferentes contextos socioculturais, fortalecem-se os argumentos e os apontamentos desenvolvidos por Meyer et al. (2007). A partir da análise de estudos feitos com crianças e adolescentes de diversos países, encontraram diferenças significativas entre amostras de diferentes estudos, reafirmando a necessidade de se realizar estudos normativos nos mais diversos contextos, corroborando os objetivos do presente estudo.

Por fim, cumpre destacar ainda que os dados presentemente encontrados podem repercutir em reflexões sobre possíveis influências das variáveis gênero, idade e procedência escolar no padrão de respostas ao Rorschach. Contudo, as evidências aqui encontradas apontaram que o número de variáveis do Rorschach afetadas pelo gênero, idade ou origem escolar foi bastante reduzido, isto é, poucas foram as diferenças estatisticamente significativas identificadas pelas análises estatísticas inferenciais realizadas entre os subgrupos. Diante destas considerações, pode-se pensar na composição de um atlas único para os adolescentes de 12 a 14 anos de idade, de ambos os gêneros e provenientes de escolas públicas e particulares do interior do Estado de São Paulo, como delineado originalmente no presente trabalho. 
6 CONSIDERAÇÕES FINAIS 
Considerando-se os objetivos propostos para a presente investigação, pode-se considerar que foi possível obter um panorama geral do desempenho de adolescentes, de 12 a 14 anos de idade, com desenvolvimento típico, diante do Psicodiagnóstico de Rorschach. O conjunto desses dados certamente poderá auxiliar as análises interpretativas e clínicas por parte dos profissionais que porventura vierem a fazer uso do material com adolescentes de mesma faixa etária, em regiões com características sociodemográficas e culturais similares às do presente estudo.

Desse modo, pode-se depreender que as evidências ainda são insuficientes para justificar a elaboração de normas avaliativas específicas para os adolescentes de 12 a 14 anos de idade em função do gênero, idade ou origem escolar. Apesar disso, certamente, os atuais achados apontam para a necessidade de se levar em consideração aspectos do contexto sociocultural dos indivíduos durante processos clínicos de avaliação psicológica por meio do Método de Rorschach, visando, sempre, interpretações adequadas e consistentes, orientadas para o conjunto da produção e não apenas em variáveis isoladas (Rausch de Traubenberg, 1998; Azoulay et al., 2007; Ikiz et al., 2010).

Cabe ainda destacar, neste momento, que o presente estudo conseguiu evidenciar, de modo claro, adequados índices de precisão para a Escola Francesa do Rorschach no contexto do Brasil. Esta perspectiva, internacionalmente valorizada, certamente atribui ao próprio sistema avaliativo maior credibilidade e sustentação técnico-científica. Além disso, o rigor alcançado nos processos avaliativos foi fruto direto da formação e do treinamento qualificado dos psicólogos envolvidos neste e em outros estudos do Método de Rorschach, o que aponta para a necessidade de adequada formação profissional para os utilizadores deste método projetivo de avaliação psicológica. Essa necessidade tem sido firmemente apontada no Brasil, como preocupação geral da área de avaliação psicológica, como já apontado, por exemplo, por Villemor-Amaral (2009) e Hutz (2009), entre outros pesquisadores brasileiros, merecendo aqui seu devido destaque.

Conforme salientam Pasian e Loureiro (2010), cabe aos profissionais da área o devido cuidado, ponderação e reflexão técnica com o intuito de se evitar excessiva generalização dos referenciais normativos aqui expostos em processos de avaliação psicológica. Ainda, de acordo estas autoras, é preciso considerar a dimensão territorial brasileira, de proporção continental, e a ampla diversidade cultural do país, que dificultam a elaboração de padrões normativos nacionais para este (e qualquer outro) instrumento de investigação psicológica. Nesse sentido, reforça-se a importância de se dar continuidade ao desenvolvimento e atualização de estudos de natureza normativa, em diversos contextos e regiões do Brasil e do 
mundo, viabilizando processos mais adequados e consistentes de avaliação psicológica para as diferentes demandas sociais.

Para finalizar, torna-se imperativo destacar que, apesar deste estudo comportar uma amostra significativa para se atingir o intuito de elaborar padrões normativos para o Método de Rorschach, ela não alcança a efetiva representação da diversidade socioeconômica e cultural dos estudantes desta faixa etária na cidade em questão, tratando-se apenas de uma forma de viabilização do presente trabalho. Nesse sentido, o tamanho da amostra $(n=174)$ oferece o devido suporte para se abarcar, em grau suficiente, uma diversidade de estilos individuais de estudantes, ainda que seja bastante circunscrita devido ao caráter regional da amostra frente à dimensão continental de um país como o Brasil. Além disso, contempla faixa etária bem específica (12 a 14 anos), restringindo ainda mais o alcance deste estudo.

Estas limitações podem, no entanto, ser atenuadas pela elaboração de novos estudos que almejem maior cobertura normativa da Escola Francesa do Rorschach e que também abrangesse outras faixas etárias (de crianças a adultos), fortalecendo o método no Brasil, conforme proposto pelo CFP. Esta perspectiva tem dirigido os trabalhos do Centro de Pesquisas em Psicodiagnóstico (CPP) da Faculdade de Filosofia, Ciências e Letras de Ribeirão Preto, da Universidade de São Paulo (FFCLRP - USP), onde a presente investigação foi desenvolvida. Frente a isso, futura possibilidade de estudo seria a contraposição de dados atuais aos de Jardim-Maran (2011), também envolvendo adolescentes, embora de mais idade, meta pleiteada pelo referido grupo de pesquisa.

Vale ressaltar que o desenvolvimento de novas pesquisas de normatização do Rorschach, além de fortalecer este instrumento de avaliação psicológica, também contribui para o aprimoramento da definição operacional em si e das evidências empíricas da Escola Francesa do Rorschach. Espera-se que, a partir do intercâmbio entre grupos de pesquisa de diferentes países, por exemplo, numa interação mais próxima com a equipe de Azoulay (na França) ou de Ikiz (na Turquia), estes objetivos possam ser alcançados em anos futuros. Enfim, vale lembrar que, não obstante o Método de Rorschach seja uma técnica extremamente reconhecida internacionalmente para avaliação da personalidade, há sempre a necessidade de estudos que atestem sua validade (bem como de seus diferentes sistemas interpretativos, como a Escola Francesa), de modo a fortalecer suas próprias bases técnicocientíficas em prol da qualificação dos processos de avaliação psicológica com a população. 


\section{REFERÊECIAS ${ }^{3}$}

\footnotetext{
${ }^{3}$ De acordo com o padrão APA - American Psychological Association, adaptado pela Universidade de São Paulo (USP).
} 
Aberastury, A.; Knobel, M. Adolescência normal. (10 ed., S. M. G. Ballve, trad.) Porto Alegre: Artes Médicas.

Adrados, I. (1976) Rorschach na adolescência normal e patológica. Rio de Janeiro: Vozes.

Adrados, I. (1985). A Técnica do Rorschach em crianças: perfil psicológico da criança dos sete aos quatorze anos. Petrópolis: Vozes.

Aguirre, A. M. B. (1995). Aspectos psicodinâmicos de adolescentes grávidas: entrevistas clínicas e Rorschach no contexto hospitalar. Tese de Doutorado, Instituto de Psicologia, Universidade de São Paulo, São Paulo.

Akkari, A. J. (2001). Desigualdades educativas estruturais no Brasil: entre estado, privatização e descentralização. Educação \& Sociedade, 22(74), pp. 163-189.

Anastasi, A. \& Urbina, S. (2000). Testagem psicológica. (M. A. V. Veronese, trad.). (7a ed.). Porto Alegre: Artmed.

Andronikof, A., Chudzik, L. \& Gillaizeau, I. (2008). Caractéristiques des Rorschach d'adolescents. In International Congress of Rorschach and Projective Methods, 19 (p. 176). Leuven, Belgium: IRS.

Anzieu, D. (1986). Os métodos projetivos. (M. L. E. Silva, trad.). (5a ed.). Rio de Janeiro: Campus.

Azoulay, C., Emmanuelli, M., Rausch de Traubenberg, N., Corroyer, D., Rozencwajg, P. \& Savina, Y. (2007). Les données normatives françaises du Rorschach à l'adolescence et chez le jeune adulte. Psychologie Clinique et Projective, 13, pp. 371-409.

Bagbag, F. (2008). Tunisian children Rorschach. In International Congress of Rorschach and Projective Methods, 19 (p. 53). Leuven, Belgium: IRS.

Balottin, U., Rossi, M., Rossi, G., Vigano, L., Nanti, M., Salini, S., Lanzi, G. \& Termine, C. (2009). The Rorschach test and Gilles de la Tourette's syndrome: a pilot case-control study. Brain and Development, 31(9), pp. 657-665.

Bandeira, D. R. et al. (2006). Considerações sobre as técnicas projetivas no contexto atual. In Noronha, A. P. P., Santos, A. A. A., Sisto, F. F. (Orgs.). Facetas do fazer em avaliação psicológica. São Paulo: Vetor.

Bellodi, P. L., Romão Jr, J. E. \& Jacquemin, A. (1997). Crianças em diálise: estudo das características de personalidade através de técnicas projetivas. Jornal brasileiro de nefrologia, 19(2), pp. 132-137.

Berant, E. (2007). Rorschach Comprehensive System Data for a sample of 150 adult nonpatients from Israel. Journal of Personality Assessment, 89(1), pp. 67-73.

Blatt, S. J., Besser, A. \& Ford, R.Q. (2007). Two primary configurations of psychopathology and change in thought disorder in long-term intensive inpatient treatment of seriously disturbed young adults. American Jounal of Psychiatry, 164(10), pp. 1561-1567. 
Bram, A. D. (2010). The relevance of the Rorschach and patient-examiner relationship in treatment planning and outcome assessment. Journal of Personality Assessment, 92(2), pp. 91-115.

Campagna, V. N. (2003). Aspectos da organização da identidade feminina no início da adolescência. Dissertação de Mestrado, Instituto de Psicologia, Universidade de São Paulo, São Paulo.

Campo, V. \& Vilar, N. (2007). Rorschach Comprehensive System Data for a sample of 517 adults from Spain (Barcelona). Journal of Personality Assessment, 89(1), pp. 149-153.

Chabert, C. (2004). Psicanálise e Métodos Projetivos. Tradução: Álvaro José Lelé e Eliane Maria Almeida Costa e Silva. 1.ed. São Paulo: Vetor Editora Psico-pedagógica.

Chaudhury, S., Sudarshan, S., Seb, K., Saluja, S.K., Srivastava, K., \& Kundeyawala, S.M. (2007). Rorschach responses of older Indians. Journal of Projective Psychology \& Mental Health, 14(1), pp. 30-43.

Cohen, L., De Ruiter, C., Ringelberg, H. \& Cohen-Kettenis, P. T. (1997). Psychological functioning of adolescent transsexuals: personality and psychopathology. Journal of Clinical Psychology, 53(2), pp.187-196.

Conselho Federal de Psicologia (2011). Ano da Avaliação Psicológica: Textos geradores. Brasília: Conselho Federal de Psicologia.

Conselho Federal de Psicologia. (2003). Resolução CFP 02/2003. Brasília: CFP.

Cruz, R. M. O processo de conhecer em avaliação psicológica. (2002) In R. M. Cruz, J. C. Alchieri, J. J. Sardá Junior (Orgs.). Avaliação e medidas psicológicas: produção do conhecimento e da intervenção profissional. São Paulo: Casa do Psicólogo.

Cunha, J. A. (2000). Estratégias de avaliação: perspectivas em psicologia clínica. In J. A. Cunha et col. Psicodiagnóstico-V. (5a ed.). Porto Alegre: Artmed.

Dao, T. K. \& Prevatt, F. (2006). A psychometric evaluation of the Rorschach comprehensive system's perceptual thinking index. Journal of Personality Assessment, 86(2), pp. 180189.

Daraglou, S. \& Viglione, D. (2007). Rorschach Comprehensive System Data for a sample of 98 adult nonpatients from Greece. Journal of Personality Assessment, 89(1), pp. 61-66.

de Ruiter, C. \& Smid, W. (2007). Rorschach Comprehensive System Data for a sample of 108 normative subjects from The Netherlands. Journal of Personality Assessment, 89(1), pp. 113-118.

Dumitrascu, N. (2007). Rorschach Comprehensive System Data for a sample of 111 adult nonpatients from Romania. Journal of Personality Assessment, 89(1), pp. 142-148.

Erikson, E.H. (1976). O ciclo vital: epigênese da identidade. In Identidade, Juventude e Crise. (A. Cabral, trad.). Rio de Janeiro: Zahar Editores. 
Estatuto da Criança e do Adolescente (1990). Recuperado em 10 de abril de 2012, de http://www.planalto.gov.br/ccivil_03/leis/L8069.htm.

Federação das Indústrias do Estado de São Paulo (FIESP). (2009). Quantidade de trabalhadores por grau de instrução na região. Ribeirão Preto, SP. Recuperado em 14 de março de 2010, de http://apps.fiesp.com.br/regional/DadosSocioEconomicos/Grau Escolaridade.aspx.

Fensterseifer, L., Werlang, B. S. G. (2008). Apontamentos sobre o status científico das técnicas projetivas. In Villemor-Amaral, A. E., Werlang, B. G. (Org.). Atualizações em métodos projetivos para avaliação psicológica. (1a ed.). São Paulo: Casa do Psicólogo, pp. 15-33.

Fernandes, C. A. (2006). Desafios na formação do psicólogo do novo século: o ensino dos métodos projetivos e o compromisso social de nossa profissão. In Congresso Nacional da Associação Brasileira de Rorschach e Métodos Projetivos, 4, (pp. 832-836). São Paulo: Vetor Editora Psico-Pedagógica Ltda.

Fernandes, S. \& Pasian, S. R. (2008). Crianças diante do Psicodiagnóstico de Rorschach: especificidades de desempenho no interior de São Paulo. In Encontro da Associação Brasileira de Rorschach e Métodos Projetivos, 5. Ribeirão Preto, SP.

Fernandes, S., Pasian, S. R., \& Bordão-Alves, D. P. (2011). Origem escolar e a produtividade no Rorschach. In Congresso Brasileiro de Avaliação Psicológica Instituto Brasileiro de Avaliação Psicológica, 5, (p. 67). Bento Gonçalves, RS: Brasil.

Fernandes, S., Pasian, S. R., Paula, R. C., \& Barrenha, R. P. L. (2009). O Rorschach Infantil: o sexo exerce efeito na produção?. In Congresso Brasileiro de Avaliação Psicológica Instituto Brasileiro de Avaliação Psicológica, 4; Conferência Internacional de Avaliação Psicológica: formas e contextos, 14 e Congresso da Associação Brasileira de Rorschach e Métodos Projetivos, 5, (p. 17). Campinas, SP.

Fernandez, P. \& Pardillo, J. (2008). Listado de respuestas populares em Cuba: un estudio de normalizacion transcultural con el Rorschach. In International Congress of Rorschach and Projective Methods, 19 (p. 136). Leuven, Belgium: IRS.

Franks, K. W., Sreenivasan, S., Spray, B. J. \& Kirkish, P. (2009). The mangled butterfly: Rorschach results from 45 violent psychopaths. Behavioral Sciences and the Law, 27(4), pp. 491-506.

Freud, S. (1905). Três ensaios sobre a sexualidade. Vol VII (1901-1905). In Obras Completas. (2 ${ }^{\mathrm{a}}$. ed.). Edição Standard Brasileira das Obras Psicológicas Completas de Sigmund Freud. Rio de Janeiro: Imago.

Ginsberg, A. M. (1950) Um estudo de 100 jovens baianos com o teste de Rorschach. Neurobiologia, 13 (1), pp. 1-50.

Grava, G., Ceroni, G. B., Rucci, P. \& Scudellari, P. (2006). Suicidal behaviors and personality structure. Suicide and Life-Threatening Behavior, 36(5), pp. 569-577.

Greenway, P. \& Milne, L. (2007). Rorschach Comprehensive System Data for a sample of 128 Adult nonpatients from Australia. Journal of Personality Assessment, 89(1), p. 20-25. 
Güntert, A. E. V. A. (2000). Técnicas projetivas: o geral e o singular em avaliação psicológica. In F. F. Sisto, E. T. B. Sbardelini, R. Primi (Orgs.). Contextos e questões da avaliação psicológica (pp. 77-85). São Paulo: Casa do Psicólogo.

Hamel, M. \& Shaffer, T. W. (2007). Rorschach Comprehensive System Data for 100 nonpatient children from the United States in two age groups. Journal of Personality Assessment, 89(1), pp. 174-182.

Hansen, K. G. (2007). Rorschach Comprehensive System Data for a sample of 75 Danish 9 year old children: a pilot study. Journal of Personality Assessment, 89(1), pp. 52-56.

Hartmann, E., Norbech, P. B. \& Gronnerod, C. (2006). Psychopathic and nonpsychopathic violent offenders on the rorschach: discriminative features and comparisons with schizophrenic inpatient and university student samples. Journal of Personality Assessment, 86(3), pp. 291-305.

Hutz, C. S. (2009). Ética na Avaliação Psicológica. In C. S. Hutz. (Org.), Avanços e polêmicas em avaliação psicológica (pp. 297-310). São Paulo: Casa do Psicólogo.

Ikiz, T.T., Zabci, N., Dusgor, B.P., Atak, I.E., Yavuz, E., Purisa, S., \& Catagy, P. (2010). Étude normative du Rorschach de la population adolescente turque. Psychologie Clinique et Projective, 16, pp. 209-232.

Ilonen, T., Heinimaa, M., Korkeila, J., Svirskis, T. \& Salokangas, R. K. (2010). Differentiating adolescents at clinical high risk for psychosis from psychotic and nonpsychotic patients with the Rorschach. Psychiatry Research, 179(2), pp. 151-156.

Instituto Brasileiro de Geografia e Estatística (IBGE). (2004). Recuperado em 14 de março de 2010, de http://www.suapesquisa.com/cidadesbrasileiras/cidade_ribeirao_preto.htm.

Instituto Brasileiro de Geografia e Estatística (IBGE). (2010). Recuperado em 14 de março de 2010, de http://www.ibge.gov.br/cidadesat/painel/painel.php?codmun=354340\#.

International Test Commition (ITC). Diretrices internacionales para el uso de los tests. Recuperado em 9 de julho de 2009, de http://www.cop.es/tests.

Ivanouw, J. (2007). Rorschach Comprehensive System Data for a sample of 141 adult nonpatients from Denmark. Journal of Personality Assessment, 89(1), pp. 42-51.

Jacquemin, A. A. (1976). O teste de Rorschach em crianças brasileiras. São Paulo: Vetor.

Japur, M. (1982). O Psicodiagnóstico de Rorschach: um estudo da afetividade em préadolescentes. Dissertação de Mestrado, Instituto de Psicologia, Universidade de São Paulo, São Paulo.

Jardim-Maran, M. L. C. (2004). A escolha profissional de adolescentes através do BBT-Br e do Questionário Desiderativo. Dissertação de Mestrado, Faculdade Filosofia, Ciências e Letras de Ribeirão Preto, Universidade de São Paulo, Ribeirão Preto.

Jardim-Maran, M. L. C. (2011). O Psicodiagnóstico de Rorschach em adolescentes: Normas e evidências de validade. Tese de Doutorado. Faculdade de Filosofia Ciências e Letras de Ribeirão Preto, Universidade de São Paulo, Ribeirão Preto, SP, Brasil. 
Kernier, N., Canoui, P. \& Golse, B. (2010). Taking care of teenagers hospitalized after a suicidal gesture or a suicidal threat. Archives de Pédiatrie, 17(4), pp. 435-441.

Kimhy, D., Corcoran, C., Harkavy-Friedman, J. M., Ritzler, B., Javitt, D. C. \& Malaspina, D. (2007). Visual form perception: a comparison of individuals at high risk for psychosis, recent onset schizophrenia and chronic schizophrenia. Schizophrenia Research, 97(1-3), pp. 25-34.

Klinteberg, B., Johansson, S. E. \& Gacono, C. (2008) Projective risk variables in early adolescence and subsequent disinhibitory psychopathology. International Journal Law Psychiatry, 31 (3), pp. 210-218.

Knobel, M. (1981). A síndrome da adolescência normal. In Aberastury, A.; Knobel, M. Adolescência normal. (10 a ed., S. M. G. Ballve, trad.) Porto Alegre: Artes Médicas, pp. 24-62.

Kochinski, S., Smith, S. R., Baity, M. R. \& Hilsenroth, M. J. (2008). Rorschach correlates of adolescent self-mutilation. Bull Menninger Clin, 72(1), 54-77.

Krishnamurthy, R. \& Archer, R. P. (2001). An evaluation of the effects of Rorschach EB style on the diagnostic utility of the Depression Index. Assessment, 8(1), pp.105-109.

Lei 8.069, de 13 de Julho de 1990. (1990). Estatuto da Criança e do Adolescente. Brasília: Ministério da Justiça.

Lelé, A. J. (2005). Perception of reality and norm: a study of the popular responses to Rorschach Psychodiagnostic in Brazil. In International Congress of Rorschach and Projective Methods, 18, (p.239). Barcelona: IRS.

Lelé, A. J. (2006). Resultados de 100 Psicodiagnósticos de Rorschach em mineiros. In Congresso Nacional da Associação Brasileira de Rorschach e Métodos Projetivos, 4, (pp. 87-99). Brasília: Vetor.

Lelé, A. J. (2008a). La diversité de resultats dans les modes d'apprehension: comparaison des donnees normatives au Rorschach. In International Congress of Rorschach and Projective Methods, 19 (p. 153). Leuven, Belgium: IRS.

Lelé, A. J. (2008b). Estudo preliminar de dados normativos brasileiros no Rorschach no estado de Minas Gerais. In: Encontro da Associação Brasileira de Rorschach e Métodos Projetivos, 5, Ribeirão Preto: ASBRo, CD-ROM.

Levisky, D. L. (2009). Adolescência: reflexões psicanalíticas. (3 ${ }^{\mathrm{a}}$. ed.). São Paulo: Casa do Psicólogo.

Lis, A., Parolin, L., Salcuni, S. \& Zennaro, A. (2007). Rorschach Comprehensive System Data for a sample of 249 adult nonpatients from Italy. Journal of Personality Assessment, 89(1), pp. 80-84.

Lis, A., Salcuni, S. \& Parolin, L. (2007). Rorschach Comprehensive System Data for a sample of 116 preadolescent and 117 adolescent nonpatients from Italy. Journal of Personality Assessment, 89(1), pp. 91-96. 
Lis, A., Salcuni, S., Parolin, L., Di Riso, D. \& Laghezza, L. (2008). Rorschach Comprehensive System Data of sample of non patient children from Italy: aged 5-7 years. In International Congress of Rorschach and Projective Methods, 19 (p. 51). Leuven, Belgium: IRS.

Loving, J. L. \& Russell, W. F. (2000). Selected Rorschach variables of psychopathic offenders. Journal of personality Assessment, 75(1), pp. 126-142.

Lunazzi, H. A., Urrutia, M. I., De la Fuente, M. G., Elias, D., Fernandez, F. \& De la Fuente, S. (2007). Rorschach Comprehensive System Data for a sample of 506 adult nonpatients from Argentina. Journal of Personality Assessment, 89(1), pp. 7-12.

Matsumoto, M., Morita, M., Suzuki, N., Tsuboi, H., Hatagaki, C. \& Shirai, H. (2008). Application of Rorschach for Japonese children: what the Rorschach means for Japonese children. In International Congress of Rorschach and Projective Methods, 19 (p. 315). Leuven, Belgium: IRS.

Matsumoto, M., Suzuki, N., Shirai, H. \& Nakabayashi, M. (2007). Rorschach Comprehensive System Data for a sample of 190 Japanese nonpatient children at five ages. Journal of Personality Assessment, 89(1), pp. 103-112.

Mattlar, C. E., Forsander, C., Carlsson, A., Norrlund, L., Vesala, P., Leppänen, T., Oist, A., Mäki, J. \& Alanen, E. (2007). Rorschach Comprehensive System Data for a sample of 343 adults from Finland. Journal of Personality Assessment, 89(1), pp. 57-60.

McCarthy, J., Loewenthal, L., Leonard, N., Herdsman, L., Bluestone, C. \& Gorman, B. (2003). Evaluation of bizarre idiosyncratic thinking scale as a measeure of thought disorder in children and adolescents with severe psychiatric disorders. Perceptual and Motor Skills, 97(1), pp.207-214.

McGrath, R. E., Pogge, D. L., Stokes, J. M., Cargnolino, A., Zaccario, M., Hayman, J., Piacentini, T. \& Wayland-Smith, D. (2005). Field reliability oh comprehensive system scoring in an adolescent inpatient sample. Assessment, 12(2), pp.199-209.

Meyer, G. J., Erdberg, P. \& Shaffer, T. W. (2007). International reference samples for the Rorschach Comprehensive System. Journal of personality assessment, 89, pp. 201-216.

Mormont, C., Thommessen, M. \& Kever, C. (2007). Rorschach Comprehensive System Data for a sample of 100 adult nonpatients from the Belgian Franch-Speaking Community. Journal of Personality Assessment, 89(1), pp. 26-34.

Nakamura, N., Fuchigami, Y. \& Tsugawa, R. (2007). Rorschach Comprehensive System Data for a sample of 240 adult nonpatients from Japan. Journal of Personality Assessment, 89(1), pp. 97-102.

Nascimento, R. S. G. F. (2002). Estudo normativo do sistema compreensivo do Rorschach para a cidade de São Paulo. Psico-USF, 7(2), pp. 127-141.

Nascimento, R. S. G. F. (2006). Estudo normativo do sistema compreensivo do Rorschach para São Paulo: resultados dos índices PTI, SCZI, DEPI, CDI, HVI, OBS e S-CON. Avaliação Psicológica, 5(1), pp. 87-97. 
Nascimento, R. S. G. F. (2007). Rorschach Comprehensive System Data for a sample of 409 adult nonpatients from Brasil. Journal of Personality Assessment, 89(1), pp. 35-41.

Nascimento, R. S. G. F. (2010). Sistema Compreensivo do Rorschach: teoria, pesquisa e normas para a população brasileira. São Paulo: Casa do Psicólogo.

Nascimento, R. S. G. F. (2011). Rorschach Sistema Compreensivo: Comparação dos resultados de estudos normativos de adolescentes e adultos moderada pela complexidade das respostas. In Congresso Brasileiro de Avaliação Psicológica Instituto Brasileiro de Avaliação Psicológica, 5, (p. 18). Bento Gonçalves, RS: Brasil.

Nascimento, R. S. G. F., Batistuzzo, M. C., Sato, T. M., Brunoni, G., Bueno, R. R. \& Marques, T. (2009). Autopercepção em adolescentes por meio do Rorschach (SC): resultados de estudo normativo em São Paulo. In: Congresso Brasileiro de Avaliação Psicológica Instituto Brasileiro de Avaliação Psicológica, 4; Conferência Internacional de Avaliação Psicológica: formas e contextos, 14 e Congresso da Associação Brasileira de Rorschach e Métodos Projetivos, Campinas, SP, CD-ROM.

Nascimento, R. S. G. F., Brunoni, G. R., Sasaki, T. N. D., Bueno R. R. \& Parsons, T. G. (2008a). Resultados preliminares de um estudo normativo com o sistema compreensivo do Rorschach em uma amostrar de adolescentes não-pacientes brasileiros. In Encontro da Associação Brasileira de Rorschach e Métodos Projetivos, 5. Ribeirão Preto, SP.

Nascimento, R. S. G. F., Brunoni, G. R., Sasaki, T. N. D., Bueno, R. R., \& Parsons, T. G. (2008b). Preliminary results of normative study of the Rorschach Comprehensive System in a non patient Brazilian adolescent sample. In International Congress of Rorschach and Projective Methods, 19 (p. 52). Leuven, Belgium: IRS.

Nascimento, R. S. G. F., Mattos, A. P., Mori Neto, A., Hisatugo, C. C., Freitas, E. S., Mucarbel, F. C. et al. (2006). Estudo normativo para o sistema compreensivo do Rorschach. In Congresso Nacional da Associação Brasileira de Rorschach e outros Métodos Projetivos, 4 (pp. 47-48). Brasília: Vetor.

Noronha, A. P. P \& Vendramini, C. M. M. (2003). Parâmetros psicométricos: estudo comparativo entre testes de inteligência e de personalidade. Psicologia: Reflexão $e$ Crítica, 16(1), pp. 177-182.

Noronha, A. P. P., Primi, R. \& Alchieri, J. C. (2005). Instrumentos de avaliação mais conhecidos/utilizados por psicólogos e estudantes de Psicologia. Psicologia: Reflexão e Crítica, 18(3), pp. 390-401.

Oliveira, K. L., Noronha, A. P. P., Dantas, M. A. \& Santarem, E. M. (2005). O psicólogo comportamental e a utilização de técnicas e instrumentos psicológicos. Psicologia em Estudo - Maringá, 10(1), pp. 127-135.

Organización Mundial de la Salud (OMS). (1965). Problemas de salud de la adolescência. Série de informes técnicos, 308. Geneva: OMS.

Paladino, E. (2005). O adolescente e o conflito de gerações na sociedade contemporânea. São Paulo: Casa do Psicólogo. 
Pasian, S. R, \& Loureiro, S. R. (2010). Reflexões sobre princípios e padrões normativos do Rorschach. In S. R. Pasian (Org), Avanços do Rorschach no Brasil (pp. 30-54). São Paulo: Casa do Psicólogo.

Pasian, S. R. (1998). O Psicodiagnóstico de Rorschach: um estudo normativo em adultos da região de Ribeirão Preto. Tese de Doutorado, Faculdade de Medicina de Ribeirão Preto, Universidade de São Paulo, Ribeirão Preto.

Pasian, S. R. (2000). O psicodiagnóstico de Rorschach em adultos: Atlas, normas e reflexões. São Paulo: Casa do Psicólogo.

Pasian, S. R. (2002). Atualizações sobre o psicodiagnóstico de Rorschach no Brasil: breve panorama histórico. Psico-USF, 7(1), 43-52.

Pasian, S. R. (2006). A avaliação psicológica: pesquisar ou praticar? In Congresso Nacional da Associação Brasileira de Rorschach e Métodos Projetivos, 4, (pp. 376-384). São Paulo: Vetor.

Pertchik, K., Shaffer, T. W., Erdberg, P. \& Margolin, D. I. (2007). Rorschach Comprehensive System Data for a sample of 52 older adult nonpatients from the United States. Journal of Personality Assessment, 89(1), pp. 166-173.

Pinheiro, R. T., Souza, P. L., Da Silva, R. A., Horta, B. L., De Souza, R. M. \& Fleming, M. (2001). Cocaine addicts and their families: an empirical study of the processes of identification. International Journal of Psychoanalysis, 82(2), pp.347-360.

Pires, A. A. (2007). Rorschach Comprehensive System Data for a sample of 309 adult nonpatients from Portugal. Journal of Personality Assessment, 89(1), pp. 124-130.

Primi, R.; \& Nunes, C. H. S. (2010). O Satepsi: desafios e propostas de aprimoramento (pp. 129-148). In Avaliação psicológica: diretrizes na regulamentação da profissão. Brasília: CFP.

Raéz, M. (2007). Rorschach Comprehensive System Data for a sample of 233 adult nonpatients from Peru. Journal of Personality Assessment, 89(1), pp. 119-123.

Raspantini, R. L. \& Pasian, S. R. (2008). Psicodiagnóstico de Rorschach em crianças de nove a 11 anos: dados preliminares. In Encontro da Associação Brasileira de Rorschach e Métodos Projetivos, 5. Ribeirão Preto, SP.

Raspantini, R. L. (2010). O Psicodiagnóstico de Rorschach em crianças de 9 a 11 anos: um estudo normativo. Dissertação de Mestrado, Faculdade de Filosofia, Ciências e Letras de Ribeirão Preto, Universidade de São Paulo, Ribeirão Preto.

Raspantini, R. L., Bordão-Alves, D. P. \& Pasian, S. R. (2009b). Psicodiagnóstico de Rorschach: a influência da procedência escolar em crianças. In Congresso Brasileiro de Avaliação Psicológica Instituto Brasileiro de Avaliação Psicológica, 4; Conferência Internacional de Avaliação Psicológica: formas e contextos, 14 e Congresso da Associação Brasileira de Rorschach e Métodos Projetivos, 5, (p. 35). Campinas, SP. 
Raspantini, R. L., Pasian, S. R. (2011). Psicodiagnóstico de Rorschach: a influência do sexo na produção infantil. In Congresso Brasileiro de Avaliação Psicológica Instituto Brasileiro de Avaliação Psicológica, 5, (p. 67). Bento Gonçalves, RS: Brasil.

Raspantini, R. L., Paula, R. C., Barrenha, R. P. L., \& Pasian, S. R. (2009a). Escola Francesa do Rorschach: evidências de precisão a partir de uma amostra infantil. In Congresso Brasileiro de Avaliação Psicológica Instituto Brasileiro de Avaliação Psicológica, 4; Conferência Internacional de Avaliação Psicológica: formas e contextos, 14 e Congresso da Associação Brasileira de Rorschach e Métodos Projetivos, 5, Campinas, CD-ROM.

Rausch de Traubenberg, N. (1998). A prática do Rorschach. (A. J. Lelé, trad.). São Paulo: Vetor.

Resende, A. C., Rezende, T. C. \& Martins, L. D. (2006). Estudo normativo do Rorschach para crianças goianienses: dados preliminares. In Congresso Nacional da Associação Brasileira de Rorschach e Métodos Projetivos, 4, (pp. 124-135). Brasília: Vetor.

Ribeiro, R. K. S. M., Yazigi, L. \& Semer, N. L. (2009). Estudo normativo do método de Rorschach em crianças de escolas públicas e privadas de Cuiabá. In Congresso Brasileiro de Avaliação Psicológica Instituto Brasileiro de Avaliação Psicológica, 4; Conferência Internacional de Avaliação Psicológica: formas e contextos, 14 e Congresso da Associação Brasileira de Rorschach e métodos projetivos, 5, Campinas, CD-ROM.

Riquelme, J., \& De Taub, F.K. (2008). Estudio normative de las variables estructurales del Sistema Comprehensivo de Exner para el Rorschach em la poblácion de Caracas. Revista de Psicologia, Escuela de Psicologia, Universidad Central de Venezuela, 27(1), pp. 7-15.

Rothschild, L., Lacoua, L. \& Stein, D. (2009, maio/junho). Changes in implicit and explicit measures of ego functions and distress among two eating disorder subgroups: outcomes of integrative treatment. Eat Disord, 17(3), 242-259.

Rothschild, L., Lacoua, L., Eshel, Y. \& Stein, D. (2008, julho). Changes in defensiveness and in affective distress following inpatient treatment of eating disorders: Rorschach comprehensive system and self-report measures. Journal of Personality Assessment, 90(4), 356-367.

Sadowski, C. M. \& Friedrich, W. N. (2000). Psychometric properties of the Trauma Symptom Checklist for Children (TSCC) with psychiatrically hospitalized adolescents. Child Maltreat, 5(4), pp.364-372.

Salcuni, S., Lis, A., Parolin, L. \& Mazzeschi, C. (2007). Rorschach Comprehensive System Data for two samples of nonpatient children from Italy: 75 aged 5-7 years and 148 aged 811 years. Journal of Personality Assessment, 89(1), pp. 85-90.

Santoantonio, J. (2001). Estudo de características de personalidade de adolescentes com lúpus eritematoso sistêmico por meio do método de Rorschach. Tese de Doutorado, Curso de Psiquiatria, Psicologia e Saúde Mental, Escola Paulista de Medicina, São Paulo.

Santoantonio, J., Yazigi, L. \& Sato, E. (2004). Adolescentes com lúpus eritematoso sistêmico: um estudo por meio do Método de Rorschach. Psicologia: Teoria e Pesquisa, 20(2), pp. 145-151. 
Santos, G. A. (2006). Método de Rorschach: atores e temas da produção científica no Brasil. In Congresso Nacional da Associação Brasileira de Rorschach e Métodos Projetivos, 4, (pp. 153-160). São Paulo: Vetor.

Sanz, I. (2007). Rorschach Comprehensive System Data for a sample of 90 adult nonpatients from Argentina. Journal of Personality Assessment, 89(1), pp. 13-19.

Shaffer, T. W., Erdberg, P. \& Haroian, J. (2007). Rorschach Comprehensive System Data for a sample of 283 adult nonpatients from the United States. Journal of Personality Assessment, 89(1), pp. 159-165.

Shaffer, T. W., Erdberg, P. \& Meyer, G. J. (2007). Introduction to the JPA special supplement on International Reference Samples for the Rorschach Comprehensive System. Journal of Personality Assessment, 89(1), pp. 2-6.

Shweta, Baipai, R.C., Sengar, K.S., Singh, A.R., \& Desai, N.G. (2010). Rorschach profile of Indian adults. Journal of Projective Psychology \& Mental Health, 17(2), pp. 180-186.

Silva, D. R., \& Dias, A. M. (2007). Rorschach Comprehensive System Data for a sample of 357 Portuguese children at five ages. Journal of Personality Assessment, 89(1), pp. 131141.

Singh, D.K., Singh, A. \& Singh, A.R. (2005). Relevance of Beck norms of Rorschach inkbot technique on Indian population - an exploratory pilot study on normal subjects. Journal of Projective Psychology \& Mental Health, 12(1), pp. 49-52.

Smith, A. M., Gacono, C. B., \& Kaufman, L. (1997). A Rorschach comparison of psychopathic and nonpsychopathic conduct disordered adolescents. Journal of Clinical Psychology, 53(4), pp. 289-300.

Smith, S. R., Baity, M. R., Knowles, E. S. \& Hilsenroth, M. J. (2001). Assessment of disordered thinking in children and adolescents: the Rorschach perceptual-thinking index. Journal of Personality Assessment, 77(3), pp.447-463.

Smith, Y. L., Cohen, L. \& Cohen-Kettenis, P. T. (2002). Postoperative psychological functioning of adolescent transsexuals: a Rorschach study. Archives of Sexual Behavior, 31(3), pp.255-261.

Souza, A. M. D. R., \& Duarte Junior, A. P. (2008). As respostas banais de sujeitos paraenses ao teste de Rorschach: Comparação com normas de populações da região sudeste e análise da estabilidade temporal dos resultados. In: Encontro da Associação Brasileira de Rorschach e Métodos Projetivos, 5, Ribeirão Preto: ASBRo, CD-ROM.

Sultan, S., Andronikof, A., Fouques, D.,Lemmel, G., Mormont, C., Réveillère,C., \& Saïas, T. (2004). Vers des norms francophones pour le Rorschach en système intégré: premiers resultants sur un échantillon de 146 adults. Psychologie Française, 49(1), pp. 7-24.

Tibon, S. \& Rothschild, L. (2009). Exploring the clinical implications of the international CS reference data for children and adolescents (Meyer, Erdberg, \& Shaffer, 2007). Journal of Personality Assessment, 91(5), pp. 497-499. 
Tibon, S. (2007). Rorschach Comprehensive System Data for a sample of 11641 adult nonpatients from Israel. Journal of Personality Assessment, 89(1), pp. 74-79.

Urbina, S. (2007). Fundamentos da testagem psicológica. (C. Dornelles, trad.). Porto Alegre: Artmed.

Valentino, M. A., Shaffer, T. W., Erdberg, P. \& Figueroa, M. (2007). Rorschach Comprehensive System Data for a sample of 42 nonpatient Mexican American children from the United States. Journal of Personality Assessment, 89(1), pp. 183-187.

Van Patten, K., Shaffer, T. W., Erdberg, P.; Canfield, M. (2007). Rorschach Comprehensive System Data for a sample of 37 nonpatient/nondelinquent adolescents from the United States. Journal of Personality Assessment, 89(1), pp. 188-192.

Vaz, C. E. (1997). O Rorschach: teoria e desempenho. Barueri: Manole.

Villemor-Amaral, A. E. (2009). Métodos Projetivos em avaliações compulsórias: indicadores e perfis. In C. S. Hutz. (Org.), Avanços e polêmicas em avaliação psicológica (pp. 157174). São Paulo: Casa do Psicólogo.

Villemor-Amaral, A. E., Yagizi, L., Nascimento, R. S. G., Primi, R. \& Semer, N. L. (2006). Elaboração do atlas e lista de qualidade formal do Rorschach no sistema compreensivo para uma amostra brasileira: comunicação preliminar. In Congresso Nacional da Associação Brasileira de Rorschach e Métodos Projetivos, 4, (pp. 70-75). Brasília: Vetor.

Villemor-Amaral, A. E., Yazigi, L., Primi, R., Nascimento, R. S. G. F., Semer, N. L., Meyer, G. J \& Viglione, D. J. (2008). Comparing location areas and frequency of responses in the Rorschach Comprehensive System considering a Brazilian sample and American data. In International Congress of Rorschach and Projective Methods, 19 (p. 110). Leuven, Belgium: IRS.

Wanderley, K. S. (1988). Estudo clínico da personalidade de pacientes diabéticos juvenis através do exame de Rorschach. Dissertação de Mestrado, Universidade Metodista de São Paulo, São Paulo.

Weil, P., Nick, E. (1971). O potencial da inteligência do brasileiro. Rio de Janeiro: CEPA.

Weiner, I. B. (1991). Editor's note: interscorer agreement in Rorschach research. Journal of Personality Assessment, 56, p.1.

Weiner, I. B. (1993). Speaking Rorschach: a tower of babel no longer. Rorschariana, 18, 1-6.

Weiner, I. B. (2000). Princípios da Interpretação do Rorschach. Tradução M. Cecília Vilhena M. Silva. São Paulo: Casa do Psicólogo.

Weiten, M. (2002). Introdução à psicologia: temas e variações. (M. L. Brasil, Z. G. Botelho, C. A. Colotto, J. C. B. Santos, trad). São Paulo: Pioneira Thomson Learning.

Werlang, B. S. G., Villemor-Amaral, A. E. \& Nascimento, R. S. G. F. (2010). Avaliação psicológica, testes e possibilidades de uso. In Avaliação Psicológica: diretrizes na regulamentação da profissão. Conselho Federal de Psicologia. Brasília: CFP. 
Yazigi, L., Ribeiro, R. \& Semer, N. L. (2008). Normative study of the Rorschach Comprehensive System in Brazilian children. In International Congress of Rorschach and Projective Methods, 19 (p. 52). Leuven, Belgium: IRS. 